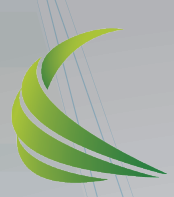

2012

AÑO INTERNACIONAL DE LA ENERGÍA SOSTENIBLE PARA TODOS

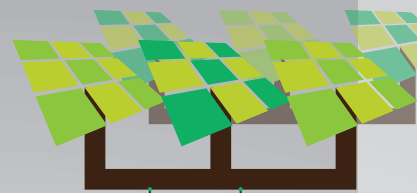

IER CONGRESO, DE ENERGIA SOSTENIBLE

\title{
nuevas ideas, nuevos procesos + limpios, eficientes y productivos
}





\section{Primer Congreso de Energía Sostenible Memorias 2012}

\section{Organizadores}

Escuela Colombiana de Carreras industriales ECCI Universidad Libre Seccional Bogotá Universidad Santo Tomas USTA Asociación Akuaippa ONG

\section{Diseño y diagramación}

Elizabeth Abril Pulido

Carlos Enrique Pachón Matute

Corrección de estilo

Erika Liliana Franco

Diana Figueroa

Manuel Alejandro Mayorga

\section{Nota Editorial}

Dionisio Humberto Malagón

Producción y digitalización

Asociación Akuaippa ONG

Publicado en Bogotá, Colombia 2012 @ 
Análisis de la viabilidad de una planta de energía geotérmica para la producción de electricidad en Colombia.

Aprovechamiento de la energía liberada en procesos biológicos de tratamiento de aguas residuales mediante celdas de combustible microbianas.

Estudio del potencial energético eólico en tunja, Colombia.

Diseño de una vivienda sostenible.

Estudio de cinco microalgas como fuentes potenciales de biodiesel.

Estudio de factibilidad para la implementación de un sistema energético alternativo en San Andrés Isla - Colombia.

Evaluación de la producción de hidrógeno empleando cepas nativas de Clostridium spp a partir de glicerol como fuente de carbono.

Vehiculo propulsado con gasohol.

Producción de biodiesel a condiciones supercríticas: resultados experimentales y evaluación de impacto ambiental.

Dimensionamiento de un sistema fotovoltaico interconectado para suplir las necesidades energéticas de la sala de tutorías de la facultad de ingeniería ambiental de la Universidad Santo Tomás.

Reporte preliminar del diseño del prototipo de un biorreactor alimentado por energía fotovoltaica, para la producción de compost, a partir de Azolla filiculoides y Typha latifolia, de la Laguna Chocolate de Une Cundinamarca.

Obtención de biodiesel a partir de aceite de higuerilla mediante el empleo de lipasas comerciales extraídas a partir de r. Oryzae y c. Rugosa.

Avances en optimización de colectores solares para secado de productos agrícolas.

Modelo de sistema solar fotovoltaico rural - caso: Escuela el Cardonal, Tibaná, Boyacá, Colombia.

Escalamiento del proceso de produccionde biodiesel a partir de aceite usado de cocina por medio de transesterificacion quimica (acido-basico).

Simulación numérica de celdas solares con capa absorbente de $\mathrm{CU}_{3} \mathrm{BIS}_{3}$ a través de WXAMPS.

Propuesta metodológica para la medición de la huella energética corporativa como indicador de sostenibilidad ambiental.

Diseño de un equipo para sintetizar películas delgadas empleadas en celdas solares de bajo costo. 
Matlab computationtal package for computation of wind and marine current turbines.

Desarrollo de una turbina hidráulica de flujo axial para generación distribuida

Modelo de optimización económica en un sistema con generación distribuida.

Gasificación por lecho fijo de la fibra obtenida del fruto de la palma de aceite, usando aire-vapor como agentes oxidantes.

Optimización matemática de los parámetros constructivos de las turbinas eólicas de eje vertical de palas rectas.

Estudio de factibilidad técnico económica para la implementación de una central de energía nuclear para la producción de energía eléctrica en Colombia.

Consumo de potencia reactiva en bombillos "ahorradores".

Práctica académica para obtencion de bioetanol a partir de residuos orgánicos.

Análisis de viabilidad del aprovechamiento de la energía contenida en las nubes de tormenta.

Prototipos del fenómeno de la concentración solar.

Vehiculos hibridos en Colombia.

Efecto de la luz y la aireación en la acumulación de aceites en la microalga Chlorella vulgaris.

Propuesta para el desarrollo tecnológico de energía por concentración solar en Colombia.

Diseño y construcción de un motor stirling para el aprovechamiento de energía térmica generada por combustibles fósiles y/o energías renovables.

Cocinas solares de acumulacion y concentracion. 
iguiendo la invitación realizada por la ONU para este año 2012 en su declaración del Año Internacional de la ENERGÍA SOSTENIBLE PARA TODOS, las Universidades Libre, Santo Tomás y la Escuela Colombiana de Carreras Industriales (ECCl) con el apoyo logístico y académico de la ONG Akuaippa se organizó el "I Congreso de Energía Sostenible". Siendo este un punto de encuentro entre organismos gubernamentales, académicos y empresariales del sector energético, con el fín de presentar su visión y posición sobre temas tan relevantes como lo son los desarrollos tecnológicos en el sector energético y la sostenibilidad energética a largo plazo.

Así pues, como lo declara la ONU, "La «energía sostenible» es aquella energía que se produce y se usa de forma que apoye a largo plazo el desarrollo humano en el ámbito social, económico y ecológico," de tal manera que es de importancia vital que en el contexto regional y mundial los investigadores colombianos se vinculen al diseño, desarrollo y análisis de factibilidad técnico económica de sistemas de generación de energía que permitan la sostenibilidad de la misma en la región, y que ello sea también en pro del desarrollo de las más zonas y comunidades más necesitadas.

Entendiendo la importancia del tema, es tarea de la Universidad Colombiana, como centro de desarrollo tecnológico, proponer y promover un espacio para la discusión y la reflexión desde diversos ángulos acerca de su papel en el desarrollo de fuentes de energía y su impacto en el medio ambiente. Dicha visión, no ha sido esquiva para el enfoque del Congreso, en donde este se convierte en espacio de discusión y divulgación de desarrollo en el tema energético pero con responsabilidad ambiental y social en la generación y uso racional de la energía.

Adicionalmente, al ser un espacio para la divulgación de los trabajos científicos desarrollados por diversas universidades y centros de desarrollo tecnológico en torno al tema energético, el Congreso busca generar potenciales redes de investigación de tal manera que se puedan unir esfuerzos alrededor de temas comunes, con el fín de plantear a futuro el desarrollo de proyectos de mayor envergadura, lo anterior con el fin de que los desarrollos locales tengan más impacto en el medio y tengan un fin y objetivo común. 
En esta Primera versión del Congreso se contó con la participación de 36 ponencias provenientes de distintas universidades del país, las cuales fueron evaluadas por el Comité Científico del Evento, con lo cual se puede evidenciar la preocupación existente en torno al tema energético. Todas las ponencias mostraron una alta calidad, así como rigurosidad científica y una alta proyección del tema energético a nivel nacional. A los autores de estos trabajos nuestros agradecimientos por la confianza depositada en el Comité Organizador.

Así pues, el resumen de estas ponencias que se pone a disposición de los participantes del Congreso, se convierte en la evidencia fehaciente de la incansable labor de soñadores y forjadores de país que trabajan por la sostenibilidad energética de un pueblo en pro de su desarrollo.

Las áreas temáticas desarrolladas en dentro del Congreso fueron:

- Biocombustibles.

- Biomasa y Bioenergía.

- Energía solar.

- Energía eólica.

- Energía Hidráulica (aplicaciones no convencionales).

- Energía geotérmica y mareomotríz.

- Desarrollo sostenible.

- Eficiencia energética.

- Auditoría Energética

ONU "Los servicios energéticos tienen un profundo efecto en la productividad, la salud, la educación, el cambio climático, la seguridad alimentaria e hídrica y los servicios de comunicación. La falta de acceso a la energía no contaminante, asequible y fiable obstaculiza el desarrollo social y económico y constituye un obstáculo importante para el logro de los Objetivos de Desarrollo del Milenio". Este es un gran desafío que debe ser resuelto, pensando en las nuevas generaciones a quienes se les debe entregar, con responsabilidad, una sociedad con acceso a los recursos energéticos y ambientales necesarios, para el desarrollo de todas sus actividades.

También, es deseo del Comité organizador y de las Instituciones vinculadas expresar el más sincero agradecimiento a los invitados nacionales e internacionales que participaron en el Congreso. Gracias por compartir en el país su experiencia y conocimiento, sus reflexiones y vivencias con seguridad enriquecerán las labores diarias de los investigadores y podrán contribuir a garantizar el acceso a la energía por parte de toda la población. 
Gracias también a los grupos de investigación que soportan los procesos investigativos de nuestras universidades: Grupo de Investigación en Aprovechamiento Tecnológico de Materiales y Energía (GIATME) y Grupo de Investigación en Diseño Mecánico y Materiales (GIDMyM) de la Escuela CoIombiana de Carreras Industriales (ECCI), Grupo de Estudios en Ingeniería Mecánica (GEAMEC) y DETECAL de la Universidad Libre.

Finalmente, gracias a todos los participantes por abrir un espacio en su agenda para participar en esta primera versión del Congreso de Energía sostenible, esperamos que el año entrante podamos contar con ustedes y de esta manera este evento se convierta en un referente nacional y regional que contribuya a la reflexión e integración alrededor de la energía y sus impactos en la sociedad.

Dionisio Humberto Malagón 


\section{COMITÉ ACADÉMICO}

Dionisio Humberto Malagón

Ingeniero Químico, c-Ph.D. Ingeniería Química

Docente Investigador

Universidad Santo Tomás

Manuel Alejandro Mayorga Betancourt

Ingeniero Químico, M.Sc. Ingeniería - Ingeniería Química

Docente Investigador

Escuela Colombiana de Carreras Industriales, ECCI.

Luis Eduardo Garcia

Ingeniero Mecánico, M.Sc. Ingeniería Mecánica

Docente Investigador

Universidad Libre - Sede Bogotá

Alexander Ladino

Ingeniero Mecánico, M.Sc. Ingeniería Mecánica

Docente Investigador

Universidad Santo Tomás

Sergio Carrión

Ingeniero Mecánico, c-M.Sc. Ingeniería Mecánica

Docente Investigador

Universidad Santo Tomás

Erika Liliana Franco Fábrega

Ingeniera Ambiental

Investigadora Asociada

Asociación Akuaippa ONG

\section{COMITÉ LOGÍSTICO Y FINANCIERO}

Carlos Garzón Ramírez.

Ingeniero Mecánico c-M.Sc Diseño, Gestion Y Direccion De Proyectos.

Docente Investigador

Escuela Colombiana de Carreras Industriales, ECCI.

Nohemy Bustacara

Ingeniera Mecánica c-M.Sc Energías alternativas.

Docente.

Escuela Colombiana de Carreras Industriales, ECCI.

Carlos Pachón Matute

Diseñador Gráfico

Presidente

Asociación Akuaippa ONG

Diana Yissel Figueroa Cubillos

Ingeniera Ambiental

Investigadora Asociada

Asociación Akuaippa ONG 



\title{
ANÁLISIS DE LA VIABILIDAD DE UNA PLANTA DE ENERGÍA GEOTÉRMICA PARA LA PRODUCCIÓN DE ELECTRICIDAD EN COLOMBIA
}

\author{
Julián Andrés Ortiz González \\ Escuela Colombiana de Carreras Industriales \\ Jaog1608@ hotmail.com
}

Palabras Clave: Flash, Geotérmica, Tasa Interna de Retorno, Valor Presente Neto, Yacimiento.

Área Temática: Energía Geotérmica

\section{INTRODUCCIÓN}

La energía geotérmica se ha venido diseminando por todo el mundo como una excelente opción para generar electricidad de manera limpia y eficiente [1], con una capacidad instalada de $8884,8 \mathrm{MW}$ en todo el globo [2], de tal manera que en lugares como Islandia representa el $26.2 \%$ de toda la energía generada [3] y según el MIT (Massachusetts Institute of Technology) de Estados Unidos, actualmente hay disponibles en el planeta alrededor de 13000 ZJ de energía geotérmica, de los cuales son aprovechables, con las tecnologías actuales, $2000 \mathrm{ZJ}$ siendo el consumo mundial al año de electricidad 0.5 ZJ [4], por lo tanto, si se profundizara más en este campo, se supliría la demanda energética, sin tener que utilizar otros medios aparte de la geotermia.

Al analizar el ámbito local se observa un gran potencial geotérmico, debido a la ubicación de Colombia sobre el Cinturón de Fuego del Pacifico, lo que ha impulsado el estudio de las siguientes zonas del territorio nacional [5]: Proyecto Chiles-Tufiño Cerro Negro (frontera colombo-ecuatoriana), Proyecto Azufral (departamento de Nariño), Proyecto de Paipa (departamento de Boyacá), Proyecto Macizo Volcánico del Ruiz (departamentos de Caldas, Tolima y Risaralda). A pesar de los datos satisfactorios, que han arrojado los diferentes estudios, hasta ahora no se ha construido ninguna planta de energía geotérmica en Colombia.

\section{MATERIALES Y MÉTODOS}

Para la realización de los cálculos termodinámicos de la planta [6], se estudiaron las diferentes tecnologías que se usan para la construcción de centrales de energía geotérmica (las cuales se basan en ciclo Rankine) [1], para de esta manera escoger el sistema que mas se ajuste a las propiedades de la zona seleccionada en el territorio colombiano. Luego, se establecieron los costos de inversión de esta clase de proyectos y los parámetros de venta de electricidad en Colombia, con el objetivo de realizar una proyección económica, aplicando las formulas del Valor Presente Neto, Tasa Interna de Retorno y Punto de Equilibrio. 


\section{RESULTADOS}

Seleccionando la zona del Macizo Volcánico del Ruiz como la más adecuada para la construcción de la planta, debido a las altas temperaturas encontradas en el posible yacimiento y las características del recurso $\left(250^{\circ} \mathrm{C}\right.$ en fase de mezcla), se optó por el sistema de una planta de flash simple [1], con tres escenarios de potencia, teniendo en cuenta las estimaciones de capacidad para este lugar [7], la legislación colombiana [8] y el hecho de que el caudal es una incógnita (Tabla 1), ya que no se ha realizado ninguna perforación para producción en este sitio.

Por lo tanto, a continuación se muestra una tabla con el caudal, el Valor Presente Neto, la Tasa Interna de Retorno y el Punto de Equilibrio, para cada escenario de potencia.

Tabla 1: Escenarios de diseño con flujo de vapor.

$\begin{array}{cccc}\text { Potencia de la central (MW) } & 10 & 20 & 50 \\ \text { Flujo vapor (kg/s) } & 17.38 & 34.76 & 76.91 \\ \text { Flujo mezcla (kg/s) } & 21.72 & 43.45 & 108.63 \\ \text { VPN (USD) } & 11.074 .082 & 30.793 .849 & 147.308 .614 \\ \text { TIR (\%) } & 8,65 & 10,17 & 15,37 \\ \text { PE (años) } & 10 & 9 & 7\end{array}$

\section{CONCLUSIONES}

Con el diseño de tres centrales de flash simple, con unos parámetros de potencia de $10 \mathrm{MW}, 20 \mathrm{MW}$ y $50 \mathrm{MW}$, acordes a las propiedades encontradas en el Macizo Volcánico del Ruiz $\left(250^{\circ} \mathrm{C}\right.$ en fase de mezcla), un VPN positivo para los tres casos y una TIR por encima del estimado nacional de $5.9 \%$, se demuestra tanto la viabilidad técnica, como la factibilidad económica del proyecto en Colombia, dilucidando las verdaderas razones por las cuales no se ejecutan este tipo de iniciativas, entre las que están, una ausencia de legislación local, para la generación de electricidad por medio de la explotación de la energía geotérmica, falta de compromiso gubernamental, el desconocimiento de estas tecnologías, entre otras. 


\section{REFERENCIAS}

[1] L. Jutglar y J. Pous, Energía Geotérmica, CEAC, 2004.

[2] Web Geothermal Data Base, Recuperado http://vmigg.iit.cnr.it/SpagoBl.

[3] Landsvirkjun, «Landsvirkjun,» Recuperado el 9 mayo 2012 www. landsvirkjun.com.

[4] Massachusetts Institute of Technology (MIT), «The Future of Geothermal Energy, Impact of Enhanced Geothermal Systems (EGS) on the United States in the 21st Century, pp. 220-230, 2006.

[5] Consorcio Energético CORPOEMA, «Volumen 2 - Diagnóstico de las Fuentes no Convencionales de Energía en Colombia,» pp. 276280, 2010.

[6] J. A. Ortiz, Estudio Técnico-Económico de una Planta Geotérmica en el Macizo Volcánico del Ruiz, Bogota, 2012, pp. 20-50.

[7] ISAGEN, «Proyecto Geotérmico Macizo Volcánico del Ruiz,» pp. 2-10, 2010.

[8] Colombia, Congreso de la República, «Ley 143: Régimen para la Generación, Interconexión, Transmisión, Distribución y Comercialización de Electricidad en el Territorio Nacional,» pp. 12-32, 1994. 


\title{
APROVECHAMIENTO DE LA ENERGÍA LIBERADA EN PROCESOS BIOLÓGICOS DE TRATAMIENTO DE AGUAS RESIDUALES MEDIANTE CELDAS DE COMBUSTIBLE MICROBIANAS
}

\author{
Néstor Ariel Algecira Enciso*, Carlos Fernando Hernández Prada* \\ "Universidad Nacional de Colombia, \\ nalgecirae@unañ.edu.co \\ cfhernandezp@unal.edu.co
}

Palabras Clave: Aguas Residuales, Celdas de Combustible Microbianas, Convertidor DC-DC tipo Boost, Energía Eléctrica, Microrganismos.

Área Temática: Biomasa y Bioenergía

\section{INTRODUCCIÓN}

Las Celdas de Combustible Microbianas permiten obtener tratamientos biológicos de aguas residuales y simultáneamente generar energía eléctrica. Esto es posible gracias a la acción de cierto tipo de bacterias, que al degradar la materia orgánica presente en aguas residuales pueden transferir electrones fuera de su pared celular mediante diferentes mecanismos.

El tratamiento de aguas residuales domésticas [1] e industriales con generación de energía eléctrica, la generación de energía eléctrica para teledetección o redes de sensores inalámbricos [2] o la implementación de un biosensor [3] para monitoreo de DBO (demanda bioquímica de oxígeno) son algunas de la aplicaciones publicadas actualmente. Otras investigaciones se han enfocado en modelar las celdas y mejorar su eficiencia variando sus principales parámetros.

\section{MATERIALES Y MÉTODOS}

Se desarrollaron tres fases de experimentación. En la primera fase se construyeron dos prototipos de celdas de combustible microbianas, uno de doble cámara y el otro de cámara sencilla. Los prototipos están compuestos por una cámara anaerobia y una cámara aerobia divididas por una membrana de intercambio protónico. En cada cámara hay un electrodo de grafito que permite medir la diferencia de potencial entre ambos compartimientos. En el electrodo negativo (Ánodo) se forma una biopelícula, de esta forma es posible captar los electrones liberados en el proceso de degradación de materia orgánica realizada por los microrganismos. Se utilizaron lodos activados provenientes de la Planta de Tratamiento de Aguas Residuales PTAR el Salitre en Bogotá como fuente de microrganismos. En la segunda fase de experimentación se construyeron 5 prototipos de celdas de una sola cámara (anaerobia) y sin membrana. Cada prototipo tuvo una concentración determinada de lodos provenientes de excremento bovino. Esta fase buscó obtener una concentración óptima para el tratamiento del agua residual doméstica y la generación 
de energía eléctrica. En la tercera fase de experimentación se construyeron 2 prototipos de celda tipo TMFC (Terrestrial Microbial Fuel Cell) utilizando excremento bovino y tierra. Esta fase se enfocó en la generación de energía eléctrica y en mostrar una aplicación práctica. Para esto se utilizó un convertidor DC-DC tipo Boost de ultra baja potencia, además de un sistema de carga de batería. El sistema está diseñado para adquirir y gestionar potencia del orden de los microvatios hasta los milivatios. De esta forma el voltaje de entrada de la celda fue elevado hasta 3.1V. Con este voltaje se cargó un capacitor y fue activado un LED con la energía generada por la celda.

\section{RESULTADOS}

En la tabla 1 se observan los mejores resultados obtenidos en cada fase de experimentación. La celda de doble cámara presentó los mejores resultados para la fase 1. La celda con concentración de lodos de $5.8 \mathrm{ml}$ por litro de agua residual presentó los mejores resultados para la fase 2 . Finalmente la celda con mayor área de los electrodos generó la mayor cantidad de energía para la fase 3. En esta celda no se evaluó el tratamiento del agua residual.

Tabla. 1 - Resultados obtenidos en las tres fases de experimentación.

\begin{tabular}{|c|c|c|c|c|c|c|c|}
\hline Fase & Prototipo & $\begin{array}{c}\text { Eficiencia } \\
\text { DQO Total \% }\end{array}$ & $\begin{array}{c}\text { Eficiencia } \\
\text { DQO } \\
\text { Soluble \% }\end{array}$ & $\begin{array}{c}\text { Voltaje } \\
\text { Max [mV] }\end{array}$ & $\begin{array}{c}\text { Corriente } \\
\text { Max [uA] }\end{array}$ & $\begin{array}{c}\text { Potencia } \\
\text { Max [uW] }\end{array}$ & $\begin{array}{c}\mathbf{R} \text { int. } \\
\text { [k } \Omega]\end{array}$ \\
\hline 1 & $\begin{array}{c}\text { Cámara } \\
\text { Doble }\end{array}$ & 62.86 & 82.80 & 330 & 37.0 & 1.95 & 8.2 \\
\hline 2 & Vlodo=5.8ml & 71.56 & - & 286 & 6.86 & 0.64 & 24 \\
\hline 3 & TMFC & - & - & 612 & 440 & 57.0 & 1.2 \\
\hline
\end{tabular}

\section{CONCLUSIONES}

En esta investigación se comprobó que es posible realizar un tratamiento biológico de aguas residuales domésticas con eficiencias significativas y simultáneamente generar energía eléctrica mediante celdas de combustible microbianas. También se mostró la flexibilidad de esta tecnología ante el uso de distintas fuentes de microorganismos. De esta forma, esta tecnología se proyecta como una solución en el autoabastecimiento energético de plantas de tratamiento de aguas residuales, como fuente de energía eléctrica para sistemas de iluminación o en aplicaciones de sensoramiento remoto o teledetección como el caso de las redes de sensores inalámbricos. 


\section{REFERENCIAS}

[1] Algecira N.A., Hernández C.F., Ibánez R. A., "Tratamiento de Aguas Residuales y Generación Simultánea de Energía Eléctrica Mediante Celdas de Combustible Microbianas.", II Congreso Internacional de Gestión Tecnológica e Innovación, Bogotá, 2010.

[2] Cooke K.G., "Distributed Sensor Network Powered by Terrestrial Microbial Fuel Cell Technology", SPIE Defense, Security, and Sensing, Somerville, MA, USA, 2010.

[3] Di Lorenzo M., Curtis T.P., Head I.M., Scott K., "A single-Chamber Microbial Fuel Cell as a Biosensor for Wastewaters", Science Direct, Newcastle University, 2009. 


\title{
ESTUDIO DEL POTENCIAL ENERGÉTICO EÓLICO EN TUNJA, COLOMBIA
}

\author{
William F. Álvarez Castañeda*, Salvador Vargas Díaz \\ "Universidad Santo Tomás \\ walvarez@ustatunja.edu.co \\ "Universidad Libre \\ salvador.vargas@unilibrebog.edu.co
}

Palabras Clave: aerogenerador, Ecuación de Weibull, Energía Eólica, Potencial Eólico

Área Temática: Energías alternativas, Energía Eólica

\section{INTRODUCCIÓN}

En los últimos tiempos la Unidad de planeación minero energética UPME desarrolló el atlas de viento y energía eólica en Colombia. En este atlas aparece ubicada la ciudad de Tunja, donde se encuentra un rango de velocidades de viento entre 2 y $8 \mathrm{~m} / \mathrm{s}$ [1]. No es novedad, pero en pleno centro de la ciudad existe una esquina muy famosa conocida por los tunjanos como la calle de la pulmonía, está esquina es famosa y recibe este nombre popular debido a los fuertes y fríos vientos que soplan en este lugar. El potencial eólico de esta ciudad siempre ha tenido especial interés dentro de los habitantes y ha formado parte de la historia. No obstante que el atlas de viento sugiere que en esta zona se tiene un rango de velocidades de viento entre 2 y $8 \mathrm{~m} / \mathrm{s}$, surge la pregunta importante sobre el tema, ¿Cuál es la capacidad y que tan fuertes son estos vientos en esta ciudad para la generación de energía eólica y que tanta energía de los vientos se podría aprovechar para satisfacer la demanda energética de esta región?

\section{MATERIALES Y MÉTODOS}

Para determinar el potencial energético eólico de la ciudad de Tunja, fue necesario registrar la velocidad, dirección y densidad del viento, pues si bien es cierto que existe el atlas de vientos desarrollado por la UPME en el 2006, es importante mencionar que este debe ser tomado únicamente como una referencia, debido al carácter global que presentan estos datos. Para el registro de los datos, el anemómetro debe ser ubicado a una altura de 10 metros, el periodo de registro debe hacerse durante un periodo mínimo de ocho meses para su posterior estudio [2].

El análisis de los datos debe hacerse teniendo presente no sólo la velocidad de los vientos en la zona de estudio sino la frecuencia promedio con que esta se presenta. Debido a que pueden existir vientos demasiados fuertes pero que sólo es posible obtener en periodos muy cortos de tiempo durante el 
día, también puede ocurrir que los vientos, existan y sean muy constantes y frecuentes, pero que la velocidad con las que se encuentran no alcancen el valor mínimo requerido para el funcionamiento promedio de un aerogenerador. Para poder determinar la frecuencia de los datos promedio de velocidad del viento en un día, es necesario realizar una clasificación de los datos registrados y obtener la curva de potencia de los mismos, posteriormente, sobre esta curva se aplica la ley de Weibull [3], la cual junto con las características de potencia de un determinado aerogenerador, permite obtener la viabilidad de un proyecto de energía eólica, a través de la obtención de el potencial de energía eólica en la zona de estudio.

\section{RESULTADOS}

Después de realizar y analizar el registro de los datos, se observo que las características de los vientos que se presentan en la ciudad de Tunja, poseen potencial para desarrollar proyectos relacionados con energía, los datos registrados que superan la velocidad de enganche de los aerogeneradores [4]. Por ejemplo, los datos registrados en el sector conocido como el Alto de Soracá presentado en la Figura 1, muestra que "la ventana de energía" se encuentran vientos superiores a la velocidad promedio de enganche necesaria para un aerogenerador, durante un periodo de tiempo aproximadamente de 20 horas los cuales se presentan en las horas de mayor demanda energética, entre el medio día y las seis y ocho de la noche respectivamente.

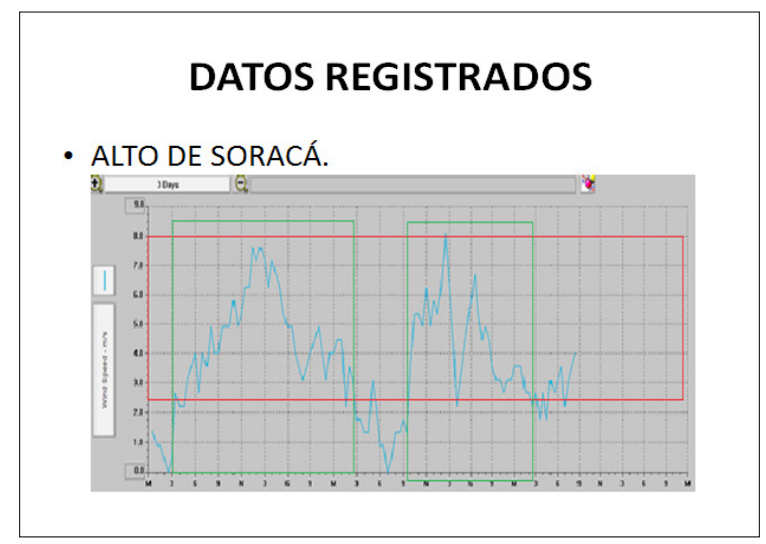

Figura 1: Datos registrados durante 2 días en la estación meteorológica ubicada en el Alto de Soracá, Tunja. Fuente. Autores

\section{CONCLUSIONES}

Los vientos presentes en la ciudad de Tunja presentan un potencial adecuado en sus diferentes variables, tales como velocidad, dirección y densidad para proponer un proyecto de energía eólica en la región llevarlo a cabo con una alta probabilidad de éxito. 


\section{REFERENCIAS}

[1] Atlas de Viento y Energía Eólica de Colombia. Unidad de Planeación Minero Energética UPME, Instituto de hidrología, meteorología y estudios ambientales IDEAM.

[2] Palese, Claudia. Gardio Jesús. Mapas de velocidad media del viento en el centro -este de la provincia de Neuquén. 2009.

[3] Guzmán Jorge. Estudio de viabilidad del parque eólico sierra de oliva. 2010.

[4] Gonzales Luis. Diseño de un sistema de calefacción alimentado por un aerogenerador. Pontificia Universidad Católica del Perú. 2007. 


\section{DISEÑO DE UNA VIVIENDA SOSTENIBLE}

Marcela Jamaica*, John Feo*, Johanna Ochoa, Lorena Santamaría.

Universidad Distrital Francisco José de Caldas

${ }^{*}$ Autores principales

marcelajamaicadelgado@gmail.com, inambiente@gmail.com

Palabras clave: arquitectura, modelación, tecnologías limpias y ambientales, vivienda sostenible.

Área temática: arquitectura sostenible.

\section{INTRODUCCIÓN}

El sector de la construcción deriva en una serie de impactos negativos que inciden sobre el ambiente y sobre la salud humana, dado el carácter insostenible del mismo debido a los altos consumos de materiales y energía, y la generación de residuos [1] durante las etapas constructiva y operativa, especialmente esta, donde se invierten altas cantidades de dinero en sistemas de calefacción y/o ventilación para lograr un ambiente confortable. Estos principios de sostenibilidad se basaron en los criterios tenidos en cuenta en varias edificaciones a nivel mundial [1], [2] y [3].

\section{MATERIALES Y MÉTODOS}

De acuerdo con la revisión bibliográfica más relevante para el tema, se establecieron criterios de sostenibilidad del diseño arquitectónico que se plasmaron en la aplicación gratuita Google SketchUp TM® para un posterior modelado energético en Trnsys17®, el cual hizo una simulación de ambientes de sistemas térmicos para el diseño para comprobar que de acuerdo con los criterios adoptados para tal diseño se logra el confort térmico, descartando gastos de energía convencional en sistemas de calefacción y/o ventilación, los cuales se traducen en gastos de dinero, derroche de energía y contaminación por emanación de gases. La medición del confort térmico se hizo por medio del concepto PMV (Voto medio estimado, Predicted Mean Vote), que muestra el confort de los espacios de la vivienda evaluado en escala de -3 a 3 (frío a caliente) y su medición considera el aislamiento térmico de la ropa, producción de energía metabólica, temperatura del aire, temperatura radiante media, velocidad relativa del aire y humedad relativa; con base en ello se obtuvo el Voto Medio Estimado (PMV), que cubre un rango de valores desde -3 a 3 , donde -3 es frío, -2 es fresco, -1 es ligeramente fresco, 0 es neutro, +1 es ligeramente caluroso, +2 es caluroso, +3 es muy caluroso [4]. La vivienda cuenta con un conjunto de sistemas de tecnologías limpias y ambientales: captación de agua potable con ariete hidráulico; recirculación de aguas grises que se unen con aguas lluvias (aguas empleadas para descargar inodoros, aseo, 
limpieza de autos y riego de jardines); suministro de energía eléctrica con paneles fotovoltaicos; suministro de agua caliente con calentador solar; tratamiento de agua residual con un sistema de canal de desbaste, aliviadero, desarenador, pozo séptico y humedal subsuperficial.

\section{RESULTADOS}

El rango de temperaturas (Figura 1) en la vivienda está entre $16^{\circ} \mathrm{C}$ (en enero, finales de marzo, octubre, noviembre y diciembre) y $35^{\circ} \mathrm{C}$ (inicios de marzo, mediados de abril, mayo, junio). Las temperaturas más elevadas se encuentran en el espacio denominado "volado" que es altillo, lo cual se debe a que es el espacio que primero recibe calor por convección transferido por la cubierta, en cuya instalación se dispone lona asfáltica color negro que funciona como absorbente de radiación solar y que lo transfiere al interior de la vivienda. El otro espacio más caliente es "cocina2" que es el segundo piso de la cocina y que se encuentra en contacto directo con el ambiente externo, permitiendo la entrada de energía solar por medio de las claraboyas, a la vez que éstas permiten el paso de luz durante todo el día, evitando gastos en energía eléctrica. El siguiente grupo de espacios calientes es "habitaciones" que abarca las 4 habitaciones y el estudio; las temperaturas más bajas se presentan a mediados de enero, pero en general el rango se temperaturas se está entre $19-29^{\circ} \mathrm{C}$, un rango adecuado para dormir o pasar un rato en el día, y que se ve favorecido por la radiación transferida por convección a través del altillo y por las ventanas que se encuentran en el balcón externo. El espacio "baño2" (baños del segundo piso) y escaleras1 (escaleras que dan al segundo piso) presentan un comportamiento similar, aunque las escaleras tienden a presentar temperaturas más elevadas con puntos críticos a finales de enero, de febrero y de octubre, noviembre y diciembre con temperatura de $19,6^{\circ} \mathrm{C}$. El espacio "cocina1" es la cocina en el primer piso, que mantiene temperaturas inferiores a "cocina2". Presenta temperaturas entre $18-26^{\circ} \mathrm{C}$ durante todo el año, con puntos críticos a mediados de enero y mediados de marzo con una temperatura aproximada de $18^{\circ} \mathrm{C}$. La sala es un espacio fresco, el rango predominante está entre $15-21^{\circ} \mathrm{C}$ debido principalmente al espacio vacío que hay entre el balcón interno y el primer piso que propicia la circulación de vientos, proporcionando frescura al espacio donde predomina el ventanal oriental, diseñado para la entrada de radiación solar e iluminación durante todo el día y que se propone que sea un vidrio templado que permita la entrada de radiación e impida su salida. Las temperaturas más bajas $\left(17-19,6^{\circ} \mathrm{C}\right)$ se presentan en el espacio "escaleras2" (escaleras que llegan al altillo) y la baja temperatura comparada con este es debido a la transición de calor que se presenta en las habitaciones y el techo, ya que el espacio vacío que hay en el balcón interior hace que los vientos circulen por el espacio más cercano que son estas escaleras, además que en la cubierta hay unas ventanas y unas aberturas que propician la circulación del aire. 


\section{CONCLUSIONES}

En términos generales se deduce que el diseño arquitectónico permite que en la vivienda se presenten temperaturas favorables tanto para el bienestar en términos térmicos como para el ahorro de energía eléctrica por la iluminación natural. Las temperaturas más bajas se presentan a mediados de enero, finales de marzo, mediados de junio, principios y mediados de agosto y octubre, noviembre y diciembre, mientras que las temperaturas más altas se presentan a finales de febrero, finales de marzo, principios de abril, mayo, junio, principios de julio, principios de agosto y principios de septiembre. Cabe aclarar que en esta simulación no se consideraron sombras proyectadas por otras construcciones, montañas, depresiones en el terreno, vegetación, y que el análisis se llevó a cabo considerando la vivienda desocupada, entonces los resultados reales pueden diferir un poco de los que aquí se presentan, sin embargo es un buen estimado del comportamiento energético de la vivienda porque Trnsys $17 \AA$ tiene acceso a una base de datos meteorológicos a nivel mundial por medio de la aplicación Meteonorm v6.0®, lo cual se constituye como una herramienta que tiene en cuenta el régimen de lluvias de la zona, nubosidad, radiación solar y vientos, tomando como referencia el punto más cercano a Subachoque que es Bogotá D.C.

\section{REFERENCIAS}

[1] Baño Nievo, Antonio et al. (2005). Guía de construcción sostenible. Recuperado el 10 de Octubre de 2011, de http://www.magrama.gob. es/es/ceneam/programas-de-educacion-ambiental/hogares-verdes/ guia-construccion-sostenible_tcm7-193266.pdf

[2] Reyes, C., Baraona Pohl, E., \& Prillo, C. (2007). Arquitectura Sostenible. 1a. Edición. España: Pencil S.L.

[3] Aurí Mellado, Enric. Guía para obtener una vivienda sostenible. España. 2005. 126 p. Ediciones Ceac.

[4] Soto, J. (2008). Sensación térmica. Recuperado el 15 de Octubre de 2011 de http://tecno.sostenibilidad.org/index.php?option=com_conten t\&task=view\&id=417\&ltemid $=1$ 


\title{
ESTUDIO DE CINCO MICROALGAS COMO FUENTES POTENCIALES DE BIODIESEL
}

\author{
Luis Miguel Serrano Bermúdez*, Luis Carlos Montenegro Ruiz**, \\ Rubén Darío Godoy*** \\ *Universidad Nacional de Colombia, Imserranob@unal.edu.co, \\ **Universidad Nacional de Colombia, Icmontenegror@unal.edu.co \\ *** Universidad Nacional de Colombia, rdgodoys@ unal.edu.co
}

Palabras Clave: Microalga, cultivo, lípidos, biodiesel.

Área Temática: Biomasa y Bioenergía

\section{INTRODUCCIÓN}

En los últimos años ha sido de gran interés el desarrollo de nuevas tecnologías para la obtención de biocombustibles, las cuales permitirían disminuir la dependencia al petróleo, uno de los combustibles responsables de la emisión al medio ambiente de $\mathrm{CO} 2$, causante del efecto de calentamiento global. Los biocombustibles actualmente empleados como el biodiesel, sin embargo, presentan también serias desventajas, estas asociadas a impactos negativos en la seguridad alimentaria y en el medio ambiente, los cuales incluyen deforestación y pérdida de biodiversidad.

Las microalgas tienen una serie de ventajas comparadas con plantas oleaginosas como la palma africana, entre las cuales están una mayor productividad de aceites por unidad de tiempo y área (hasta 23 veces) [1], posibilidad de cultivo en zonas no aptas para la agricultura como los desiertos, e incluso pueden ser cultivadas con agua de mar [2], Algunas de las microalgas que son capaces de acumular grandes cantidades de aceite son Botryococcus braunii, Nannochloropsis sp. Chlorella vulgaris, Isochrysis sp. y Scenedesmus $\mathrm{sp}$, para los cuales se ha reportado concentraciones de aceite de hasta $75 \%$, $68 \%, 56 \%, 33 \%$ y $27 \%$ de la biomasa seca, respectivamente $[1,3,4]$.

Colombia es un país tropical con condiciones adecuadas para el cultivo de microalgas, haciendo necesario realizar estudios que permitan seleccionar microalgas con perspectivas para su uso como posible materia prima de aceites para la producción de biodiesel, lo anterior fue el objetivo de la presente investigación, en la cual se cultivaron a escala laboratorio las microalgas colombianas Chlorella vulgaris, Scenedesmus ovalternus, Nannochloropsis sp. e Isochrysis sp. y la cepa foránea Botryococcus braunii UTEX 572, esta última empleada como microalga de referencia.

\section{MATERIALES Y MÉTODOS}

El cultivo de las diferentes microalgas se realizó por triplicado en botellas de vidrio. Se emplearon lámparas fluorescentes como fuente de iluminación 
artificial. El tiempo de cultivo fue hasta llegar a fase estacionaria. Al finalizar el cultivo se recuperó la biomasa por centrifugación, se llevó a peso seco por liofilización y se extrajeron los lípidos producidos según método de Bligh \& Dyer [5] y se cuantificaron según metodología de Marsh \& Weistein [6], finalmente fueron caracterizados empleando cromatógrafo de gases Shimadzu GC-14A y FAME Mix 35077 como patrón estándar.

\section{RESULTADOS}

Las microalgas de agua dulce Scenedemus y Chlorella presentaron las mayores productividades de lípidos: 18,8 y 18,7 mg.L-1.día-1, respectivamente, mientras que las microalgas marinas Nannochloropsis e Isochrysis tuvieron las menores productividades de lípidos: 10,8 y 4,9 mg.L-1.día ${ }^{-1}$, respectivamente. La productividad de lípidos de la microalga Botryococcus fue 10,0 mg-L-1 día $^{-1}$. Las anteriores productividades de lípidos son entre 1,1 y 4,1 veces mayores que la productividad de aceite de la palma africana, actual materia prima empleada en Colombia para la producción industrial de biodiesel. De acuerdo con la caracterización de los ácidos grasos producidos por las microalgas estudiadas, todas pueden ser empleadas en la producción de biodiesel, debido a la similitud de éstos con aceites ya empleados en la producción de biodiesel.

\section{CONCLUSIONES}

Las microalgas cultivadas resultaron tener productividades de lípidos lo suficientemente altas como para ser consideradas como una fuente potencial para la obtención de biodiesel, en especial las microalgas de agua dulce. Pues para el caso de la microalga Chlorella tuvo una productividad equivalente a 4,1 veces la productividad de la palma africana, actual materia prima empleada en Colombia para la obtención de biodiesel. La anterior productividad es claramente susceptible de mejora, dado que ha sido demostrado que el empleo de aire enriquecido con $\mathrm{CO} 2$ aumenta considerablemente la producción de lípidos. La anterior microalga, adicionalmente presentó una relación de ácidos grasos saturados, monoinsaturados y poliinsaturados similar a los del aceite de soya, actual segunda fuente mundial empleada en la producción de biodiesel, haciéndola potencialmente propicia para obtención de biodiesel.

\section{REFERENCIAS}

[1] Chisti, Y. (2007). Biodiesel from microalgae. Biotechnology Advances, 25(3), 294-306.

[2] Doan, T. T., Sivaloganathan, B. and Obbard, J. P. (2011). Screening of marine microalgae for biodiesel feedstock. Biomass and Bioenergy, 35(7), 2534-2544. 
[3] Lin, Q. and Lin, J. (2011). Effects of nitrogen source and concentration on biomass and oil production of a Scenedesmus rubescens like microalga. Bioresource Technology, 102(2), 1615-1621.

[4] Liu, Z.-Y., Wang, G.-C. and Zhou, B.-C. (2008). Effect of iron on growth and lipid accumulation in Chlorella vulgaris. Bioresource Technology, 99(11), 4717-4722.

[5] Bligh, E. and Dyer, W. (1959). A rapid method for total lipid extraction and purification. Canadian Journal of Biochemistry and Physiology, 37(8), 911-917.

[6] Marsh, J. B. and Weinstein, D. B. (1966). Simple charring method for determination of lipids. The Journal of Lipid Research, 7(4), 574-576. 


\title{
ESTUDIO DE FACTIBILIDAD PARA LA IMPLEMENTACIÓN DE UN SISTEMA ENERGÉTICO ALTERNATIVO EN SAN ANDRÉS ISLA - COLOMBIA
}

\author{
Jonathan Ramírez*, Rodrigo Gamba-Blanco*, Iván Rodríguez* \\ "Universidad de América, \\ jogla88@gmail.com \\ "Terra Consultores, \\ contacto@terraconsultores.com
}

Palabras Clave: Aerogeneradores, Oferta ambiental, San Andrés Isla - SAI, Sistemas de Generación Energética No Convencionales.

Área Temática: Energía Eólica

\section{INTRODUCCIÓN}

Actualmente San Andrés Isla (SAI) cuenta con un proceso de obtención de energía eléctrica que utiliza para su funcionamiento combustible fósil; interviniendo 12 máquinas generadoras que se abastecen de Diesel, generando como residuo $\mathrm{CO}_{2}$, el cual contamina el medio ambiente.

En total se obtienen $150 \mathrm{GWh}$ anuales, con un promedio de $12,5 \mathrm{GW} / \mathrm{mes}$, presentando una cobertura del $98,7 \%[1,2]$ del total de los usuarios de la isla. La generación de esta cantidad de energía produce un total de 346,12 toneladas de $\mathrm{CO}_{2} / \mathrm{año}[3]$.

\section{MATERIALES Y MÉTODOS}

Se evaluaron los siguientes sistemas de generación de energía no convencionales: eólico, solar, conversión de biomasa, geotérmico, undimotriz, mareomotriz e hidráulica; se analizaron características como la capacidad de producción, costos de instalación y operación, oferta ambiental presentada por SAI y mínimo requerido. Una vez establecido el sistema, se evalúo la selección del terreno, del proveedor de los aerogeneradores, costos de instalación y transporte desde la casa matriz del proveedor.

Se evaluó la posibilidad de ofrecer en el mercado la venta de bonos de carbono (CER'S) equivalentes a las toneladas de dióxido de carbono que se dejarían de emitir al implementar un sistema energético alternativo.

\section{RESULTADOS}

En la tabla 1 se contrasta la oferta ambiental de SAI respecto a los mínimos requeridos para el óptimo funcionamiento de cada sistema; y realizando la evaluación multifactorial de factibilidad se obtuvo como resultado que el sistema de generación de energía no convencional con la mayor factibilidad técnica y ambiental de implementación en San Andrés Isla es el eólico. 
Sobre este sistema se realizó un estudio de proveedores, evaluando los costos de adquisición de las torres aerogeneradoras, el transporte desde el país de producción, el costo de instalación, seleccionando entre 6 proveedores (Gamesa, General Electrics Energy, Furhlander, Nordex y Vestas) a Nordex como proveedor de los aerogeneradores (Nordex N100-2500) de 2,5 Mw.

Tabla 1. Mínimos requeridos para el óptimo funcionamiento de los sistemas energéticos alternativos comparado con la oferta ambiental presentada por SAI

\begin{tabular}{|l|l|l|l|}
\hline Sistema alternativo & \multicolumn{1}{|c|}{ Mínimo funcional } & \multicolumn{1}{|c|}{ Oferta SAl } & $\begin{array}{c}\text { Factibilidad } \\
\text { SAI }\end{array}$ \\
\hline Eólica promedio & Entre $4 \mathrm{~m} / \mathrm{s}$ y $5 \mathrm{~m} / \mathrm{s}$ & Entre $4 \mathrm{y} 7 \mathrm{~m} / \mathrm{s}$ & Óptimo \\
\hline Solar & Entre $0,45 \mathrm{y} 1,35 \mathrm{kWh} / \mathrm{m} 2$ & Entre $4,4 \mathrm{y} 6 \mathrm{kWh} / \mathrm{m} 2$ & Óptimo \\
\hline Biomasa & $\begin{array}{l}0,700 \mathrm{~m} 3 / \mathrm{hora} \text { para la } \\
\text { generación de } 1 \mathrm{~kW} / \mathrm{h}\end{array}$ & $3,05 \mathrm{~m} 3 / \mathrm{hora}$ & Óptimo \\
\hline Geotérmica & $\begin{array}{l}\text { Profundidad superior a los } \\
3000 \text { metros con temperatu- } \\
\text { ra de } 148^{\circ} \mathrm{C}\end{array}$ & Nulo. & Nulo \\
\hline Undimotriz & $\begin{array}{l}15 \mathrm{~kW} \text { por metro de ancho } \\
\text { de la ola (onda senoidal de } \\
\text { amplitud constante) }\end{array}$ & $\begin{array}{l}\text { Entre } 2,36 \mathrm{y} 15,01 \mathrm{~kW} \text { por } \\
\text { metro de ancho de la ola }\end{array}$ & Funcional \\
\hline Mareomotriz & $\begin{array}{l}\text { Amplitud de la marea de } 5 \\
\text { metros }\end{array}$ & $\begin{array}{l}\text { Amplitud de marea promedio } \\
\text { de } 0,23 \mathrm{~m} .\end{array}$ & Mínimo \\
\hline Entre $10 \mathrm{y} 100 \mathrm{MW}$ & Nulo & Nulo \\
\hline
\end{tabular}

De acuerdo a las características del viento en SAI y las especificaciones técnicas de NORDEX cada torre N100 tendría la capacidad de generar un total de 14,48 Gwh/año. El análisis financiero obtuvo los siguientes resultados: una T.I.O. de $12 \%$ (exigida para proyectos energéticos por el gobierno nacional); un V.P.N. de \$95'259'285.641,6; y una T.I.R. de 36\%. Lo cual evidencia que el proyecto es financieramente viable.

\section{CONCLUSIONES}

SAl cuenta con un sistema energético contaminante, generando un estimado total para el 2012 de 346,12 toneladas de $\mathrm{CO}_{2}$. SAl Cuenta con una gran oferta ambiental para lograr la implementación de energías alternativas, gracias 
a su posición dentro de la zona intertropical. El sistema energético actual es un sistema de producción costoso, generar un kWh cuesta $\$ 323,93$ para el 2012 generando sobrecostos en la factura de pago, mientras que el sistema eólico tendría un costo promedio de \$96,9 una diferencia por kWh de \$227,03. El impacto ambiental generado por el sistema energético eólico, se establece como un impacto global moderado implicando una invasión mínima al medio ambiente.

\section{REFERENCIAS}

Gobernación de San Andrés, Consejo Comunal San Andrés. Recuperado el 15 de febrero de 2011 de http://www.ipse.gov.co /index.php? limitstart $=60$ \&lang $=\mathrm{es}$

Ministerio de Minas y Energía. Sector Energía eléctrica. Recuperado de http://www.minminas.gov.co/minminas/downloads/UserFiles/File/Memorias/Memorias_2010/04-energia_electrica\%20(2).pdf

Environmental Protection Agency [EPA]. Recuperado de http://www.epa. gov/oms/climate/420f05001.html 


\title{
EVALUACIÓN DE LA PRODUCCIÓN DE HIDRÓGENO EMPLEANDO CEPAS NATIVAS DE Clostridium spp A PARTIR DE GLICEROL COMO FUENTE DE CARBONO
}

\author{
Lizeth Tinoco, ${ }^{3}$ Luz Torres, ${ }^{3}$ Dionisio Malagón-Romero, ${ }^{2}$ \\ José Bernal, ${ }^{1}$ Dolly Montoya, ${ }^{1}$ \\ ${ }^{1}$ Universidad Nacional de Colombia, Instituto de Biotecnología, \\ dhmalagonr@unal.edu.co \\ 2 Universidad Santo Tomás, ${ }^{3}$ Universidad de América-Bogotá \\ Katerine890911@gmail.com
}

Palabras claves: Biocombustibles, Fermentación anaerobia, Glicerol, Hidrógeno, Modelo matemático.

\section{INTRODUCCIÓN}

La producción de biodiesel está generando altos volúmenes de glicerol que conllevan a procesos alternos de separación y purificación. Una alternativa para su uso, lo constituye el empleo como fuente de carbono para la producción de hidrógeno, producto de valor agregado, empleando microorganismos del género Clostridum spp [1]. En el presente trabajo investigativo se estandarizó la producción de hidrógeno utilizando glicerol como sustrato usando 13 aislamientos nativos de Clostridium spp pertenecientes al cepario del Instituto de Biotecnología de la Universidad Nacional.

\section{MATERIALES Y METODOS}

Se emplearon 2 cepas patrón y 13 cepas nativas, provenientes del banco de cepas y genes del Instituto de Biotecnología de la Universidad Nacional de Bogotá (IBUN), aisladas de suelos colombianos y caracterizadas bioquímica y molecularmente en estudios anteriores [2]. Se utilizaron dos medios de cultivo: reinforced culture medium (RCM) para mantener los microorganismos en forma esporulada y para cultivar los pre-inóculos y medio industrial con glicerol, para realizar los inóculos necesarios en el desarrollo de las curvas de crecimiento. El crecimiento microbiano fue evaluado mediante peso seco de la biomasa; la cuantificación de ácidos, solventes y consumo de sustrato se realizó a través de Cromatografía Liquida de Alto Rendimiento (HPLC). Los gases generados en la fermentación fueron cuantificados mediante Cromatografía de Gases (GC). Se seleccionó la cepa nativa más promisoria para realizar una fermentación por lote en un reactor R'ALF Plus (Bioengineering), con un volumen de trabajo de 4 litros en las siguientes condiciones: $37^{\circ} \mathrm{C}$, agitación de $200 \mathrm{rpm}$ y pH inicial de 7.0, empleando medio Industrial. Finalmente, a partir de los datos cinéticos obtenidos se llevó a cabo el ajuste de un modelo matemático usando las herramientas disponibles en MATLAB $®$, que describe la formación de biomasa, producto y consumo de sustrato, empleando modelos no estructurados. 


\section{RESULTADOS Y ANALISIS}

A partir de los resultados obtenidos se seleccionó la cepa más productora de ácido butírico e hidrógeno (IBUN 18S), debido a que no se presentó producción de butanol. Se obtuvo una productividad de $0,0152 \mathrm{~g}$ ac. but. $\mathrm{l}^{-1} \mathrm{glicerol}$ $\mathrm{h}^{-1}$ y $0,3167 \mathrm{mg} \mathrm{H}_{2} \mathrm{l}^{-1}$ glicerol. $\mathrm{h}^{-1}$ y un rendimiento de $0,2138 \mathrm{~mol}^{-1}$ ac. But mol${ }^{1}$ glicerol y $0,1962 \mathrm{~mol} \mathrm{H}_{2} \cdot \mathrm{mol}^{-1} \mathrm{glicerol}$. El modelo ajustado para describir el comportamiento cinético corresponde al de Luedenking-Piret y LuedenkingPiret modificado, para la cinética de crecimiento celular, producción de ácido butírico e hidrógeno y consumo de sustrato, obteniendo los coeficientes de determinación superiores a 0,95 para biomasa y sustrato y de 0,77 y 0,87 para los productos.
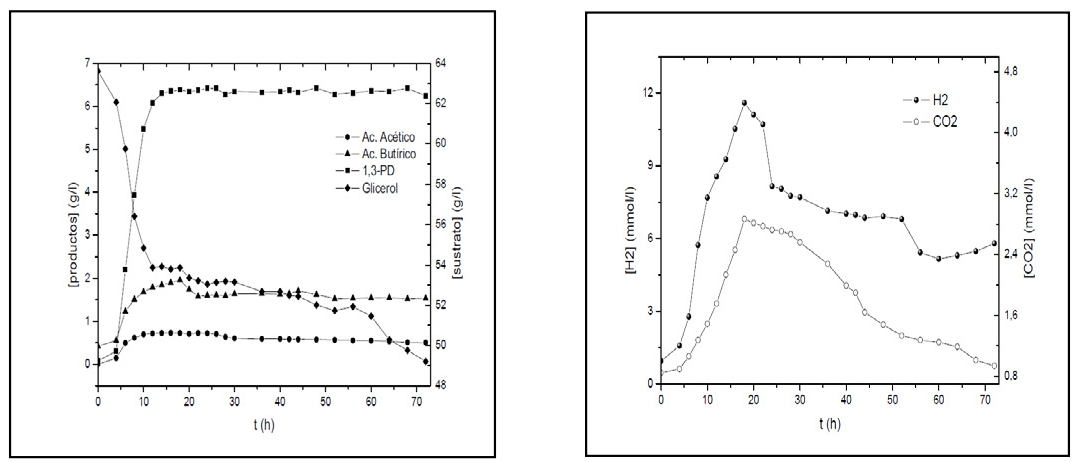

Figura 1. Perfiles de fermentación de la cepa IBUN $18 \mathrm{~S}$ evaluados en reactor por lote.

Tabla 1. Parámetros cinéticos ajustados a los modelos no estructurados
Parámetros
valor
$\mathbf{R}^{2}$

Biomasa: Ecuación Logística
$\mu_{m} \mu_{m}\left(\mathrm{~h}^{-1}\right)$
0,2959
$X_{m} X_{m}\left(g . l^{-1}\right)$
1,0153

Sustrato: Luedeking-Piret Modificado
$\gamma_{\gamma}\left(\mathrm{gS} . \mathrm{gx}^{-1}\right)$
13,5839
$\delta_{\delta}\left(\mathrm{gS} \cdot \mathrm{gx}^{-1} \cdot \mathrm{h}^{-1}\right)$
0,0497 
Ácido Butírico : Luedeking-Piret
$\alpha \alpha\left(\right.$ gBut.gx $\left.^{-1}\right)$
2,0391
$\boldsymbol{\beta}_{\beta}\left(\mathrm{gBut} . \mathrm{gx}^{-1} \cdot \mathrm{h}^{-1}\right)$
$-0,0048$

Hidrógeno: Luedeking-Piret

$\begin{array}{crc}\alpha_{\alpha}\left(\mathrm{gH}_{2} \cdot \mathrm{gx}^{-1}\right) & 12,4842 & 0,77 \\ \beta_{\beta}\left(\mathrm{gH}_{2} \cdot \mathrm{gx}^{-1} \cdot \mathrm{h}^{-1}\right) & -0,0666\end{array}$

\section{CONCLUSIONES}

Se seleccionó la cepa IBUN 18 por presentar una productividad volumétrica mayor respecto al hidrógeno de $0,3167 \mathrm{mgH}_{2} \mathrm{l}^{-1} \cdot \mathrm{h}^{-1}$. No se generó butanol por parte de las cepas nativas ni patrón, se obtuvieron rendimientos molares de $0,1962 \mathrm{molH}_{2} \cdot \mathrm{mol}^{-1}$ glicerol y 0,2138 mol ac. Butírico mol-1 $\mathrm{glicerol}$ Se ajustaron los modelos matemáticos satisfactoriamente en la mayoría de los casos obteniendo los coeficientes de determinación superiores a 0,95 para biomasa y sustrato y de 0,77 y 0,87 para los productos. Estos resultados resultan prometedores y plantean una posibilidad de uso de sub-productos asociados a la producción de biodiesel para la generación de hidrógeno al compararlos con lo reportado internacionalmente [3]

\section{REFERENCIAS}

[1] ARAGÓN, Oscar Leonardo. Estudio de la viabilidad técnica de la producción de 1,3-Propanodiol a partir de glicerol con nuevas cepas colombianas de Clostridium sp.(IBUN). Bogotá, 2007.

[2] MONTOYA, Dolly; SPITIA, Sandra; SILVA Edelberto and WOLFGANG $H$. SCHWARZ. Isolation of mesophilic solvent-producing clostridia from Colombian sources: physiological characterization, solvent production and polysaccharide hydrolysis. Journal of Biotechnology 79, 2000. p.2

[3] HALLENBECK, Patrick C; ABO-HASHESH, Mona and GHOSH,Dipankar. Strategies for improving biological hydrogen production. Département de microbiologie et immunologie, Université de Montréal.,El sevier. Bioresource Technology, 2012. 


\section{VEHICULO PROPULSADO CON GASOHOL}

Fabio Mora, Christian Rubiano, Carlos Arévalo, Santiago Nieves,

Brayan Hernández, Jesse Fritz

Escuela Colombiana de Carreras Industriales

fking_m@ @otmail.com

Escuela Colombiana de Carreras Industriales

Camilorg07@ hotmail.com el_gatofritz@ hotmail.com; brayanshd29@ hotmail.

com; santiman_90@ hotmail.com;carlos.arevalo2011@ hotmail.com

apaolagv@gmail.com

alejo_mayorga@yahoo.com

"El agua es el combustible del futuro." Julio Verne.

Palabras Clave: Contaminación, combustibles, propulsiones, biomasa. Área Temática: Energías renovables.

\section{INTRODUCCIÓN}

Este proyecto busca contribuir a la disminución del efecto invernadero causado por las emisiones de diferentes gases (derivados de los combustibles fósiles); remplazando el combustible de los vehículos por una combinación óptima de porcentajes de gasolina y etanol (gasohol) que genere mayor rendimiento en el vehículo sin que la vida útil del motor disminuya, aprovechando el auge del etanol como fuente de energía alternativa, teniendo en cuenta que este sea mezclado con gasolina. Dependiendo de los porcentajes de la mezcla será necesario realizar cambios al sistema de encendido y carburación del motor [1]. El etanol al ser utilizado como combustible es un alcohol libre de agua, con un octanaje mayor al de la gasolina y es producido por la fermentación de azucares de procedencia natural, al agregar un $10 \%$ de etanol a la gasolina se obtiene una reducción del $40 \%$ de las emisiones como monóxido de carbono y dióxido de carbono. [2]

La desventaja, es que en comparación con la energía que se consume para producirlo es muy poca la que aprovecha en su utilización, por lo cual todavía no se está usando de manera óptima. El etanol producido a base de productos agrícolas genera polémicas muy fuertes pues para algunos sería un recurso energético que tendría un crecimiento potencialmente sostenible que puede generar un gran impacto ambiental ya que no dependería tanto de los combustibles fósiles, mientras que para otros este tipo de producción de etanol genera grandes deforestacionesa la par que se amplía la frontera agrícola (cambio de uso de suelo), por lo cual surge un alza en el precio de los alimentos de la economía local. 


\section{MATERIALES Y MÉTODOS}

Para verificar la eficacia del gasohol se harán pruebas enfocadas al funcionamiento del motor y rendimiento como los ensayos de potencia y temperatura, igualmente se hará una comparación entre ensayos tomados entre etanol 5\% 10\% 25\% (etanol tomado de residuos naturales como desechos orgánicos o industriales), junto con pruebas de impurezas, densidad y color, los ensayos de emisión de gases son fundamentales para comprobar la importancia del gasohol como combustible, se necesitara la base de etanol y gasolina para crear gasohol de diferente composición, mirar los cambios producidos en el ambiente y el automóvil para encontrar el mas adecuado para su implementación en los autos de Colombia.

\section{RESULTADOS}

Se espera encontrar la mezcla adecuada que permita el mejor funcionamiento del motor.El etanol puro al estar en combustión en el interior del motor puede reaccionar o disolver materiales de goma y plásticos, por lo cual al motor con el que se pretende demostrar el proceso de funcionamiento de una mezcla saturada en etanol se le deben realizar cambios en su estructura.

Para realizar el cambio en un automóvil que trabaja con gasolina pura a uno que utilice una mezcla de "gasohol", sé requiere un carburador con mayor potencia y caudales más grandes (aumentando el área en un 30\% o 40\%) [3]. Para lograr que un motor funcione con una mezcla de gasohol saturada en etanol se deben realizar además cambios como el sistema de arranque, ya que va a pasar a necesitar un sistema de arranque en frio para asegurar la suficiente de vaporización con temperaturas por debajo de $15^{\circ} \mathrm{C}$ a $11^{\circ} \mathrm{C}$ para maximizar la combustión, evitar problemas de arranque con el motor frío y para reducir al mínimo la no combustión de etanol no vaporizado.

\section{CONCLUSIONES}

Con la elaboración de este proyecto de investigación se realizara la conversión en un vehículo de motor a cuatro tiempos de ciclo Otto de ignición por chispa para que trabaje con una mezcla de "gasohol" saturado en etanol verificando que esta produzca los mejores resultados en la eficiencia del motor, también se espera fortalecer el sentido de pertenencia y compromiso con el ambiente ya que el proyecto plantea una nueva forma para la producción de etanol a partir de la fermentación de los residuos orgánicos comunes y no como se está produciendo ahora a partir de un monocultivo. 


\section{REFERENCIAS}

[1] "CEPAL: Especificaciones de la calidad del etanol y del gasohol (mezcla de gasolina y etanol) y normas técnicas para la infraestructura" Recuperada el 27 de septiembre de dhttp://www.eclac.cl/publicaciones/xml/6/26436/L741-1.pdf

[2] ClanEco. Bioetanol. Recuperado el 27 de septiembre de 2012 http:// www.claneco.com/cl/ecopedia/bioetanol/.

[3] Estévez Somolinos, S. (s.f.). El motor de gasolina. Recuperado de http://www.claneco.com/cl/ecopedia/bioetanol/

Video. Recuperado el 10 de marzo de 2012 de http://www.youtube.com/ watch?v=Aif37y3rEX4

Video. Recuperado de http://www.mineducacion.gov.co/cvn/1665/article-117028.html

Diario el país Congreso aprueba proyecto de ley de etanol y biocombustibles. Publicada: Viernes 17, Diciembre 2004 19:31 (GMT -0400).

Naciones Unidas, Comisión económica para América Latina y el Caribe - Cepal, Especificación de la calidad del Etanol Carburante y de Gasohol (Mezcla de Gasolina y Etanol) y Normas Técnicas de Infraestructura. Recuperado de http://www.eclac.cl/publicaciones/xml/6/26436/L741-1.pdf

Gasohol Competition Act of 1980, United States. Recuperado de http:// www.scirus.com/srsapp/search?q=gasohol\&t=all\&sort=0\&g=s

M.A. Johnson. Emission of polycyclic aromatic hydrocarbons from gasohol and ethanol Atmospheric Environment, Volume 43, Issue 3, January 2009, Pages 648-654

On gasohol and energy analysis. Energy, Volume 8, Issue 3, March 1983, Pages 225-233 


\title{
PRODUCCIÓN DE BIODIESEL A CONDICIONES SUPERCRÍTICAS: RESULTADOS EXPERIMENTALES Y EVALUACIÓN DE IMPACTO AMBIENTAL
}

\author{
Víctor Marulanda* \\ *Universidad de La Salle, Bogotá \\ vfmarulanda@unisalle.edu.co
}

Palabras Clave: biodiesel, transesterificación supercrítica, evaluación ambiental

Área Temática: Biocombustibles

\section{INTRODUCCIÓN}

La transesterificación supercrítica (TS), proceso llevado a cabo a temperaturas en el rango 250 a $350^{\circ} \mathrm{C}$ y presiones de 100 a 300 bar, ha demostrado ser un método eficiente para la producción de biodiesel, al superar las limitaciones que en cuanto a materia prima y uso de catalizadores presentan los procesos convencionales catalizados por ácido o base [1,2]. Sin embargo, las altas relaciones molares de alcohol a triglicéridos requeridas han retrasado el escalado de esta tecnología a nivel industrial. Estudios recientes han mostrado que es posible usar relaciones molares moderadas de reactantes $(6: 1$ a 18:1) a temperaturas de reacción más altas $\left(350\right.$ a $\left.400{ }^{\circ} \mathrm{C}\right)$, con el fin de reducir el consumo energético de las operaciones de recuperación del exceso de alcohol [3].

En este trabajo se discuten los resultados experimentales de la TS en un proceso batch y uno continuo de grasas animales y aceite crudo de palma, con metanol y etanol, respectivamente, en el rango de temperaturas de 350 a $400{ }^{\circ} \mathrm{C}$, presiones de 100 a 300 bar y relaciones molares de reactantes de 9:1 a 15:1. Con base en estos resultados, y por medio de una metodología de ingeniería de procesos, se planteó el diseño de una planta industrial y se realizo la simulación con el fin de obtener la composición de todas las corrientes y el consumo energético. Esta información permitió realizar una evaluación de impacto ambiental del proceso supercrítico vs el proceso convencional catalizado por bases.

\section{MATERIALES Y MÉTODOS}

Grasa animal, procedente de una industria de procesamiento de alimentos, y aceite crudo de palma, obtenido de una industria Colombiana de producción de biodiesel por medio del método convencional, fueron sometidas a TS con metanol y etanol, respectivamente. El avance de la reacción fue seguido por medio del análisis de glicerol libre y unido, de acuerdo con la metodología ASTM, en un cromatógrafo de gases con detector de ionización de llama. 
La simulación de un proceso continuo a nivel de planta industrial para la TS de grasa animal y metanol se realizó por medio del simulador de procesos químicos Aspen Plus. La evaluación de impacto ambiental, con base en la información obtenida del simulador, se realizó por medio del software WARGUI, desarrollado por la EPA.

\section{RESULTADOS}

Tanto el proceso continuo de TS de grasa animal con metanol y el proceso batch de TE de aceite crudo de palma con etanol permitieron obtener biodiesel con una conversión mayor a $99.9 \%$ de los triglicéridos a temperaturas de $400{ }^{\circ} \mathrm{C}$ y relaciones molares de 9:1 a 15:1, respectivamente. Adicionalmente, debido a las condiciones extremas de reacción, se verificó la descomposición del subproducto glicerol en distintos compuestos, tales como éteres, los cuales tienen el potencial de usarse como parte del combustible y mejorar algunas propiedades del biodiesel obtenido.

Las condiciones óptimas de operación para el proceso continuo de TS de grasa animal con metanol fueron la base para el diseño y simulación del proceso industrial de producción y obtención de biocombustible al 99.8\%. A pesar de la elevada temperatura de reacción, la simulación mostro que el consumo energético del proceso supercrítico es menor que el del proceso convencional, debido al menor número de operaciones de separación y purificación del biodiesel en el primero. Por medio del software WAR-GUI (Waste Reduction Algorithm Graphical User Interface), se evaluó el potencial de impacto ambiental para el proceso propuesto y el convencional, con base en ocho categorías de potencial de impacto terrestre y humano. El indicador global, obtenido de la ponderación del impacto de las diferentes categorías, permitió concluir que el proceso supercrítico produce un menor potencial de impacto ambiental, al tener un consumo energético menor y al no generar aguas residuales debido a la ausencia de catalizador y a la posibilidad de usar los productos derivados del glicerol como parte del biocombustible.

\section{CONCLUSIONES}

El proceso de transesterificación supercrítica para la producción de biodiesel ha despertado un gran interés en la última década debido a sus ventajas en comparación con el proceso convencional de catálisis ácida y básica [2]. En este trabajo se estudio un proceso continuo y uno batch de TE a partir de grasas animales y aceite crudo usando metanol y etanol. El biodiesel obtenido cumple con el estándar ASTM para glicerol libre y unido, incluso sin operaciones adicionales de tratamiento. Adicionalmente, la simulación del proceso, con base en los resultados experimentales, mostro un mejor desempeño ambiental en comparación con el proceso convencional al tener un menor consumo energético y menos subproductos. 


\section{REFERENCIAS}

[1] Sawangkeaw R., Bunyakiat K., Ngamprasertsith S. A review of laboratory-scale research on lipid conversion to biodiesel with supercritical methanol (2001-2009). J Supercrit. Fluids, 55, 1-13, 2010.

[2] Pinnarat T., Savage, P.E., Assessment of noncatalytic biodiesel synthesis using supercritical reaction conditions. Ind. Eng. Chem. Res., 47, 6801-6808, 2008.

[3] Marulanda, V., Anitescu,G., Tavlarides, L. Biodiesel fuels through a continuous flow process of chicken fat supercritical transesterification. Energy \& Fuels., 24, 253-260, 2010 


\title{
DIMENSIONAMIENTO DE UN SISTEMA FOTOVOLTAICO INTERCO-
} NECTADO PARA SUPLIR LAS NECESIDADES ENERGÉTICAS DE LA SALA DE TUTORÍAS DE LA FACULTAD DE INGENIERÍA AMBIENTAL DE LA UNIVERSIDAD SANTO TOMÁS

\author{
Julián Aristizábal, Alejandra Torres, Ivonne Parrado, Amelia Pérez \\ Universidad Santo Tomás,
}

andres.aristizabal@usantotomas.edu.co, mariaatorres@usantotomas.edu.co, ivonneparrado@usantotomas.edu.co, ameliaperez@usantotomas.edu.co

Palabras Clave: Dimensionamiento, energía solar, potencia, sistema fotovoltaico.

Área Temática: Energía Solar.

\section{INTRODUCCIÓN}

En los últimos años, la industria fotovoltaica ha tenido un crecimiento explosivo como consecuencia de las políticas gubernamentales de subsidio al uso residencial de sistemas fotovoltaicos. Como consecuencia de esto, la industria fotovoltaica ha crecido en los últimos 5 años a un ritmo del $30 \%[1]$.

Mas del $80 \%$ de la producción mundial actual de módulos FV corresponde a la tecnología de silicio mono y policristalino mientras que la tecnología de capa delgada contribuye con alrededor del $12 \%$. Dentro de la tecnología de capa delgada, 3 materiales fotovoltaicos permitieron fabricar celdas solares que en la actualidad se producen industrialmente: silicio amorfo (a-Si), CdTe y CulnSe2 (CIS) [2]. El precio promedio de $1 \mathrm{kWh}$ cobrado por la empresa de servicios públicos de Energía de Bogotá (Codensa) para el estrato 3 de servicio residencial es de $\$ 222.25$ pesos colombianos (11 centavos de dólar, tomando en cuenta que US $\$ 1=\$ 1970$ pesos colombianos) [3]. Los significativos avances en la eficiencia de las celdas FV podría llevar a sistemas con un costo de instalación de sólo US $\$ 3 / \mathrm{W}$, produciendo electricidad a un costo de 8-10 centavos de dólar por kWh, lo cual haría la energía solar competitiva dentro del mercado mundial, ya que el costo por kWh en dólares varía entre 6.21-20.70 centavos de dólar [3]. En ese trabajo se presenta el dimensionamiento para calcular la potencia necesaria de un sistema fotovoltaico interconectado con la red eléctrica que permita suministrar perfiles del $100 \%$ y el $70 \%$ de la carga que demanda la sala de tutorías de la Facultad de Ingeniería Ambiental de la Universidad Santo Tomás.

\section{MATERIALES Y MÉTODOS}

Se realiza el cálculo de la potencia pico que debe entregar el generador FV y el inversor: 


$$
P_{G F V}=\frac{\sum_{i=1}^{\mathcal{L}} \frac{E_{i}}{H S S_{i} \cdot N_{i} \cdot R}}{\mathcal{L}}
$$

$$
F_{\mathbb{D}}=\frac{P_{\text {máxima }, \text { Inversor }}}{P_{\text {nominal }, \text { Generador }}}=\frac{P_{\max , I}}{P_{\max , G}}
$$

Donde Ei es la producción promedio de electricidad solar mensual (en kWh/ mes) que se define por el usuario, y que en éste caso sería la energía consumida en la instalación. HSS es el número de horas de radiación solar estándar promedio mensual de la localidad, $\mathrm{Ni}$ es el número de días del respectivo mes y $P R$ es el factor de rendimiento del sistema: permite introducir un sobredimensionamiento del $10-20 \%$ del generador FV por seguridad y oscila entre 0,7 y 0,9 . Para llevar a cabo el dimensionamiento del inversor, se define el tamaño relativo Generador-Inversor (ecuación 2) de forma tal que se sobredimensione el generador fotovoltaico con respecto al inversor.

En Bogotá existen 3,5 HSS [4] y se tuvo en cuenta para el cálculo un factor de rendimiento del $20 \%$, un FDI de 0,83 y las características eléctricas de paneles FV's marca Isofotón de 150W [5] e inversores marca Xantrex de 3000 y $5000 \mathrm{~W}[6]$.

\section{RESULTADOS}

La carga de la sala de tutorías de la Facultad de Ingeniería Ambiental está compuesta por un circuito de iluminación de 12 lámparas fluorescentes de $17 \mathrm{~W}$ c/u para un total de $204 \mathrm{~W}$ y un conjunto de 12 computadores de escritorio de $135 \mathrm{~W}$ c/u para un total de $1620 \mathrm{~W}$. De esta forma, la potencia total consumida asciende a $1824 \mathrm{~W}$; y teniendo en cuenta que la sala opera 12 horas diarias, la energía total diaria consumida representa $21888 \mathrm{Wh}$-día. En la Tabla 1 se presenta el dimensionamiento que cubriría el $100 \%$ y el $70 \%$ de la demanda de la carga:

\begin{tabular}{|l|l|l|}
\hline Características & $\begin{array}{l}\text { Para cubrir el 100\% de la car- } \\
\text { ga }\end{array}$ & $\begin{array}{l}\text { Para cubrir el 70\% } \\
\text { de la carga }\end{array}$ \\
\hline $\begin{array}{l}\text { Generador FV: paneles } \\
\text { isofotón 150W, 8,12A } \\
\text { (Imax), 18,5V (Vmax), } \\
\text { 12V nom paneles }\end{array}$ & $\begin{array}{l}35 \\
(5250 \mathrm{~W})\end{array}$ \\
\hline $\begin{array}{l}\text { Inversor Xantrex 300W- } \\
\text { 5000W (Psalida), } \\
\text { 208Vac, 60Hz, 200- } \\
\text { 400V (MMPT) }\end{array}$ & 2 inversores de 3000W (6000W) & 1 inversor (5000W) \\
\hline
\end{tabular}

Tabla 1. Dimensionamiento del sistema FV interconectado y características de los equipos. 


\section{CONCLUSIONES}

El dimensionamiento para cubrir el $100 \%$ de la carga permitiría independizar el consumo de energía de la red eléctrica y el sistema FV apoyaría a ésta última cuando los usuarios no utilicen el total de la carga. Este primer sistema tendría un costo aproximado de $\$ 109.000 .000$ (sólo generador FV e inversores). En el caso del cubrimiento del $70 \%$, la sala consumiría en teoría un $30 \%$ de energía de la red eléctrica y el intercambio energético con ésta variaría según los índices de uso de la carga. En este último caso, el sistema tendría un costo aproximado de $\$ 81.000 .000$. En ambas situaciones la recuperación económica de la inversión no sería posible dado que la vida útil de los paneles fv oscila entre 25-30 años, el costo del kWh convencional es mucho más bajo que el FV y las políticas gubernamentales de Colombia para éste tipo de fuente de energía distribuida no subsidia la inversión inicial ni compra al usuario el kWh extra inyectado a la red, como si ocurre en países como Alemania, Japón, entre otros.

\section{REFERENCIAS}

[1] W. Hoffman, 17th European Photovoltaic Solar Energy Conference, Munich (2001)851.

[2] A. Jaeger, "A European Road map for PV R\&D," E-RMS Spring Meeting, 2003.

[3] Proyecto de acuerdo 162 de 2008. Secretaría General de la Alcaldía Mayor de Bogotá D.C. Recuperado el 30 de agosto de 2012 de http:// www.alcaldiabogota.gov.co/sisjur/normas/Norma1.jsp?i=29525

[4] N. Forero. "Desarrollo de un prototipo de estación autónoma de medición automática de radiación solar velocidad de viento y temperatura ambiente."Tesis doctoral. Departamento de Física, Universidad Nacional de Colombia, Bogotá, Colombia, 2006.

[5] Módulo monocristalino ISF-145/150, marca Isofotón. Recuperado el 1 de Octubre de 2012 de http://www.isofoton.com/sites/default/files/ ESP\%20ISF\%20145-150.pdf

[6] Inversores dc/ac XPower de alta potencia marca Xantrex. Recuperado el 1 de Octubre de 2012 de http://www.xantrex.com/power-products/ power-inverters/xpower-inverters-high-power.aspx 


\title{
REPORTE PRELIMINAR DEL DISEÑO DEL PROTOTIPO DE UN BIORREACTOR ALIMENTADO POR ENERGÍA FOTOVOLTAICA, PARA LA PRODUCCIÓN DE COMPOST, A PARTIR DE AZOLLA FILICULOIDES Y TYPHA LATIFOLIA, DE LA LAGUNA CHOCOLATE DE UNE CUNDINAMARCA
}

\author{
Juan Israel Torres Usechi*, Fredy Giovanny Mesa* \\ israeltor@ hotmail.com \\ fgmesar@gmail.com \\ *Universidad Libre
}

Palabras Clave: Biorreactor, compost, fotovoltaico, macrófitas, eutrofización Área Temática: Biomasa, energía fotovoltaica

\section{INTRODUCCIÓN}

La rápida proliferación de Azolla filiculoides y Typha latifolia en la laguna Chocolate ubicada en el municipio de Une Cundinamarca, está generando un gran impacto ambiental. Además, la laguna es de vital importancia, ya que es la segunda fuente de abastecimiento del acueducto del casco urbano del municipio; y ya que estas plantas pueden deteriorar rápidamente un ecosistema y perjudicar a las personas que dependen de una u otra forma de este [1], se plantea una solución alternativa que propende por garantizar la cantidad y calidad del recurso hídrico del que se dispone, pues este se constituye en un recurso vital para sus habitantes; que al extraer las plantas, no se disponga simplemente de ellas en la orilla, pues su proceso de descomposición natural altera el ecosistema, sino que se aproveche la biomasa de estas especies para la producción de compost; para lo cual, se está estudiando este proceso en un sistema cerrado, energizado fotovoltaicamente y controlado para acelerarlo.

\section{MATERIALES Y MÉTODOS}

Se está estudiando el comportamiento del proceso de compostaje para la mezcla de estas macrófitas en un biorreactor piloto, pues el resultado final de este proceso depende de las características fisicoquímicas del sustrato y de las condiciones ambientales de la zona, ya que cuando se desea biorremediar usando macrófitas, es necesario realizar estudios previos a escala, como afirma Arroyave en su estudio acerca de las aplicaciones de Lemna minor: "se necesita instalar plantas piloto para evaluar variables de diseño específicas para cada región, cada planta y cada tipo de efluente" [2], y se decidió estudiar el proceso en un sistema cerrado, ya que "el diseño de biorreactores para la fermentación en medio sólido ha avanzado lentamente en la última década debido a problemas de operación, fenómenos de transporte y escalamiento, por lo que es una tarea de la biotecnolog ía que se encuentra en un estado de intenso desarrollo" [3], y además, en un sistema cerrado se puede controlar y acelerar el proceso. 
Se construyó un bioreactor piloto de bajo costo, dotado de sensores de humedad, temperatura, $\mathrm{pH}$ y Oxígeno; y dado que a la laguna no llega la red eléctrica, se ha implementado un sistema de suministro de energía fotovoltaica para el biorreactor acorde a las condiciones climáticas de la zona. Se realizaron análisis fisicoquímicos y microbiológicos de agua cruda de la laguna, de composición elemental y de metales para las macrófitas y con los resultados de estos análisis se determinó su fórmula empírica, para calcular la demanda estequiométrica de Oxígeno y la tasa de aireación requerida [4]. Luego, se calculó la relación $\mathrm{C} / \mathrm{N}$ necesaria para iniciar el proceso, se diseñó el biorreactor para manejar una carga de $10 \mathrm{~kg}$ de mezcla y se dimensionó el sistema fotovoltaico para suministrar energía al sistema electrónico y de sensores, teniendo en cuenta la demanda de energía, y que el promedio multianual global de radiación solar para esta región es de 3,5-4 $\mathrm{kWh} / \mathrm{m}^{2}$ y su promedio multianual de brillo solar es de $4-5$ horas de sol al día [5]. Actualmente, la investigación se encuentra en la etapa de toma de datos del proceso de compostaje dentro del biorreactor controlando el nivel de $\mathrm{O}_{2}$ sin inoculación.

\section{RESULTADOS}

Los análisis fisicoquímicos y microbiológicos de agua cruda mostraron que ésta no contiene metales pesados ni elementos patógenos. Los análisis de composición de metales en las macrófitas confirmaron la ausencia de estos metales. Con los análisis de composición elemental y de composición de metales en las macrófitas se calculo la fórmula empírica y se llegó a:

Fórmula empírica Azolla filiculoides: $\mathrm{C}_{35} \mathrm{H}_{56} \mathrm{O}_{20} \mathrm{~N}$

Fórmula empírica Typha latifolia: $\mathrm{C}_{64} \mathrm{H}_{124} \mathrm{O}_{54} \mathrm{~N}$

Al balancear la ecuación, se calculó la demanda de Oxígeno estequiométrico y la tasa de aireación:

Azolla f: $\mathrm{C}_{35} \mathrm{H}_{56} \mathrm{O}_{20} \mathrm{~N}+153 \mathrm{O}_{2} \stackrel{\begin{array}{c}\text { Bacterias } \\ \text { Hongos }\end{array}}{\longrightarrow} 140 \mathrm{CO}_{2}+106 \mathrm{H}_{2} \mathrm{O}+4 \mathrm{NH}_{3}$ $7,69^{*} 10^{-3} \mathrm{~m}^{3}$ aire $/ \mathrm{g}$ Azolla f.

Typha I: $4 \mathrm{C}_{64} \mathrm{H}_{124} \mathrm{O}_{54} \mathrm{~N}+269 \mathrm{O}_{2} \stackrel{\begin{array}{c}\text { Bacterias } \\ \text { Hongos }\end{array}}{\longrightarrow} 256 \mathrm{CO}_{2}+242 \mathrm{H}_{2} \mathrm{O}+4 \mathrm{NH}_{3}$ $6,19^{*} 10^{-3} \mathrm{~m}^{3}$ aire/g Typha I.

La relación $\mathrm{C} / \mathrm{N}$ calculada para una mezcla de $9 \mathrm{~kg}$ de Azolla f. $+1 \mathrm{~kg}$ de Typha I. fue: $\mathrm{C} / \mathrm{N}=30,3$ valor que se encuentra dentro del rango reportado para asegurar que se inicia el proceso [4]. El sistema fotovoltaico dimensionado fue: 1 panel solar de $30 \mathrm{~W}$ 12VDC, un regulador para 1,74 A y una Batería con una capacidad de 3,57 Ah con una autonomía de 2 días. 


\section{CONCLUSIONES}

Se estableció la composición elemental de Azolla filiculoides y Typha latifolia de esta región, y los análisis realizados muestran que el compost que se produzca, se podría aplicar como fertilizante para agricultura de consumo humano, con lo cual se podrían generar después estrategias para transformar la problemática ambiental de la represa Chocolate en cuanto a sobrepoblación de maleza acuática, en una oportunidad de desarrollo sostenible.

\section{REFERENCIAS}

[1] Gutierrez, F. Estado de conocimiento de especies invasoras, propuesta de lineamientos para el control de los impactos. Instituto de Investigación Alexander Von Humboldt, 2006.

[2] Arroyave, M. La lenteja de agua (Lemna minor L.): una planta acuática promisoria. Revista Escuela de Ingeniería de Antioquia, No. 1, pp. 3338, Febrero 2004.

[3] Ruiz, H., Rodriguez, R. Diseño de biorreactores para fermentación en medio sólido. Revista Mexicana de Ingeniería Química, Vol. 6 No. 001 pp. 33-40, 2007.

[4] Haug, R.T. The practical handbook of compost engineering, Lewis publishers, 1993.

[5] Atlas de radiación y brillo solar de Colombia, IDEAM, 2005. 


\title{
OBTENCIÓN DE BIODIESEL A PARTIR DE ACEITE DE HIGUERILLA MEDIANTE EL EMPLEO DE LIPASAS COMERCIALES EXTRAÍDAS A PARTIR DE R. ORYZAE Y C. RUGOSA
}

\author{
Andrea, Ramírez; Dalia, Alarcón*; Dionisio, Malagón-Romero** \\ *Universidad Santo Tomás, Semillero Energía y Termofluidos, \\ andrea11_2005@ hotmail.com \\ **Universidad Santo Tomás, Semillero Energía y Termofluidos, \\ serenasakino@gmail.com \\ **Universidad Santo Tomás, Grupo de Investigación GEAMEC, \\ dionisiomalagon@usantotomas.edu.co
}

\begin{abstract}
Palabras Clave: Aceite de higuerilla, biodiesel, bioproceso, lipasas, Área Temática: Biocombustibles
\end{abstract}

\section{INTRODUCCIÓN}

La ruta química se ha convertido en la más empleada para la obtención de biodiesel a partir de aceite de palma, en la cual se emplean como catalizadores Hidróxido de Sodio o Hidróxido de Potasio. Sin embargo, el dilema ético surgido en los últimos años con respecto al uso de aceites comestibles para la obtención de energía ha llevado a la búsqueda de nuevas fuentes de aceites como Jatropha curcas e higuerilla. Otra alternativa que puede ser empleada para la obtención del biodiesel es mediante catálisis enzimática, en la cual se emplean lipasas (triacilglicerol éster hidrolasas EC. 3.1.1.3), lo cual conlleva algunas ventajas tales como condiciones moderadas para llevar a cabo la reacción, facilidad en la separación de subproductos. El aceite de ricino es un triglicérido de varios ácidos grasos y su singularidad se debe a su alto contenido de ácido ricinoléico (87-90\% peso), el cual estructuralmente corresponde al ácido cis-12-hidroxyoctadeca-9-enoico [1].

\section{MATERIALES Y MÉTODOS}

Las enzimas empleadas son tipo lipasa extraídas de Candida rugosa y de Rhizopus oryzae suministradas por MERQUIAND (Bogotá). Los demás reactivos empleados fueron Hexano 99\% y Metanol $(99,8 \%)$ grado analítico (Panreac). Aceite de higuerilla y de palma grado comercial. El aceite se caracterizó en cuanto a viscosidad (Viscosímetro Brookfield Engineering Laboratorires LV), contenido de humedad y materia volátil (NTC 287), índice de acidez (NTC 218) e índice de saponificación (NTC 335). Se evaluó la actividad enzimática mediante la cuantificación de ácidos grasos liberados a través del tiempo, a través de titulación con una solución de $\mathrm{NaOH}$. Adicionalmente, se evaluó la generación de metil ésteres (biodiesel) usando las enzimas libres e inmovilizadas en una matriz de alginato de calcio. La reacción se llevó a cabo durante 9 horas a 40 C con agitación; se evaluó la carga enzimática (3\%, 5\% y 10\%) en una relación molar aceite/alcohol constante, seleccionada como 1:4. La 
caracterización del biodisel obtenido se realizó mediante cromatografía de gases (GC) para la detección de metil-ésteres.

\section{RESULTADOS}

La caracterización del aceite de higuerilla mostró resultados acordes a los reportados en la literatura cumpliendo lo establecido por la Norma ASTM D-960. El análisis de varianza realizado para determinar el efecto del agua y del hexano en la actividad catalítica de la enzima obtenida de C. rugosa y de $R$. orizae se concluye que el porcentaje de agua y hexano presentan efecto sobre la actividad catalítica por lo cual se obtiene que los mejores porcentajes son $5 \%$ de hexano y $10 \%$ de hexano para C. rugosa y $5 \%$ de hexano y $8 \%$ de agua para $R$. oryzae. Cierta cantidad de solvente es necesaria para mejorar la estabilidad operacional de la lipasa, influyendo en la solubilidad del triglicérido de carácter hidrófobo y el metanol de carácter hidrofílico y el recubrimiento de la enzima por la glicerina producida en el proceso [2]; a partir de un análisis de varianza (ANOVA) se demostró que no existe diferencia significativa entre los dos porcentajes de lipasa evaluados (3\% y 10\%), por lo cual se escogió un porcentaje del 3\%. La producción de biodie-sel mostró que la conversión obtenida para $R$. oryzae es del $14,8 \%$ y para C. rugosa es del $10 \%$ los cuales son valores prometedores; los porcentajes de metilésteres fueron de $15 \%$ para la enzima $R$. oryzae y $10 \%$ para la lipasa C. rugosa. La separación de la glicerina fue sencilla a pesar de la alta viscosidad del aceite de higuerilla. La Figura 1 muestra los metil-ésteres obtenidos para las 2 lipasas empleadas.
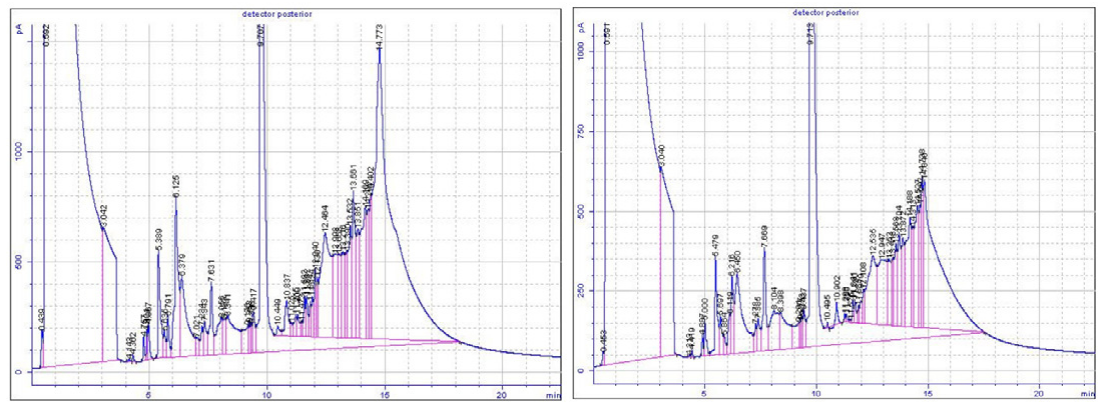

Figura 1. Determinación de metil-ésteres para C. rugosa (Izquierda) y para R. oryzae (derecha) a 9 horas de reacción.

\section{CONCLUSIONES}

Mediante el presente trabajo se estandarizó un proceso para la obtención de biodiesel empleando lipasas comerciales de C. rugosa y $R$. oryzae, el cual es una alternativa para la obtención por la vía química. La facilidad para separar la glicerina, frente a la vía química resulta una ventaja comparativa. 


\section{REFERENCIAS}

[1] Puthli, Meenal S., Rathod., Virendra K. y Pandit, Aniruddha. 2006. Enzymatic hydrolysis of castor oil: Process intensification studies., Biochemical Engineering Journal, Vol. 31, págs. 31-41.

[2] Delgado, Claudia y Pashova, Veselina. 2010, Producción enzimática de ésteres etilicos del aceite de ricino. Revista Facultad de Ingeniería Universidad de Antioquia, págs. 9-19. 


\title{
AVANCES EN OPTIMIZACIÓN DE COLECTORES SOLARES PARA SECADO DE PRODUCTOS AGRÍCOLAS
}

\author{
Carlos Armando De Castro*, Orlando Porras Rey* \\ "Universidad de los Andes \\ ca.de961@uniandes.edu.co \\ *Universidad de los Andes \\ oporras@uniandes.edu.co
}

Palabras Clave: Calentador de aire, colector placa plana, energía solar, secador solar

Área Temática: Energía solar

\section{INTRODUCCIÓN}

En los procesos productivos agrícolas el secado de los productos es de vital importancia para garantizar su conservación. El secado solar tiene un amplio uso debido a su disponibilidad en prácticamente cualquier lugar del planeta, su bajo costo debido a que sólo se necesita la construcción inicial y poco mantenimiento, agregando que no hay consumo de electricidad o combustibles. Sin embargo, la mayoría de los sistemas de secado solar utilizados en el campo colombiano son construcciones rústicas y sin técnica, por lo que los procesos de secado tienden a ser ineficientes y por lo tanto lentos. En la literatura colombiana y mundial se encuentran muchas recomendaciones empíricas para la construcción de secadores, pero no hay métodos de diseño o criterios de selección para optimizar el proceso, el cual es el objetivo principal del proyecto que se trabaja como tesis de maestría en la Universidad de los Andes. Este artículo presenta los avances que se han hecho hasta el momento en el modelamiento y optimización del área de colección para calentar el aire utilizado para el secado de los productos.

\section{MATERIALES Y MÉTODOS}

El método es enteramente teórico y de simulación, consiste en modelar y simular en computador el flujo de aire, transferencia de calor, transferencia de masa y psicrometría dentro de secadores solares de túnel para convección natural y convección forzada. De acuerdo a los modelos obtenidos, desarrollar criterios de diseño y/o selección de secadores solares de túnel óptimos de acuerdo a los resultados de las simulaciones.

\section{RESULTADOS}

Se realizan balances de calor sobre tres elementos principales del colector (aire interno, placa colectora y cubierta) para determinar sus temperaturas [1], [2] y [3]. Con el modelo se hizo un estudio paramétrico para observar el cambio en la respuesta del sistema a variaciones en las dimensiones del colector. 


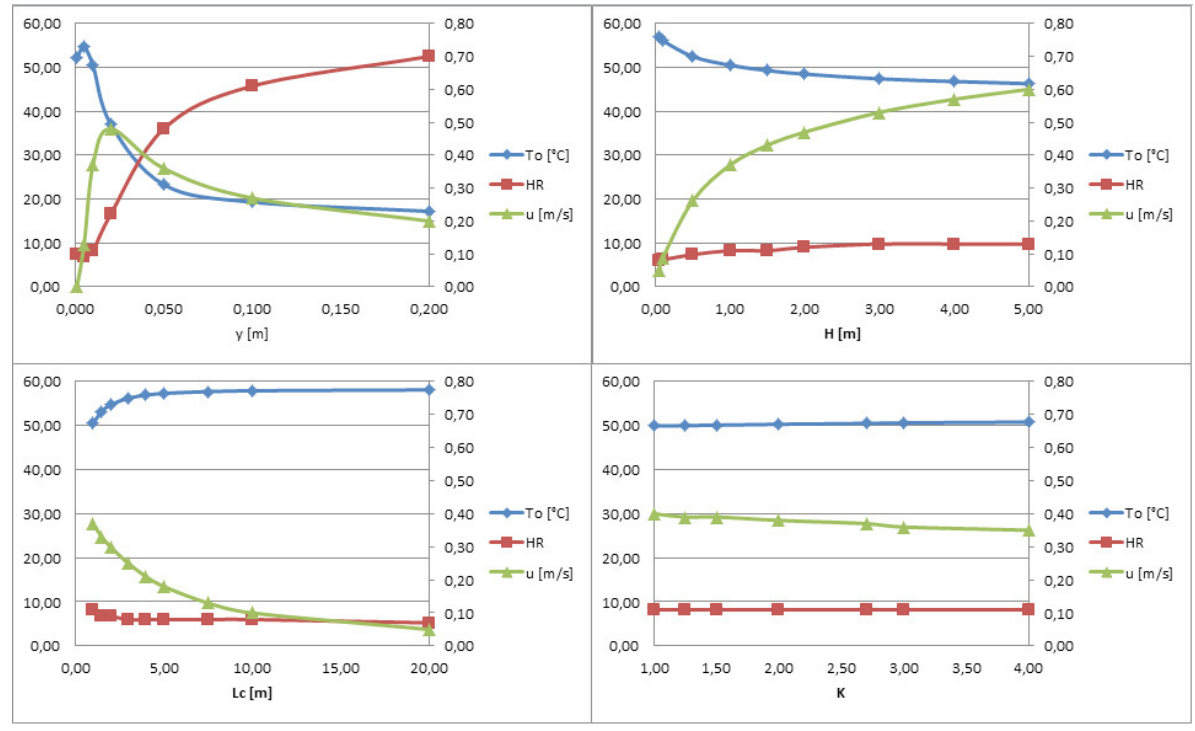

Figura 1. Curvas del estudio paramétrico en el colector.

\section{CONCLUSIONES}

Se han hecho los modelos de la zona de colección y se han determinado los factores que afectan el rendimiento de ésta zona en secadores solares. La altura de la cubierta influye de forma grande en la ganancia de calor y la velocidad del flujo de aire, como se observa en la Figura 1. Esto contradice directamente los resultados de Bala [4]. Llega un momento donde no se debe alargar más la zona de colección. Se ha hallado una cota inferior para la altura de la cubierta en la zona de colección en forma puramente teórica y de simulación. Hasta ahora no se ha encontrado esto en la literatura consultada.

\section{REFERENCIAS}

[1] Duffie, John and Beckman, William. Solar Engineering of Thermal Processes. $2^{\text {nd }}$ edition. John Wiley \& Sons. 1980.

[2] Incropera and De Witt. Introduction to Heat Transfer. $2^{\text {nd }}$ edition. John Wiley \& Sons. 1990.

[3] Swinbank, W.C. (963). Long-wave radiation from clear skies, Quarterly Journal of the Royal Meteorological Society, 89: 339-348.

[4] B. K. Bala. Solar Drying Systems. $1^{\text {st }}$ edition. Agrotech Publishing Company. 1998. 


\title{
MODELO DE SISTEMA SOLAR FOTOVOLTAICO RURAL - CASO: ESCUELA EL CARDONAL, TIBANÁ, BOYACÁ, COLOMBIA
}

\author{
Ing. Andrea Catalina Alvarado Fajardo*, PhD. Hernán Carvajal Osorio* \\ "Universidad Libre de Colombia, Bogotá, \\ andrea.alvaradof@unilibrebog.edu.co \\ *Universidad La Gran Colombia, Bogotá, Colombia, \\ hernan.carvajal@ugc.edu.co
}

Palabras Clave: Modelo de sistema solar FV, energía solar fotovoltaica, energía solar social

Área Temática: Desarrollo sostenible

\section{INTRODUCCIÓN}

La energía solar fotovoltaica (FV) cada vez adquiere mayor importancia en el mundo, en aprovechamiento de dicho recurso gratuito y a favor del medio ambiente. Los costos de producción de las celdas FV se han reducido considerablemente, lo cual beneficia su utilización. Colombia, por su ubicación en la zona ecuatorial, cuenta con abundante recurso solar, hasta ahora no aprovechado suficientemente, a pesar de contar con regiones rurales con servicio de electricidad nulo o muy deficiente. Los sistemas solares pueden ser muy convenientes donde la demanda de energía es dispersa y la conexión a la red externa es a menudo más costosa [1].

La Escuela rural El Cardonal, ubicada en el Municipio de Tibaná, Departamento de Boyacá, Colombia, imparte educación de primer nivel a niños pobres de la zona, con el inconveniente de un servicio de energía eléctrica muy deficiente, pero que se hace indispensable para el buen funcionamiento de la nevera, los computadores, un televisor y la iluminación. Cotidianamente se presentan dificultades en el servicio, en oportunidades prolongándose por varios días, situación que afecta las actividades diarias de la Escuela y, en este caso, además, involucra la nutrición de los niños por falta de conservación adecuada de los alimentos que se les suministra a diario.

\section{MATERIALES Y MÉTODOS}

El proyecto permite demostrar las bondades de un sistema eléctrico solar fotovoltaico sencillo y económico, garantizando, gracias a su diseño adecuado a las condiciones de la Escuela, un abastecimiento confiable de energía eléctrica, en especial, a la nevera que es utilizada para la conservación de los alimentos que se suministran a los niños en un programa de nutrición infantil. Esto permite que se continúe el desarrollo normal de las actividades escolares, en condiciones de salubridad y nutrición apropiadas. Se agrega la particularidad que los estudiantes están involucrados en 
el proyecto, en la recolección de parte de la información de las condiciones meteorológicas del sitio por medio de un formato sencillo, con lo que se familiarizan con el buen uso de los recursos naturales y el aprovechamiento de las energías renovables protegiendo el medio ambiente. Se ha venido recogiendo por un año la información de la energía solar disponible en el lugar, por medio de una estación meteorológica moderna instalada en la Escuela por la Universidad.

\section{RESULTADOS}

Se han determinado las condiciones meteorológicas y de radiación solar en el sitio (figura 1), las primeras, estimando periodos de nubosidad, lluvia y días sin brillo solar, con datos recolectados por los estudiantes de la Escuela. De acuerdo a la disponibilidad del recurso solar en el sitio, se diseñó un sistema autónomo, pero con entrada en operación de forma manual, según las condiciones de suministro eléctrico de la red externa. Se calculó para abastecer las necesidades básicas hasta por tres días continuos, con un banco de baterías adecuado, alimentado por un par de paneles fotovoltaicos de $75 \mathrm{~W}$ cada uno (figura 2). La fuente externa de energía puede usarse como respaldo cuando presente buen servicio; de lo contrario, se desconectará automáticamente.

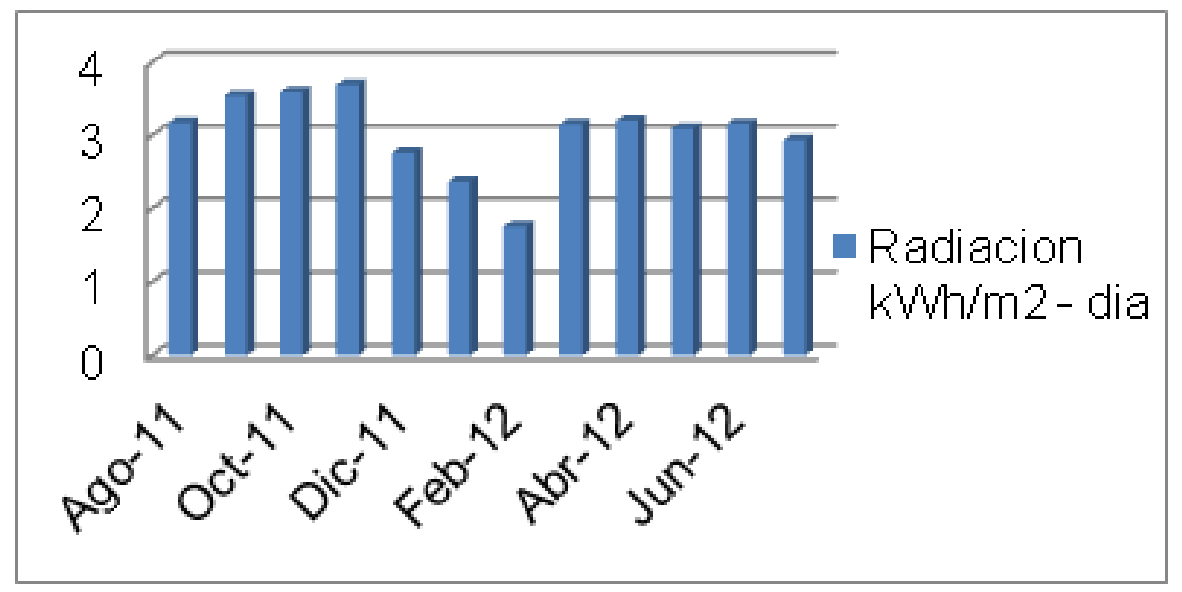

Figura 1. Radiación solar media diaria en la Escuela El Cardonal.

El sistema será instalado en los próximos meses una vez completada su financiación, actualmente en negociación. Puesto en operación, se probará y se comprobará el cumplimiento de las condiciones de servicio en validación del diseño. El gobierno local se ha comprometido a aportar los equipos, con la firma de un convenio entre la Alcaldía de Tibaná y la Universidad Libre Bogotá. 


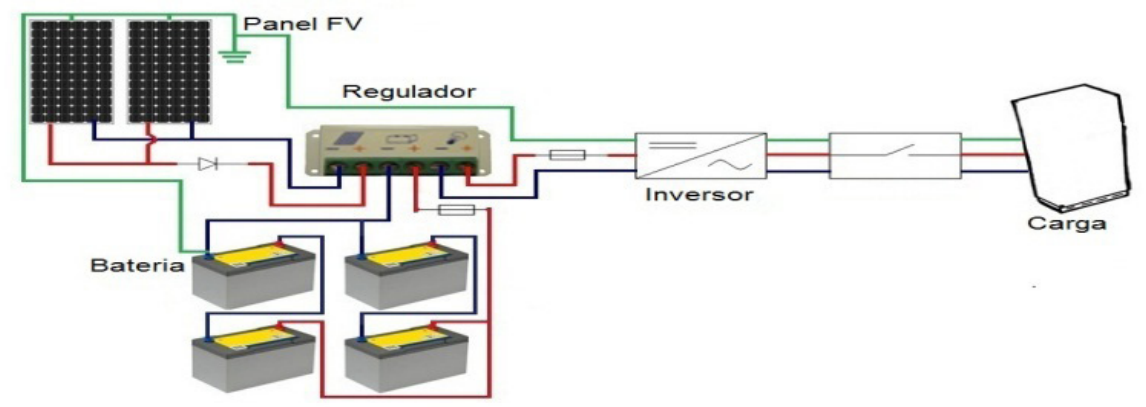

Figura 2. Sistema solar fotovoltaico diseñado.

\section{CONCLUSIÓN}

El sistema fotovoltaico presenta gran ventaja, por su bajo mantenimiento y alta durabilidad, sencillez de instalación y operación, siendo relativamente económico. El sistema solar aquí diseñado permite plantearlo como modelo a ser replicado en comunidades pequeñas y para instituciones en condiciones similares, tales como escuelas rurales, centros médicos, puestos de seguridad pública y de atención de desastres. El vincular a los niños en el proceso desde temprana edad, como en este caso, hace que se sientan comprometidos con su institución, a la vez que comprendan los beneficios de las energías renovables, y, además, con la satisfacción de aportar a su propia formación. También se está apoyando a los programas de nutrición y salud infantil en un sector social deprimido.

\section{REFERENCIAS}

[1] Unidad de Planeación Minero Energética (UPME). Citado por Mundo Andino (TheAndeanWorld). Recuperado en línea agosto de 2010: http://www.mundoandino.com/Colombia/Renewable-energy-in-Colombia. 


\title{
ESCALAMIENTO DEL PROCESO DE PRODUCCIONDE BIODIESEL A PARTIR DE ACEITE USADO DE COCINA POR MEDIO DE TRANSESTERIFICACION QUIMICA (ACIDO-BASICO)
}

\author{
Luisa López; Julián Martínez; Dionisio Malagón-Romero* \\ Semillero Energía y Termofluidos \\ Universidad Santo Tomas \\ *dionisiomalagon@usantotomas.edu.co
}

Palabras Clave: Aceites usados, Biodiesel, catálisis ácida - básica, Transesterificación,

Área Temática: Biomasa y Bioenergía.

\section{INTRODUCCIÓN}

El uso de distintas materias primas para la obtención de biodiesel, es uno de los temas que actualmente se investigan a nivel global, con miras a reducir costos y aprovechar distintas fuentes de triglicéridos, hasta el momento desaprovechados. Una de esas materias primas es el aceite usado de cocina, que se presenta como una fuente económica y en ciertas regiones excesiva e indeseada. El aceite se convierte en un desecho en la mayoría de las cadenas de restaurantes, cadenas de hoteles, asaderos, entre otros. A través del presente trabajo, se estandarizó el proceso de obtención de biodiesel por vía química usando aceite usado procedente del Club de Sub-oficiales de Bogotá y se realizó el escalamiento a escala 5 litros (planta a escala banco).

\section{MATERIALES Y MÉTODOS}

Reactivos: Se emplearon metanol (99,8\%, Panreac), hidróxido de sodio y potasio (marca Merck), aceite usado de cocina proveniente del Club de Suboficiales en Bogotá.

Equipos y dispositivos. Se empleó un reactor de laboratorio con capacidad $100 \mathrm{ml}$ fabricado en vidrio, provisto con un chaqueta para la calefacción mediante el empleo de un baño termostatado; adicionalmente, está provisto de un condensador. También se empleó una planta piloto diseñada por la Universidad Santo Tomás que consta de un calderín, reactor y decantador en acero inoxidable. El reactor consta de un sistema de agitación consistente de un agitador provisto con una turbina Roushton, chaqueta de calentamiento con vapor y control de temperatura.

Caracterización del aceite. El primer paso al que se sometió el aceite fue a un calentamiento a ${ }^{8} 0^{\circ} \mathrm{C}$ y posterior filtración mediante el empleo de papel filtro cuantitativo con miras a eliminar partículas en suspensión. Después de lo anterior, se realizó la caracterización del aceite en cuanto a densidad 
(NOC 336), viscosidad (viscosímetro Brookfield Engineering Laboratories LV), índice de acidez (NTC 218), índice de saponificación(NTC 335), índice de yodo(NTC 283) e índice de peróxido(NTC 236).

Diseño experimental: En el presente estudio se evaluaron 3 relaciones molares metanol:aceite $(6: 1,9: 1$ y 12:1), dos tipos de catalizadores (hidróxido de sodio e hidróxido de potasio), dos porcentajes de catalizador (1\% y $2 \%$ ). Todos los ensayos se realizaron por duplicado.

Procedimiento para la fabricación del biodiesel. Se colocó el catalizador seleccionado en el porcentaje a evaluar, se disolvió en metanol. Una vez disuelto, se adicionó el aceite y se cronometró el tiempo hasta 2 horas. Se detuvo el sistema y se colocó a decantar. Se esperó a que se separaran las fases y se recogió el biodiesel. Se sometió a lavado para neutralización y se recogió para análisis cromatográfico [1].

\section{RESULTADOS}

La caracterización del aceite usado muestra que el contenido de ácidos grasos libres no es alto, por lo cual no se hace necesario la esterificación en condiciones ácidas. El análisis de varianza (ANOVA) para para el contenido de ésteres metílicos se presenta en la tabla 1 y como se puede apreciar ninguno de los factores evaluados tiene influencia con respecto al contenido de ésteres metílicos. Con base en estos resultados se puede concluir que las condiciones para obtener biodiesel usando aceite usado proveniente del Club de Sub-oficiales es: catalizador hidróxido de sodio, relación molar alcohol:aceite (6:1), porcentaje de catalizador $(0.5 \%)$; estas condiciones son similares a las propuestas en la literatura [2]. Con estas condiciones el proceso se escaló a un nivel de banco con un volumen de 5 litros.

Tabla 1. Análisis de varianza (ANOVA) para el contenido de ésteres metílicos.

\begin{tabular}{|l|c|c|c|c|c|}
\hline FUENTE & SUMA DE CUADRADOS & $\begin{array}{l}\text { GRADOS DE } \\
\text { LIBERTAD }\end{array}$ & $\begin{array}{l}\text { CUADRADO } \\
\text { MEDIO }\end{array}$ & COCIENTE -F & P-VALOR \\
\hline \multicolumn{7}{|l|}{ Efectos principales } \\
\hline \multicolumn{7}{|l|}{ Tipo de catalizador } & 8,88024 & 1 & 8,88024 & 0,23 & 0,6418 \\
\hline $\begin{array}{l}\text { Porcentaje de } \\
\text { catalizador }\end{array}$ & 52,7376 & 1 & 52,7376 & 1,36 & 0,2685 \\
\hline Relación molar & 27,9851 & 2 & 13,9925 & 0,36 & 0,7053 \\
\hline Residuos & 427,103 & 11 & 38,8276 & & \\
\hline Total corregido & 507,914 & 15 & & & \\
\hline
\end{tabular}




\section{CONCLUSIONES}

Los estudios realizados permiten concluir que es factible el uso del aceite usado de cocina del Club de Sub-oficiales para la generación de biodiesel. Adicionalmente, las condiciones evaluadas a nivel de laboratorio se pudieron mantener a escala banco con una alta reproducibilidad. De esta forma, es posible aprovechar subproductos con alto contenido de triglicéridos para la generación de biodiesel.

\section{REFERENCIAS}

[1] Narvaez P. C., Sánchez F., Torres J.A., Ponce de Leon L.F. Determinación por Cromatografía de Gases de alquil ésteres (metílico y etílico) de ácidos grasos, en presencia de mono, di y trigicéridos. Ingeniería e Investigación. Vol 57. (2005) p.58-62.

[2] Yong Wang, SHIYI Ou, Pengzhan Liu, Zhisen Zhang. Preparation of biodiesel from waste cooking oil via two-step catalyzed process. Energy Conversion and Management Vol. 48, (2007) p. 184-188 


\title{
SIMULACIÓN NUMÉRICA DE CELDAS SOLARES CON CAPA ABSOR- BENTE DE $\mathrm{Cu}_{3} \mathrm{BiS}_{3}$ A TRAVÉS DE wXAMPS
}

\author{
Vladimir Ballesteros Ballesteros*, Fredy Giovanni Mesa Rodríguez* \\ "Facultad de Ingeniería - Universidad Libre, \\ vladimir.ballesterosb@unilibrebog.edu.co \\ *Facultad de Ingeniería - Universidad Libre, \\ fredyg.mesar@unilibrebog.edu.co
}

Palabras Clave: $\mathrm{Cu}_{3} \mathrm{BiS}_{3}$, Parámetros Fotovoltaicos, wxAMPS, SCAPS, Simulación Numérica.

Área Temática: Energía Solar

\section{INTRODUCCIÓN}

Las energías renovables han generado un creciente interés en los últimos años, otorgando un lugar privilegiado a la energía solar y constituyéndose en una opción interesante para mitigar la dependencia existente de los combustibles fósiles. Se han realizado múltiples investigaciones en el campo de los materiales para celdas solares, de las que hoy se han obtenido algunas conclusiones. Las celdas solares de silicio (Si) requieren un complejo procesamiento al vacío, altas temperaturas y silicio de alta pureza, por lo que el costo de producción se convierte en una limitante como fuente alterna de energía [1-3]. Por otra parte, el excesivo incremento en los costos de producción de algunos materiales y la pronunciada escasez de otros, por ejemplo el Telurio (Te), hacen evidente la necesidad de abordar otros materiales, no tóxicos y abundantes, destinados a la construcción de capas absorbentes en celdas solares. El United States Geological Survey (USGS), estimó en 2010 que la reserva mundial de bismuto se encontraba alrededor de $320.000 \mathrm{t}$, con un costo aproximado de US $\$ 20 / \mathrm{kg}$, mientras que la misma reserva para el indio escasamente alcanzaba las $20.000 \mathrm{t}$ con un costo promedio de US\$500/kg [4]. En congruencia con lo anterior y teniendo en cuenta la baja toxicidad del bismuto, el ternario $\mathrm{Cu}_{3} \mathrm{BiS}_{3}$ constituye una opción favorable para el desarrollo de nuevos materiales para dispositivos fotovoltaicos.

Finalmente, la herramienta wxAMPS constituye actualmente una importante aplicación para simulación de celdas solares con alta confiabilidad y un diseño mejorado, respecto a su antecesor AMPS, que incorpora principios físicos relativos a fenómenos fotovoltaicos y utiliza un nuevo método para la solución de algoritmos, combinando los enfoques de Newton y Gummel, lo que proporciona mayor estabilidad y velocidad de computación.

\section{MATERIALES Y MÉTODOS}

Para el desarrollo de esta investigación se utilizó un computador PowerEdge T320, con procesador Intel囚 Xeon®, 8GB RDIMM, HD de 500GB 7.2K RPM, 
sistema operativo Red Hat Enterprise Linux (RHEL 6.0), la versión para Linux del software libre wxAMPS distribuido por la Universidad de Illinois y la versión para Linux del software SCAPS. Por otra parte, se acudió a la simulación numérica con parámetros fotovoltaicos conocidos con el propósito de estimar magnitudes desconocidas y diagramas asociados.

\section{RESULTADOS}

A continuación, se presentan los diagramas obtenidos con wXAMPS y SCAPS para una celda solar con capa absorbente de $\mathrm{Cu}_{3} \mathrm{BiS}_{3}$. En la figura de la izquierda, se puede apreciar el diagrama de energía de bandas que muestra un voltaje de polarización de $0.845 \mathrm{~V}$ bajo iluminación, mientras que en el diagrama de la derecha se presenta las curvas de corriente-voltaje en condiciones dark/ light.
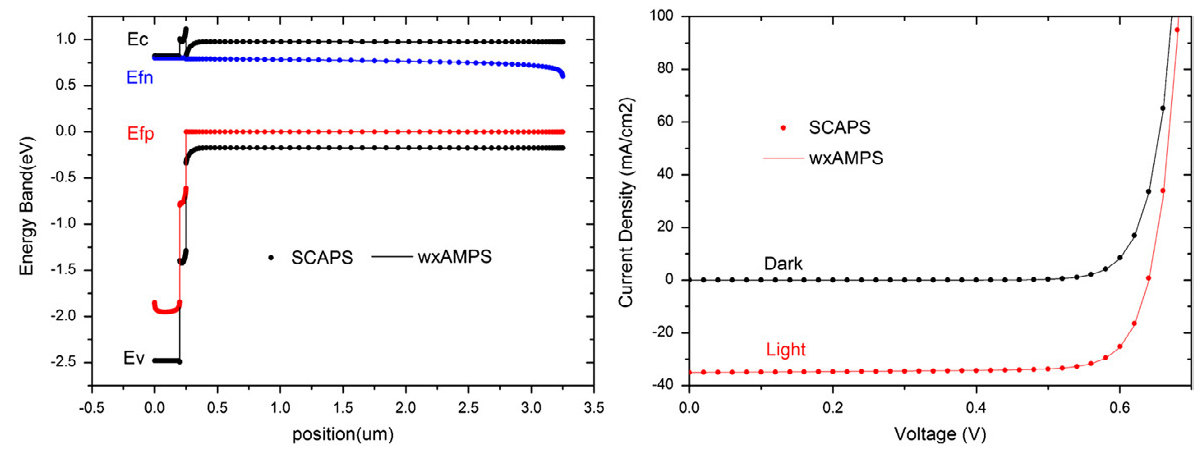

\section{CONCLUSIONES}

En condiciones iniciales wXAMPS predice que para una celda solar con capa absorbente de $\mathrm{Cu}_{3} \mathrm{BiS}_{3}$ se obtiene $\mathrm{V}_{\mathrm{oc}}=0.712511 \mathrm{~V}, \mathrm{~J}_{\mathrm{sc}}=36.25412 \mathrm{~mA} / \mathrm{cm}^{2}$, FF $=79.54275 \%$, y una eficiencia de $19.86521 \%$, lo que permite inferir que el $\mathrm{Cu}_{3} \mathrm{BiS}_{3}$ constituye una destacada alternativa en el diseño de dispositivos fotovoltaicos.

\section{REFERENCIAS}

[1] S.-S. Sun, N.S. Sariciftci, Organic Photovoltaics: Mechanisms, Materials, and Devices (Optical Engineering), CRC Press, Boca Raton, 2005.

[2] M.K. Siddiki, J. Li, D. Galipeau, Q. Qiao, A review on polymer multijunction solar cells, Energy and Environmental Science 3 (2010) 867-883. 
[3] T. Xu, Q. Qiao, Conjugated polymer-inorganic semiconductor hybrid solar cells, Energy and Environmental Science 4 (2011) 2700-2720.

[4] J.F. Carlin, U.S. Geological Survey, Reston, Virginia, 2011, p. 198.[5] $\mathrm{H}$. Zhu, et al. Applications of AMPS-1D for solar cell simulation in: Proceedings of the National Center for Photovoltaics (NCPV) $15^{\text {th }}$ Program Review Meeting, Denver, Colorado, USA, 1999, pp.309-314. 


\title{
PROPUESTA METODOLÓGICA \\ PARA LA MEDICIÓN DE LA HUELLA ENERGÉTICA CORPORATIVA COMO INDICADOR DE SOSTENIBILIDAD AMBIENTAL
}

\author{
MSc. William E. Rodríguez Delgado ${ }^{1}$ \\ Universidad Distrital Francisco José de Caldas UDFJC \\ Escuela Colombiana de Carreras Industriales ECCI \\ Corporación Ambiental E3² \\ willirodel@gmail.com
}

Palabras Clave: Huella energética, análisis de ciclo de vida, gestión ambiental, sostenibilidad ambiental, economía ecológica.

Áreas Temáticas: Eficiencia Energética - Auditoria Energética - Desarrollo Sostenible.

\section{INTRODUCCIÓN}

La crisis ambiental que esta afrontando la humanidad en la actualidad se ve motivada en gran medida por el desconocimiento y la incapacidad de acceder a herramientas metodológicas, tecnológicas y practicas que permitan establecer los criterios de manejo de los recursos. En los últimos tiempos se ha avanzado significativamente en la creación de indicadores de gestión, que privilegian el análisis de ciclo de vida de los productos y servicios, motivados, en metodologías como las propuestas por la familia de normas ISO 14040 [1]. Es este el caso de la medición de Huella Ecológica [2], [3], indicador que mide la presión de las personas, países, empresas o actividades sobre el medio ambiente y los recursos naturales. Así mismo, es evidente la reciente masificación del concepto de Huella de Carbono [4] a nivel organizacional y empieza a tomar cada vez más fuerza el concepto de Huella Hídrica organizacional [5]; pero no existe uno que mida el compromiso de las empresas con la promoción de las energías renovables y la eficiencia energética a lo largo de sus procesos.

El trabajo de investigación realizado, busca la formulación de una metodología que de forma sencilla, permita a las organizaciones medir la Huella Energética de sus actividades. En este sentido, el concepto de Huella Energética es entendido como la cantidad de energía equivalente consumida a lo largo del ciclo de vida, para la producción de un bien, prestación de un servicio o para la realización de un proyecto, y es medida en toneladas equivalentes de petróleo (toe). Este indicador puede reflejar el comportamiento energético, asociado además a la gestión ambiental de las empresas y puede convertirse en un mecanismo para reconocer la sostenibilidad de sus productos, servicios y proyectos.

1. MSc Energías Renovables y Eficiencia Energética UCLM; Docente de la Facultad de Medio Ambiente y Recursos Naturales UDFJC; Docente de la Facultad de Ingeniería Ambiental ECCI.

2. Entidad Sin Ánimo de Lucro, patrocinadora de la investigación. 


\section{MATERIALES Y MÉTODOS}

Para la generación del indicador y su posterior implementación, se ha dividido la investigación varios pasos metodológicos; algunos de ellos ya realizados y otros en procesos de implementación. El primero fue la definición de la metodología para la implementación de la Huella Energética como indicador de sostenibilidad ambiental; posteriormente se realizará un reconocimiento de las implicaciones de la metodología de medición de huella energética en el marco de la sostenibilidad ambiental y la responsabilidad social corporativa; luego se procederá a la identificación de las variables para la medición de la huella ecológica corporativa en el entorno colombiano; y por ultimo, se reconocerán los factores de éxito para la implementación de la metodología a una escala generalizada.

\section{RESULTADOS}

El establecimiento de la metodología para la medición de la Huella Energética separa la cantidad de energía consumida a lo largo del ciclo de vida del producto, servicio o proyecto en: La Huella Energética Verde, que es la cantidad de energía equivalente consumida en dicho ciclo que se ha obtenido de fuentes de energía renovables y que tiene por lo tanto, un menor grado de impacto ambiental; y la Huella Energética Roja, que es la cantidad de energía equivalente consumida en el ciclo de vida del producto, servicio o proyecto, que ha sido obtenida de fuentes de energía no renovables y por lo tanto, tiene un impacto ambiental considerablemente mayor, atribuible a la organización.

La perspectiva de la aplicación del indicador, dentro de la implementación metodológica del mismo, conlleva a la orientación de los consumos de la organización en el sentido de reducir la Huella Energética Roja y aumentar la Huella Energética Verde, lo que evidenciaría el compromiso institucional con la sostenibilidad ambiental. Este cambio puede estar motivado en varios factores, entre ellos, la aplicación de los conceptos de eficiencia energética en la organización, la inversión en proyectos de energía renovable distribuida y la promoción y exigencia de una mayor participación de las energías renovables en la matriz energética nacional, entre otros.

\section{CONCLUSIONES}

Los indicadores que introducen el concepto de análisis de ciclo de vida de los productos, servicios y proyectos, reflejan de una forma consistente el comportamiento ambiental de las organizaciones y su compromiso con la sostenibilidad. La metodología de medición de la Huella Energética propuesta, puede cumplir con separar el consumo energético de las organizaciones en renovable y no renovable, generando un sentido de responsabilidad mayor al darles conciencia de este factor. La sostenibilidad energética organizacional puede lograrse mediante diversas estrategias, pero solo puede constatarse dicho lo- 
gro con la medición de un indicador que refleje claramente el comportamiento energético organizacional y la evolución en el mismo, y dicho aspecto puede ser constatado con la Huella Energética.

\section{REFERENCIAS}

[1] ISO (Organización Internacional de Normalización), Norma Internacional ISO 14040:2006 Gestión ambiental - Evaluación del ciclo de vida - Marco de referencia

[2] Doménech, J.L; 2006; "Guía metodológica para el calculo de la hueIla ecológica corporativa," 2008. Terceros Encuentros Internacionales sobre Desarrollo sostenible y población. Universidad de Málaga; julio, 2006

[3] Wackernagel, M., Rees, W.E.; 1996; "Our Ecological Footprint: Reducing Human Impact on the Earth". New Society Publishers, Philadelphia.

[4] Wiedmann, T. y J. Minx; 2008; A Definition of Carbon Footprint In: C. C. Pertsova, Ecological Economics Research Trends: Chapter 1; Nova Science Publishers; Hauppauge NY, USA.

[5] Hoekstra, Arjen Y; Chapagain, Ashok K.; Aldaya, Maite M; Mekonnen, Mesfin M.; "Water Footprint Manual"; Water Footprint Network, 2009. 


\title{
DISEÑO DE UN EQUIPO PARA SINTETIZAR PELÍCULAS DELGADAS EMPLEADAS EN CELDAS SOLARES DE BAJO COSTO
}

\author{
Fernando Morales López*, Mónica A. Botero L.* \\ *Universidad Santo Tomas \\ fernandomorales@usantotomas.edu.co
}

\begin{abstract}
Palabras Clave: Celda solar, evaporación, kesteritas Área Temática: Energía Solar
\end{abstract}

\section{INTRODUCCIÓN}

El crecimiento exponencial de la población ha constituido un aumento en la demanda energética mundial, proporcionando cambios en los países, que llevan a la necesidad de incentivar fuentes de energía alternativas, que sustituyan la generada por los combustibles fósiles. La energía solar ha tenido el mayor incremento de las energías renovables, debido a sus grandes ventajas, ya que no genera contaminantes en el medio ambiente durante su uso, proviene de una fuente de energía en teoría inagotable (el sol), con un tiempo de vida promedio de 20 años, además se puede usar de manera autónoma, lo cual genera una ventaja para las poblaciones rurales, pues hoy en día en pleno siglo XXI aun hay sectores del planeta que no poseen abastecimiento energético, por su localización [1].

Las celdas solares basadas en kesteritas (CZTS), han sido recientemente investigadas ya que contienen materiales menos tóxicos como Azufre (S) y más abundantes en la naturaleza como el zinc (Zn), estaño (Sn) comparadas con las de CIGS [2]. Estas son de bajo costo, presentan un gap directo de $1.5 \mathrm{eV}$ y un alto coeficiente de absorción [3], actualmente el factor más importante que limita la eficiencia de estas películas, es la estequiometria del material [4]. Se han empleado métodos de deposición como sputtering, spray pyrolysis, electro-deposition, co-evaporation, pulsed laser deposition y sulfurización [5].

La co-evaporación es uno de los métodos más empleado para sintetizar películas delgadas ya que es económico, usado en la industria y laboratorios de investigación [6]; además mediante este método se puede controlar estequiometria evaporando cada elemento por separado mejorando la eficiencia, por lo tanto la cámara se diseñara para emplear este método en la Universidad Santo Tomas.

\section{MATERIALES Y MÉTODOS}

Se diseñó una cámara en acero inoxidable 304 de forma cilíndrica, conectada a un sistema de alto vacío compuesto por una bomba mecánica y una bomba 
turbo molecular, se instalaran sensores pirani y de cátodo caliente que serán conectados mediante pasa muros soldados con plasma de argón.

Se usaran tres crisoles de Molibdeno para evaporar el Cu, Zn y Sn y una celda de efusión para evaporar el S. Se empleara un porta sustrato con una resistencia de grafito que permitirá calentar por radiación el sustrato de vidrio cuya temperatura será controlada mediante un sistema PID ((proporcional, integral diferencial) [7].

Se empleara un monitor espesor con sensor de cuarzo, debido a que la gran sensibilidad de la micro balanza de cuarzo, y la buena precisión obtenida para películas muy finas y uniformemente depositadas, permite utilizar este cristal como elemento de monitorización de espesores [8].

\section{RESULTADOS}

La figura 1 muestra el diseño del equipo para fabricar películas delgadas de kesteritas (CZTS) mediante evaporación de los precursores en un sistema de alto vacío sobre un sustrato de vidrio soda lime previamente calentado.

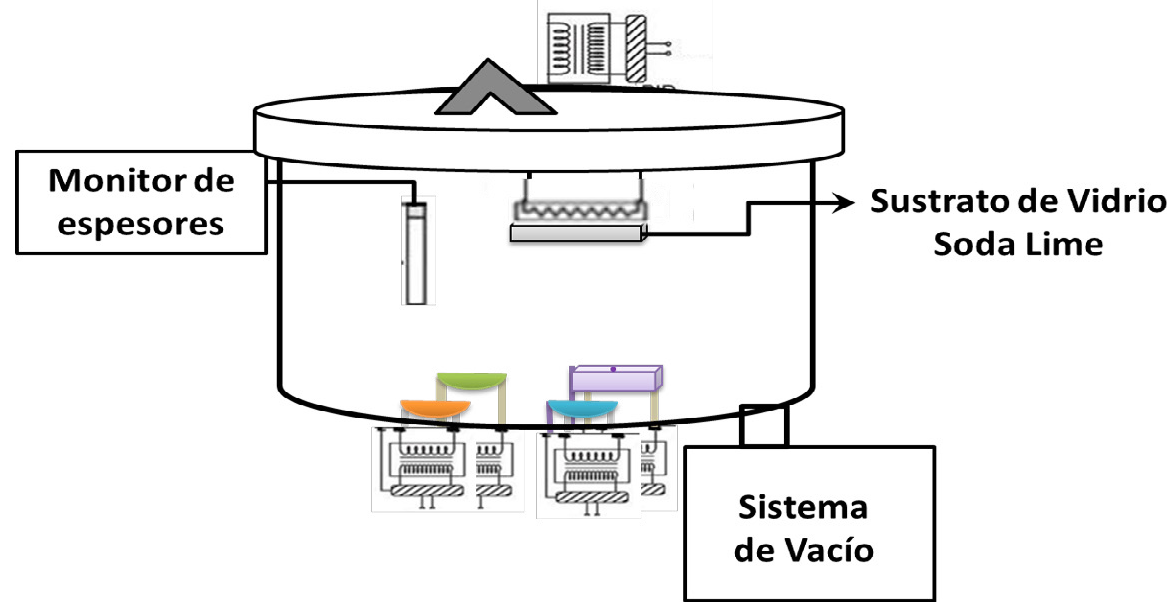

Figura 1. Diseño de un equipo para fabricar celdas solares de bajo costo

\section{CONCLUSIONES}

Para la síntesis de las películas delgadas CZTS, se ha diseñado una cámara de co-evaporación en acero inoxidable que cumpla con la condición de ser menos contaminante y de menor costo que las que se encuentran actualmente en el mercado y con la ventaja de variar las fracciones molares de los precursores para mejorar la eficiencia de la película. 


\section{REFERENCIAS}

[1] Renewables 2012 Global Status Report, junio de 2012.

[2] J. Zhao, A. Wang And M.A Green, Prog. In Photovoltaics, 2 (1994) 227.

[3] K. Muska Et Al. Synthesis of Cu2znsns4 Monograin Powders With Different Compositions. European Materials Research Society Conference Symp. Advanced Inorganic Materials And Concepts For Photovoltaics. Energy Procedia 10 ( 2011 ) 203 - 207.

[4] Redinger A, Berg Dm, Dale Pj, Siebentritt S. The Consequences Of Kesterite Equilibria For Efficient Solar Cells. J Am Chem Soc 2011;133:3320- 3323.

[5] H. Yoo, J. Kim. Growth Of Cu2znsns4 Thin Films Using Sulfurization Of Stacked Metallic Films. Thin Solid Films 518 (2010) 6567-6572.

[6] O’Neil, Shane, Et Al., Atmospheric Pressure Chemical Vapour Deposition Of Titanium Dioxide Coatings on Glass, J. Mater. Chem. 13, 56-58, 2003.

[7] BOTERO L., Mónica A. "Síntesis y caracterización de nuevos materiales no tóxicos empleados como capa buffer y capa absorbente en la fabricación de celdas solares". Tesis Doctoral. Universidad Nacional de Colombia, Bogotá, 2008.

[8] Díaz Román F. "Estudio y análisis del efecto rugoso sobre la respuesta del sensor de cuarzo en medios fluidos". Tesis Doctoral. Universidad Politécnica Valencia España, valencia. 


\title{
MATLAB COMPUTATIONTAL PACKAGE FOR COMPUTATION OF WIND AND MARINE CURRENT TURBINES
}

\author{
Ladino Alexander* \\ *Universidad Santo Tomás, \\ jairladino@usantotomas.edu.co
}

Keywords: Blade Element Momentum, MATLAB, Renewable Energy Fields: Wind Power, Marine power, numerical simulation.

\section{INTRODUCTION}

A MATLAB package for computation of Horizontal Axis and Vertical Axis Wind and Marine Current Turbines is presented. The package is divided in two programs: Horizontal Wind \& Marine Current Turbines (HW\&MCT) based on Bahaj [1] - [3], and Vertical Turbine of Voith - Scheider Kind based on [4].

The first program is based on the Blade Element Momentum with variation of aerodynamics coefficients as function of local Reynolds Number along the blade. On the other hand, the second program is based on angular momentum balance in a control volume for a single rotating disk - single streamtube model representing the vertical turbine.

\section{MATERIALS AND METHODS}

Th package was developed in MATLAB script intereface with vectorized routines for high performance, as both were divided in classical three modeling phases: Preprocessing, solution and posprocessing stages. Preprocessing phase define, dimensionless geometry, Tip speed Ratio range, aerodynamic coefficients and blade angle. Solution phase in both programs are developed in individual routines and solving is based on successive substitutions. Posprocessing provides global and local information of aero/hydro dynamic conditions along blades: Local Aero/hydro coefficients as function of dimensionless span, local and global Power coefficient and Thrust coefficient as functions of TSR. Also, Pressure Distribution along blades for Cavitation computation for marine turbines.

\section{RESULTS}

The benchmark case is the same as Bahaj in [1], For a 20m diameter Marine Current Turbine. Local results slightly differ due to differences in aerodynamic coefficients for same NACA profiles computed using X-FOIL [5]. In the context of global performance coefficients peak and slope values of Power Coefficient and Thrust Coefficients are in agreement with the reported in literature.

On the other hand, the vertical axis wind and marine turbines code was validated with geometry defined by Camporeale in [4], showing numerical agree- 
ment between. Finally, both codes are completely divided in subroutines and functions that allow to be easily modified and implemented with other routines or be used in other code implementation.
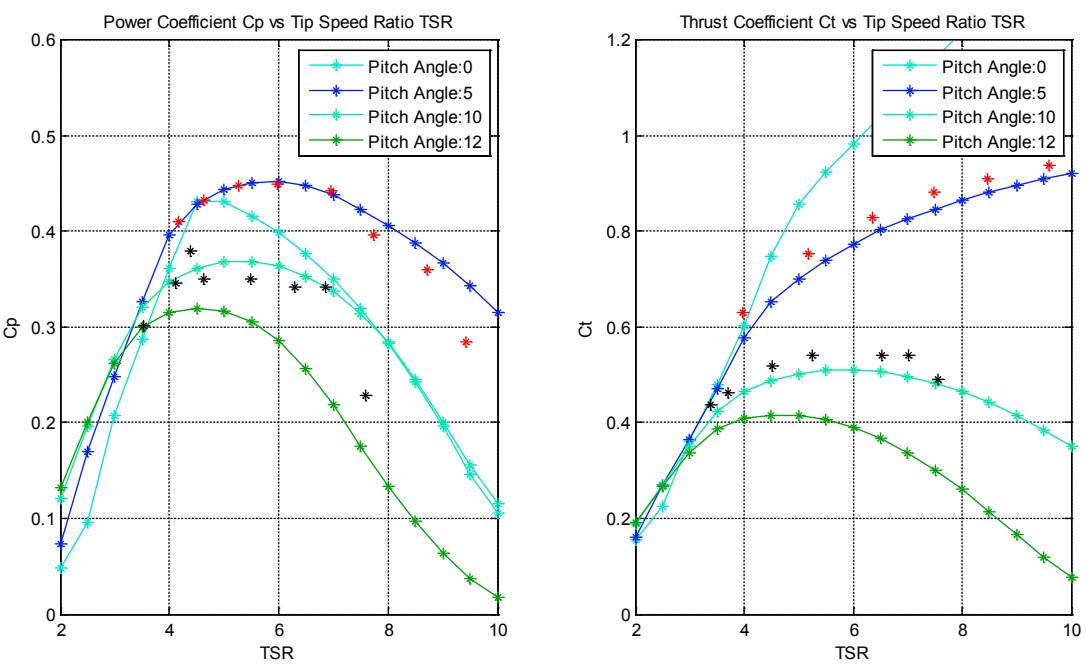

Figure 1. Power and Thrust coeficients amd experimental results from [1]
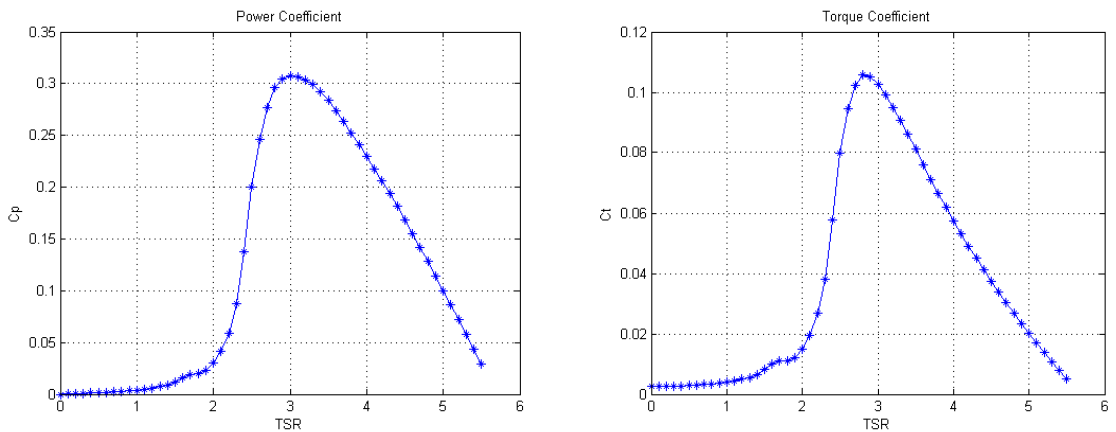

Figure 2. Power coefficient and Torque coefficient simulations for vertical axis marine turbine given in [4]

\section{CONCLUSIONS AND FURTHER WORK}

A numerical and computational implementation of two codes for vertical and horizontal marine current turbines was implemented in MATLAB. Numerical results are in agreement compared with literature in the design region 
providing confident information about aero and hydrodynamic behavior for general design of horizontal and vertical wind or marine current turbines.

The package is developed to be open source in order to be completed with different algorithms such as cavitation inception and control algorithms for full simulation of distributed systems.

\section{REFERENCES}

[1] W.M.J. Batten, A.S. Bahaj, A.F. Molland, J.R. Chaplin . The Prediction of Hydrodynamic Performance of Marine Current Turbines. Renewable Energy. Vol. 01, pp. 1085 1096, 2008.

[2] A. Bahaj, A. Molland, J. Chaplin. W Batten. Power and thrust measurements of marine current turbines under various hydrodynamic flow conditions in a cavitation tunnel and a towing tank. Renewable Energy, vol 32, pp. 407 426, 2007.

[3] L. Myers, A. Bahaj. Power output performance characteristics of a horizontal axis marine current turbine. Renewable Energy. vol 31, pp. 197 208, 2006.

[4] CAMPOREALE, S.M, MAGI, V., Streamtube Model for Analysis of Vertical Axis Variable Pitch Turbine for Marine Currents Energy Conversion. Energy Conversion and Management. Vol 41(16), pp. 1811 27, 2000.

[5] XFOIL. Available at: http://web.mit.edu/drela/Public/web/xfoil/ 


\title{
DESARROLLO DE UNA TURBINA HIDRÁULICA DE FLUJO AXIAL PARA GENERACIÓN DISTRIBUIDA
}

\author{
Jorge E. Vaz Torres \\ Consultor Independiente \\ jorgevaztorres@gmail.com
}

Palabras Clave: Energía hidroeléctrica, generación distribuida, diseño de turbina hidráulica

Área Temática: Energía Hidráulica y Mareomotriz (No convencional)

\section{INTRODUCCIÓN}

Este trabajo abordó el diseño de una turbina de bajo salto luego de un análisis de datos sobre Curvas de Caudales Clasificados de pequeños ríos en Córdoba, Argentina. Adicionalmente se definió el salto nominal para un aprovechamiento objetivo con el valor de $4 \mathrm{~m}$ teniendo en cuenta que ello permite flexibilizar la ubicación de un aprovechamiento. El caudal de diseño resulto ser de $10 \mathrm{~m} 3 / \mathrm{s}$, adoptando como tipología una máquina tipo "bulbo". También se consideró lo relativo a mantenimiento y confiabilidad en el proceso de diseño, a partir de la simplificación de mecanismos y una ingeniería adecuada en los elementos críticos.

El diseño hidráulico y mecánico de la máquina ha sido cumplimentado a través de una marcha de cálculo, obtenida a partir del análisis pormenorizado de bibliografía específica y elaboración propia, lo que permitió establecer las dimensiones y geometría de la máquina [1], [2].

A partir de ello ha sido posible el establecimiento de, a) Pasaje hidráulico o corte meridional de la turbina, b) Diseño del distribuidor y selección de los perfiles NACA para los álabes componentes de la corona directriz y ajuste de los ángulos de calado y c) Selección de los perfiles NACA para los álabes componentes del rodete y ajuste de los ángulos de calado del mismo [3], [4]. Asimismo, comprende el modelado en sistema CAD de toda la geometría de la máquina.

Otra cuestión importante es que se determinó el costo aproximado de producción de un módulo de potencia, el cual está pensado para replicarlo en una serie pequeña de producción, dada la versatilidad de la máquina para instalarla en múltiples aprovechamientos.

Finalmente, se utilizaron las estimaciones de costo de inversión, para analizar la rentabilidad que obtendría una distribuidora Cooperativa si ejecutara un proyecto de microhidráulica con las condiciones tarifarias imperantes. 


\section{MATERIALES Y MÉTODOS}

El trabajo desarrollado, insumió la utilización de hojas de cálculo por el carácter fuertemente iterativo del proceso de diseño en el dimensionamiento geométrico de la máquina en atención a lograr un rendimiento hidráulico aceptable. En forma paralela, se utilizaron programas específicos para la evaluación de parámetros aerodinámicos de perfiles tipo NACA. Finalmente se recurrió a programas $C A D$ con módulos de ingeniería asistida para verificar los ensambles, esfuerzos y demás aspectos en la concepción de la máquina. Como método general de diseño, se ha basado en un análisis bidimensional del flujo en el seno de la máquina considerando nula la componente radial, estableciendo de esta forma estaciones de trabajo desde la raíz a la puntera del rodete. Adicionalmente, se han utilizado hipótesis de régimen estacionario y estable, flujo monofásico y no viscoso y escurrimiento inicial con potencial de velocidades.

\section{RESULTADOS}

Se ha generado la totalidad de los componentes de la máquina estableciendo también las hojas de proceso, en el caso de componentes no comerciales (ejes, rodamientos, bujes, sellos, acoples, etc.). Asimismo, se posee una metodología de diseño propia para establecer los componentes hidráulicos principales que intervienen en la transformación de energía hidráulica y su control, como ser: Álabes del distribuidor, Palas del rodete y Tubo de aspiración.

Actualmente, está en estudio el sistema de control de la máquina, el análisis de las protecciones y demás componentes eléctricos necesarios para vincular de manera segura la máquina a la red conforme al estándar IEEE 1547.

\section{CONCLUSIONES}

El trabajo realizado, permitió obtener el formato de una máquina concebida de manera de abaratar sensiblemente los costos de fabricación como también costos de mantenimiento posteriores, a expensas de un mínimo sacrificio del rendimiento hidráulico. De esta manera se demuestra que es posible tornar rentables los pequeños aprovechamientos utilizando desarrollos locales y señalando que el concepto de generación distribuida puede tornarse parte de la solución a los problemas de expansión del consumo y la falta de inversión oportuna en redes de transporte, supeditado a utilizar una máquina versátil compatible con la mayor cantidad de aprovechamientos posibles.

\section{REFERENCIAS}

[1] MATAIX, Claudio. Turbomáquinas Hidráulicas. Editorial ICAI, 1975. 
[2] FLAD. Roland. Turbines Kaplan. Institute de Machines Hydrauliques, Ecole Polytechnique Federal de Lausanne. Mai 1983.

[3] SCHWEIGER, B. F.,GREGORY, J. Developments in the Design of Bulb Turbines. Water Power and Dam Construction, September 1988.

[4] De SIERVO, B. F.,De LEVA, F. Modern Trends in Selecting and Designing Kaplan Turbines. Water Power and Dam Construction, December 1977 and January 1978. 


\title{
MODELO DE OPTIMIZACIÓN ECONÓMICA EN UN SISTEMA CON GENERACIÓN DISTRIBUIDA
}

\author{
María Ximena Cáceres Prado*, Nicolás Quintana Ruiz*, \\ Francisco David Moya Chaves ${ }^{* *}$ \\ "Universidad de la Salle \\ Mcaceres30@unisalle.edu.co \\ "Universidad de la Salle \\ Nquintana44@unisalle.edu.co \\ "Universidad de la Salle \\ Fmoya@unisalle.edu.co
}

Palabras Clave: Generación distribuida, Modelo de Optimización Económica, DER-CAM, Energías Alternativas.

Área Temática: Desarrollo Sostenible, Generación Distribuida

\section{INTRODUCCIÓN}

El presente documento parte del apresurado crecimiento del empleo de la generación distribuida en el mundo, y de la necesidad que con dicho crecimiento ha aparecido, en cuanto al entendimiento y manejo de las variables que intervienen a la hora de decidirse o no a la implementación de este sistema. El método que se plantea en el documento parte de la implementación del modelo de optimización económica simplificado DER-CAM [1], y a partir de los resultados obtenidos de este, la realización de una simulación e implementación por medio del modulo Transient Network Analyzer (TNA) que permita al usuario la visualización tanto de los resultados de la optimización en el software, como del control del suministro de potencia activa a los generadores distribuidos (maquinas síncronas).

El desarrollo de la metodología planteada inicia con la caracterización del usuario que se toma en cuenta para el caso de estudio. Para ello se determinan los costos en los que se incurre por consumo de energía eléctrica para varios tamaños de unidades de tres tecnologías diferentes. Determinados los costos de operación, y siguiendo con la caracterización del usuario se selecciona y adecua una curva de demanda típica, convirtiéndola en la curva de demanda para el usuario a considerar. Del mismo modo se divide el país en regiones que determinaran la disponibilidad de recursos energéticos para este.

Con la caracterización del cliente, se lleva a cabo la construcción e implementación de un modelo de optimización económica desarrollado en Gams, en el cual se obtiene como resultado la potencia a generar por cada unidad, con el fin de suplir la demanda del usuario en un periodo de tiempo específico. Este comportamiento obtenido como resultado, se simula posteriormente en MATLAB, con el fin de observar por medio de la simulación la implementación de estos en un sistema previamente construido. 


\section{MATERIALES Y MÉTODOS}

El desarrollo del trabajo se dividió en cuatro fases empleándose materiales y métodos diferentes para cada una de éstas. La primera fase consistió en la recopilación de datos para emplear como entradas al modelo de optimización. Los materiales empleados en esta actividad fueron básicamente los datos proporcionados por entidades como el IPSE, IDEAM y UPME.

En la segunda fase se desarrolló y empleó un modelo de optimización. El modelo DER-CAM empleado como base para el desarrollo de dicho modelo fue el material y método empleado. La fase siguiente consistió en la simulación de los resultados obtenidos del modelo de optimización. Para ello se empleó MATLAB.

Finalmente en la fase cuatro del desarrollo del trabajo se implementaron los resultados de la optimización en el modulo TNA. El modulo TNA es la herramienta que permite la implementación de los resultados obtenidos en la optimización y simulación del sistema de potencia, ya que permite la realización de un montaje que en términos eléctricos asemeja a un sistema real.

\section{RESULTADOS}

Al final del desarrollo del trabajo se obtuvo como resultado de éste, una herramienta de guía para el usuario en la selección optima de nuevas tecnologías de generación de energía en sistemas de generación distribuida, la elaboración del cronograma de operación óptimos de las plantas instaladas y/o a instalar y la determinación del mínimo costo de suplir una demanda.

\section{CONCLUSIONES}

La fortaleza del modelo desarrollado es que permite una toma de decisión sobre el tipo de tecnología a utilizar, depende de la sofisticación matemática del modelo mismo, así como de la veracidad de los datos de entrada. Se busca que con dicho modelo se limite la interacción del usuario a que proporcione únicamente datos básicos de ubicación o periodo de tiempo en el que desea la optimización. El aporte del trabajo realizado radica en el desarrollo de una herramienta de toma de decisión en cuanto a inversión en unidades de generación (tecnología y potencia) y gestión de la energía producida en un sistema de generación distribuida.

\section{REFERENCIAS}

[1] B. Lab, "DER-CAM Microgrids." 2000. 


\title{
GASIFICACIÓN POR LECHO FIJO DE LA FIBRA OBTENIDA DEL FRUTO DE LA PALMA DE ACEITE, USANDO AIRE-VAPOR COMO AGENTES OXIDANTES
}

\author{
Ismael Márquez*, Gerardo Gordillo Ariza*, \\ "Universidad libre, \\ ismael.marquezl@unilibrebog.edu.co \\ "Universidad de los Andes, \\ g.gordillo43@uniandes.edu.co
}

Palabras Clave: Gasificación (gasification), gasificador (gasifier), lecho fijo (fixed bed), aire-vapor (air-steam), Fibra de palma (palm fiber)

Área Temática: Biomasa y Bioenergía

\section{INTRODUCCION}

Gasificación de biomasa es un proceso de combustión incompleta para producir un combustible gaseoso llamado gas de síntesis, una mezcla de $\mathrm{CO}, \mathrm{CH} 4, \mathrm{H} 2, \mathrm{CO} 2, \mathrm{~N} 2, \mathrm{H} 2 \mathrm{O}$ y trazas de otros hidrocarburos tales como $\mathrm{C} 2 \mathrm{H} 6$ y $\mathrm{C} 2 \mathrm{H} 4$. La composición final del gas depende básicamente del tipo de gasificador y del agente oxidante $[1,2]$. La gasificación de madera y carbón con aire como agente oxidante, para producir mezclas ricas en $\mathrm{CO}$ y $\mathrm{CH} 4$, ha sido usada desde hace mucho tiempo. Sin embargo, actualmente se están estudiando otros agentes oxidantes y otras biomasas para producir gases más limpios (mezclas ricas en H2). La gasificación de biomasa con aire-vapor es un proceso que se puede realizar adiabáticamente para producir mezclas ricas en $\mathrm{H} 2$, con un bajo contenido de $\mathrm{CO}(3 \%)$ y $\mathrm{CH} 4$ $(1 \%)[3,4]$. Algunos autores han publicado resultados sobre la gasificación de algunas biomasas (cultivos energéticos y desechos agroindustriales) usando como agente oxidante aire [5]. No obstante, no existen datos publicados sobre la gasificación, en lecho fijo, de la fibra de la palma de aceite con aire-vapor como agente oxidante. Consecuentemente, en este artículo se presenta un estudio experimental sobre la gasificación de fibra de palma de aceite con aire-vapor.

\section{MATERIALES Y MÉTODOS}

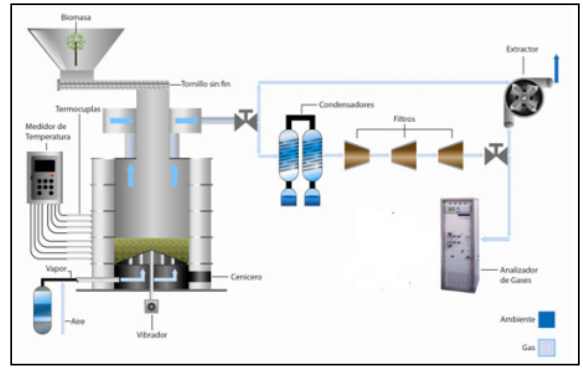

Un esquema del equipo de gasificación se muestra en la Figura 1. El gasificador es de lecho fijo en contracorriente, en el que los agentes oxidantes (vapor de agua y aire), ingresan por la parte inferior del equipo, en tanto que la biomasa ingresa por la parte su- 
perior. La alimentación del combustible al reactor se lleva a cabo mediante un tornillo sinfín con velocidad de alimentación regulable.

Los gases producidos son conducidos a los condensadores y filtros y finalmente analizados mediante el analizador de gases.

\section{RESULTADOS}

Las figuras 2 y 3 muestran algunos resultados obtenidos sobre los perfiles de temperatura dentro del gasificador y la composición de gases para unas determinadas condiciones de operación (relación de equivalencia (ER) y la relación vapor combustible(S:F))

Figura 2. Perfil de temperaturas

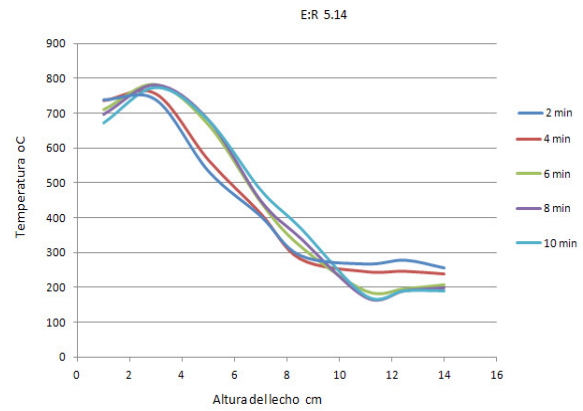

Figura 3. Composición de gases

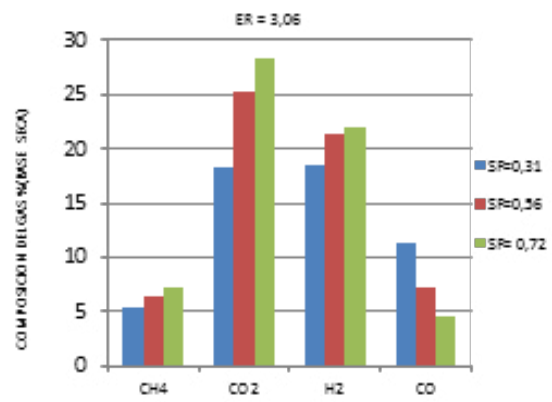

\section{CONCLUSIONES}

La zona de máxima temperatura corresponde a la zona de combustión, donde el char reacciona con el agente gasificante suministrado y depende de la concentración de $\mathrm{O} 2, \mathrm{H} 2 \mathrm{O}$ y $\mathrm{CO} 2$. En la zona de pirolisis y secado, la temperatura disminuye debido a que la mayoría de las reacciones son endotérmicas. Al aumentar la relación de equivalencia $\mathrm{ER}$, manteniendo la relación $S: F$ fija disminuye el punto máximo de la temperatura de gasificación, esto es debido a la menor cantidad de oxigeno presente en la reacción. Al aumentar la relación S:F, manteniendo la relación ER fija, disminuye el pico de la temperatura de gasificación, esto es debido a la mayor cantidad de vapor de agua, siendo esta una reacción endotérmica.

En la región del lecho, que está en contacto con la parrilla, la temperatura comienza a decrecer debido a la formación de cenizas.

Para un mismo valor de $\mathrm{ER}$, al aumentar la relación S:F, aumenta la concentración de $\mathrm{CO} 2$ y $\mathrm{H} 2 \mathrm{CH} 4$, mientras las concentraciones de $\mathrm{CO}$ disminuyen 


\section{REFERENCIAS}

Gordillo Ariza, G. (2009). Fixed Bed Counter Current Low Temperature Gasification of Dairy Biomass and Coal-Dairy Biomass Blends Using Air-Steam as Oxidizer. Ph.D. thesis, Texas A\&M university, College Station Texas, 2009.

Annamalai, K., \& Puri, I. K. (2007). Combustion Science and Engineering. Boca Raton: CRC Press/Taylor and Francis.

Gordillo G, Annamalai K, Gasification of coal and dairy manure with airsteam as oxidizing agent. ASME-JSME Thermal engineering summer heat transfer conference, Vancouver, Canada; July 2007.

[Gordillo g, Annamalai, Adiabatic fixed bed gasification of dairy biomass with air and steam. Renewable Energy Journal. Vol. 34, pp. 2789-2729, 2009.

Annamalai K, Priyadarsan, Arumugam, Energy Conversion: Principles of coal, animal waste, and biomass fuels. Encyclopedia Energy Eng Technol vol 1, pp. 476-97, 2007. Fedepalma. (2008).

Anuario Estadístico 2008. Bogotá: Fedepalma 


\title{
OPTIMIZACIÓN MATEMÁTICA DE LOS PARÁMETROS \\ CONSTRUCTIVOS DE LAS TURBINAS EÓLICAS \\ DE EJE VERTICAL DE PALAS RECTAS
}

\author{
Manuel F. Mejía De Alba, Luis E. García Fernández, \\ Mónica A. Gutiérrez Almonacid \\ Universidad de América \\ manuel.mejia@profesores.uamerica.edu.co \\ luis.garcia@profesores.uamerica.edu.co \\ monica.gutierrez@estudiantes.edu.co
}

Palabras Clave: Optimización (Optimization) Parámetros Geométricos (Geometric Parameters), Rendimiento (Performance), Turbina eólica de eje vertical (Vertical Axis Wind Turbine, VAWT).

Área Temática: Energía Eólica.

\section{INTRODUCCIÓN}

Hasta ahora la sociedad ha dependido de combustibles fósiles para suministrar la mayor parte de la energía que necesita, pero a medida que aumenta la contaminación debido a las emisiones de gases efecto invernadero que provocan el cambio climático, la necesidad de utilizar fuentes de energía sostenible se agudiza. Una de las fuentes más prometedoras es el viento, por lo tanto, es importante diseñar aerogeneradores que puedan extraer la mayor cantidad de energía posible de esta fuente. Las turbinas eólicas de eje vertical de palas rectas pueden cumplir con este objetivo, especialmente para la generación de energía eléctrica de baja potencia [1]. Sin embargo, las eficiencias registradas están por debajo del $40 \%$. Para lograr la mayor extracción de energía del viento, hay que tener especial cuidado en el diseño del rotor y comprender cual es la influencia de sus parámetros geométricos tanto en la eficiencia de extracción de energía como en el torque que genera [2].

Muchos estudios se han llevado a cabo en aras de comprender y diseñar de mejor forma turbinas eólicas. En especial nos interesan los estudios realizados sobre turbinas de eje vertical. Estos se podrían clasificar dependiendo de los aportes que realizaron en:

- Efectos geométricos y perfil usado: Kirke [3], Paraschivoiu [4], M. El-Samanoudy, et al [5].

- Modelos de comportamiento: Paraschivoiu [4], Howel y Qin [5], Wang and Zhang [6], L.B. Wang and L. Zhang [7], Islam and ting [8].

Este estudio se ha realizado debido a que las turbinas de eje vertical de palas rectas pueden ser una buena alternativa para la generación de energía eléctrica de baja potencia, teniendo en cuenta que tienen varias ventajas sobre 
las de eje horizontal y, la razón por la que no se pueden aprovechar estas ventajas es que no aceleran hasta el TSR óptimo. Es por esto que se vio la necesidad de optimizar los parámetros geométricos como la relación altura/ radio, solidez, ángulo de ataque y perfil aerodinámico, de tal manera que se pueda aumentar su rendimiento para ser instaladas en zonas remotas no interconectadas a las redes de energía eléctrica.

\section{MATERIALES Y MÉTODOS}

En este artículo se propone un modelo de optimización de los parámetros constructivos, cuyo objetivo es el de maximizar el $\mathrm{Cp}$ de la turbina. Se elabora un modelo matemático para predecir el comportamiento de la turbina, y éste es utilizado como base para desarrollar la función objetivo del problema. Se determinan unas restricciones propias para el problema de optimización. Al resolver el problema de optimización se obtienen los valores de los parámetros que optimizan el desempeño de la turbina.

\section{RESULTADOS}

Como resultado de este trabajo se obtiene una metodología para el diseño de turbinas eólicas, basado en la optimización matemática de los parámetros constructivos de ésta. Se obtienen los valores de los parámetros que optimizan el desempeño de la turbina para el caso específico de un modelo de turbina eólica de eje vertical para suplir las necesidades de consumo de un hogar promedio colombiano de una zona no interconectada. Luego se generó la gráfica de desempeño de dicha turbina que cumple con todos los requerimientos planteados inicialmente.

\section{CONCLUSIONES}

El modelo de optimización propuesto, al estudiar simultáneamente la influencia de las características constructivas de las que depende el $\mathrm{Cp}$., permite observar que con la obtención de los valores óptimos de dichas características se puede lograr el porcentaje teórico de extracción de energía del viento que alcanza una turbina de eje horizontal, además, se superan los problemas en el arranque, lo cual es la principal causa de desinterés en la investigación de turbinas de eje vertical.

\section{REFERENCIAS}

[1] G. García. Energías del siglo XXI: de las energías fósiles a las alternativas. Ediciones Mundi-Prensa, Madrid, 2008.

[2] R. Bastianon. Energía del viento y diseño de turbinas eólicas. Tiempo de cultura ediciones. Buenos Aires. 2000. 
[3] B.Kirke. Evaluation of self-starting vertical axis wind turbines for stand-alone applications. PhD Thesis. Griffith University, Faculty of Engineering and Information Technology. School of Engineering. Australia, 1998.

[4] I. Paraschivoiu. Wind turbine design: with emphasis on Darrieus concept. Politechnich International press. Canada, 2002.

[5] M. El-Samanoudy, et al. Effect of some design parameters on the performance of a Giromill vertical axis wind turbine. Ain Shams Engineering Journal. pp. 1 -11, 2010.

[6] R. Howell and N. Qin. Wind tunnel and numerical study of a small vertical axis wind turbine. Renewable Energy 35, pp. 412-422, 2010.

[7] L.B. Wang and L. Zhang, A potential flow 2-D vortex panel model: Applications to vertical axis straight blade tidal turbine, Energy Conversion and Management 48, pp. 454-461, 2007.

[8] M. Islam and D. Ting. Aerodynamic models for Darrieus-type straightbladed vertical axis wind Turbines. Renewable and Sustainable Energy Reviews 12, pp. 1087-1109, 2008. 


\title{
ESTUDIO DE FACTIBILIDAD TÉCNICO ECONÓMICA PARA LA IMPLE- MENTACIÓN DE UNA CENTRAL DE ENERGÍA NUCLEAR PARA LA PRODUCCIÓN DE ENERGÍA ELÉCTRICA EN COLOMBIA
}

\author{
David Edgardo González C., Hernán Guillermo Bolaños H., \\ Edwin Alonso Rodríguez F. \\ Escuela Colombiana de Carreras Industriales ECCI \\ david_ego@ hotmail.com; hernanbolaos@yahoo.com.ar; \\ auto.edwin@gmail.com
}

Palabras Clave: Energía, Generación, Nuclear, Reactor, Sostenible. Área Temática: Desarrollo sostenible. Generación de energía eléctrica a través de la Energía Nuclear.

\section{INTRODUCCIÓN}

Colombia tuvo un incremento del consumo eléctrico de un 33\% entre 1990 y 2005, así mismo se aumentó el uso de carbón para la producción de energía eléctrica de $28,7 \%$ a $46,9 \%$ para este tiempo [1], lo que muestra una clara tendencia del aumento del uso de combustibles fósiles para la generación de energía eléctrica, debido en gran parte a la crisis energética que sufrió el país en el año 1992, la cual fue provocada por el Fenómeno del Niño y la dependencia casi exclusiva de las hidroeléctricas. Para el año 2011 la producción de energía eléctrica a partir de fuentes hídricas tuvo una participación del 63,7\% y la proveniente de fuentes térmicas un 31,5\% [2].

En el mundo hay 439 reactores nucleares en funcionamiento, seis de ellos en América Latina. ARGENTINA: Dos centrales proveen el 6,2\% de la electricidad que usa el país. Atucha 1: Potencia de $335 \mathrm{MW}$, Embalse: Potencia de 600 MW, Atucha 2: Potencia de 692 MW. BRASIL: El 3,1\% de la energía eléctrica proviene de centrales nucleares. Angra I: Potencia de $657 \mathrm{MW}$. Angra II: Potencia de 1.350 MW. Angra III: Potencia de 1.405 MW. MÉXICO: Laguna Verde aporta el $4 \%$ de la electricidad del país, tiene dos generadores de 655 MW cada uno [3].

\section{MATERIALES Y MÉTODOS}

La metodología a emplear es la investigación de los temas relacionados para construir un documento claro y concreto; tendrá información recopilada de fuentes fiables, contundentes y precisas. El objetivo de este estudio va en un principio a explicar el proceso de transformación de energía, desde el uso de la reacción nuclear hasta la generación eléctrica; teniendo adicionalmente consideraciones referentes a los costos de implementación y operación, impactos a nivel social y ambiental y análisis de ingeniería básica de los equipos a emplear. 


\section{RESULTADOS}

Del estudio que se está adelantando, los resultados más relevantes consisten en el análisis de la situación actual de la infraestructura eléctrica del país, de donde es posible afirmar que Colombia depende en un $70 \%$ de fuentes hídricas para la generación eléctrica que suple el consumo interno y su tasa de exportaciones a los países vecinos, el porcentaje restante de la energía eléctrica consumida proviene principalmente de plantas termoeléctricas, éstas emplean combustibles como: gas natural, carbón y combustibles derivados del petróleo. Dadas estas condiciones, queda en evidencia la dependencia de Colombia de dos fuentes de energía, que son inestables y generan impactos a nivel ambiental y social. En Colombia, aparte de los recursos citados también existen reservas de Uranio que pueden ser empleadas en la generación eléctrica [4].

\section{CONCLUSIONES}

La energía eléctrica que se consume en Colombia depende principalmente de centrales hidroeléctricas [2], lo que pone la continuidad del fluido eléctrico del país en condición de vulnerabilidad ante fenómenos climáticos; mientras que la operación de centrales nucleares es viable desde el punto de vista de la seguridad y el manejo ambiental, esto se ha comprobado en varios países en los que la energía nuclear es una fuente segura y confiable con varios años de operación continua. Este tipo de energía es muy cuestionada debido a los residuos altamente radioactivos que genera, sin embargo, una fuga o una explosión es poco probable en las centrales nucleares modernas. [5]

Para el año 2015 existe una proyección de deficiencia energética para Colombia de aproximadamente $2700 \mathrm{MW}$ [6], demandas energéticas como esta podrían ser suplidas con fuentes de generación nuclear, mejorando de esta forma la confiabilidad del sistema eléctrico colombiano, teniendo en cuenta que la legislación colombiana permite la competencia entre diferentes fuentes de energía en igualdad de condiciones en el mercado; lo que supone un panorama viable desde este punto de vista para la entrada de la energía nuclear, ya que la generación basada en reactores nucleares se presenta como una de las más económicas. [7]

\section{REFERENCIAS}

[1] Co-eficiencia: mejora de la eficiencia energética en los edificios unidad de planeación minero energética y ministerio de minas y energía de Colombia. Octubre de 2009

[2] http://www.xm.com.co/Pages/DescripciondelSistemaElectricoColombiano.aspx Consultada el 12 de Septiembre de 2012 
[3] http://www.180.com.uy/articulo/17710 Consultada el 3 de Octubre de 2012.

[4] http://www.ingeominas.gov.co/Noticias/General/Areas-EstrategicasMineras.aspx Consultada el 3 de Octubre de 2012.

[5] http://www.revistavirtualpro.com/ediciones/energias_alternativas energia_nuclear_y_geotermica-2009-11-01_25 Consultada el 03 de Octubre de 2012.

[6] Plan de expansión de referencia generación - transmisión 201020244.2 hidroelectricidad y fuentes no convencionales de energía.

[7] CORPOEMA, Formulación de un plan de desarrollo para las fuentes no convencionales de energía en Colombia (pdfnce) Volumen 1. Diciembre 2010. 


\title{
CONSUMO DE POTENCIA REACTIVA EN BOMBILLOS “AHORRADORES”
}

\author{
Holman Yesid Piñeros*, Manuel Alejandro Mayorga*, Armando Díaz* \\ "ESCUELA TECNOLÓGICA INSTITUTO TÉCNICO CENTRAL \\ *ESCUELA COLOMBIANA DE CARERAS INDUSTRIALES, ECCI \\ holman.pineros@gmail.com \\ alejo_mayorga@yahoo.com \\ diaz_escobar_armando@ hotmail.com
}

Palabras Clave: Eficiencia energética, potencia reactiva, luminarias ahorradoras, luminarias incandescentes, iluminación

Área Temática: Eficiencia Energética

\section{INTRODUCCIÓN}

La forma más utilizada para solucionar el problema de la iluminación es mediante el uso de luminarias eléctricas, que tradicionalmente han sido incandescentes, (funcionan por efecto termoiónico), ya que al ser una carga puramente resistiva no consume potencia reactiva [1]. Sin embargo, en los últimos años se ha extendido el uso de las luminarias fluorescentes compactas [2], gracias al desarrollo, en décadas anteriores, de la electrónica de potencia. La expansión de su uso se debe a que para producir cierto nivel de iluminación consumen menos potencia activa que su contraparte incandescente. Este incremento de la eficiencia en la producción de luz se manifiesta en menores costos en la facturación dado que a nivel residencial se mide únicamente la potencia activa $[3,4]$. El objetivo de este trabajo es medir el consumo tanto de potencia activa y reactiva para el mismo nivel de iluminación para ambos tipos de luminaria y evaluar el consumo de potencia reactiva y hacer un balance sobre la eficiencia real teniendo en cuenta el consumo tanto de energía activa como de reactiva, ya que la energía reactiva incrementa las pérdidas de cualquier sistema [5]. "Las características de un sistema eléctrico, que normalmente hacen referencia a la demanda de energía activa, cambian completamente al tener en cuenta la energía reactiva consumida por los elementos del sistema. Por esta razón es muy conveniente estudiar la energía reactiva en forma parecida a la energía activa, es decir, se deben estudiar las características del sistema eléctrico considerando las cargas reactivas y las pérdidas que producen" [6]. Varios autores citan como desventajas de las luminarias fluorescentes compactas compactas; la incidencia de la temperatura del color de luz en la salud humana y los armónicos que generan $[7,8,9,10,11,12]$. De igual forma, a nivel de las pequeñas industrias colombianas se ha generado inquietud sobre el elevado consumo de potencia reactiva y su incidencia en el factor de potencia [13]. No se encontró en el estado del arte realizado, mayor referencia al consumo de potencia reactiva de las luminarias fluorescentes compactas. 


\section{MATERIALES Y MÉTODOS}

En una prueba preliminar se utilizó como equipo de medición un analizador de calidad de energía trifásico marca AEMC instruments modelo PowerPad 3945-B. Se energizaron 4 luminarias compactas de $15 \mathrm{~W}$ (potencia activa) cada una marca Westinghouse y dos PHILIPS de $15 \mathrm{~W}$ (potencia activa). Para medir la corriente se utilizó [5] la sonda de corriente modelo NM93 de la misma marca. La razón de utilizar varias luminarias compactas para efectuar la medición es incrementar la corriente para entrar en el rango mínimo de sensibilidad de la sonda de corriente, que es $500 \mathrm{~mA}$. Se conectaron las seis luminarias compactas en paralelo.

\section{RESULTADOS}

Se obtuvieron las siguientes mediciones:

\begin{tabular}{|l|l|}
\hline Tensión (Valor eficaz): & $122.4 \mathrm{~V}$ \\
\hline Corriente (Valor eficaz): & $1.2 \mathrm{~A}$ \\
\hline Potencia activa: & $92.1 \mathrm{~W}$ \\
\hline Potencia reactiva: & $116.9 \mathrm{VAR}$ \\
\hline Potencia aparente: & $148.8 \mathrm{VA}$ \\
\hline Factor de potencia: & 0.619 Capacitivo \\
\hline
\end{tabular}

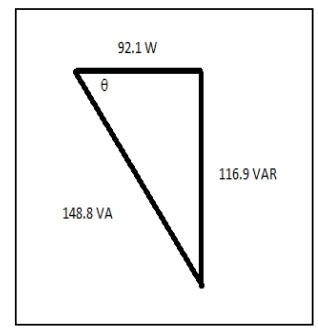

\section{CONCLUSIONES}

La magnitud de la potencia reactiva es mayor que la magnitud de la potencia activa, lo que origina dos fenómenos: que el factor de potencia sea bajo y que la magnitud de la potencia aparente sea mayor que la magnitud de la potencia activa [14]. Lo anterior es muy importante en la medida que el ahorro en una luminaria no debe medirse exclusivamente con respecto a la potencia activa sino también a la aparente, y en este caso puede que este tipo de luminarias no sean tan ahorradoras como suele creerse. A pesar que a nivel residencial no se facture la potencia reactiva, el consumo de reactivos si afecta el sistema de potencia, ya que la potencia reactiva debe generarse, es decir se requiere energía para su producción, así como también debe transportarse y distribuirse con las consecuentes pérdidas en la totalidad de la cadena de energía eléctrica.

\section{REFERENCIAS}

[1] A. Gunawardana y N. Wickramarachchi, «Energy Saving Lamps and Electronic Ballasts,» de Power Electronics Desing Handbook, Boston, Newnes, 1998, pp. 229-242. 
[2] A. Mills, «LED 2005 illuminates,» The Advaced Semiconductor Magazine, vol. 18, no 9, pp. 32-35,

[3] J. Trifunovic, J. Mikulovic, J. Djurisic y J. Kostic, «Reductions in electricity losses in the distribution power system in case of the mass use of compact fluorescent lamps,» Electric Power Systems Research, vol. 81, pp. 465-477, 2011.

[4] C. H. Duarte y R. Schaeffer, «Economic impacts of power electronics on electricity distribution systems,» Energy, vol. 35, pp. 4010-4015, 2010.

[5] M. Á. Graña López, Significado y Medida de los Fenómenos de Desfase en los Sistemas Trifásicos Desequilibrados, Lineales. Aplicación a la Medida en Sistemas con Conducto Neutro. (TESIS DOCTORAL), Valencia: Universidad Politécnica de Valencia, 2010.

[6] CEAC, Ediciones, «Instalaciones de Baja Tensión. Cálculo de Líneas Eléctricas.,» de Enciclopedia CEAC de Electricidad, Ediciones CEAC, 4a Edición, Junio, 1982.

[7] E. F. El-Saadany y M. A. Salama, «Effect of interactions between voltage and current harmonics on the net harmonic current produced by single phase non-linear loads,» Electric Power Systems Research, vol. 40, pp. 155-160, 1997.

[8] E. F. El-Saadany y M. A. Salama, «Reduction of the net harmonic current produced by singlephase non-linear loads due to attenuation and diversity effects, 》 Electrical Power \& Energy Systems, vol. 20, oㅡ 4, pp. 259-268, 1998.

[9] Z. e. a. Radakovic, «The voltage distortion in low-voltage networks caused by compact fluorescent lamps with electronic gear, " Electric Power Systems Research, vol. 73, no 2, pp. 129-136, 2005.

[10] M. A. Choudhry y S. Rahman, "Generic algorithm to select buildinglighting technologies for minimizing total harmonic distortion,» Energy, vol. 20, no 10, pp. 1027-1039, 1995.

[11] Z. Radakovic, F. V. Topalis y M. Kostic, «The voltage distortion in lowvoltage networks caused by compact fluorescent lamps with electronic gear,» Electric Power Systems Research, vol. 73, pp. 129-136, 2005.

[12] F. V. Topalis, I. F. Gonos y G. A. Vokas, «Arbitrary waveform generator for harmonic distortion tests on compact fluorescent lamps,» Measurement, vol. 30, pp. 257-267, 2001.

[13] J. Giraldo Castaño, «Las pymes en Colombia se preocupan por el factor de potencia,» Mundo Eléctrico, vol. 26, no 88, pp. 102-104, 2012.

[14] N. Khan y N. Abas, "Comparative study of energy saving light sources, » Renewable and Sustainable Energy Reviews, vol. 15, pp. 296-309, 2011. 


\title{
PRÁCTICA ACADÉMICA PARA OBTENCION DE BIOETANOL A PARTIR DE RESIDUOS ORGÁNICOS
}

\author{
Stella Monroy*, Germán López*. \\ "Escuela Tecnológica Instituto Técnico Central, \\ stellamon1961@gmail.com, germanlopezm@yahoo.es
}

Palabras Clave: Aprendizaje significativo, bioetanol, energías renovables, fundamentos de investigación, residuos orgánicos.

Área Temática: Biocombustibles

\section{INTRODUCCIÓN}

Es importante que los estudiantes del nivel tecnológico y de ingeniería, cuenten con un conocimiento amplio acerca de los beneficios en el uso de las energías renovables. Se deben generar espacios para la innovación pedagógica, replanteando estrategias didácticas de tal manera que faciliten el proceso de enseñanza-aprendizaje. Se diseñaron dos prácticas pedagógicas diferentes, a nivel de prueba piloto, con el tema de producción de bioetanol a partir de cáscaras de naranja y plátano. Estas actividades se desarrollaron en un laboratorio de química básica, y fueron aplicadas a estudiantes de primer y segundo año de programas de tecnología e ingeniería.La biomasa es la materia orgánica originada en un proceso biológico utilizada como fuente de energía [1]. Esta energía también se conoce como bioenergía. Cuando se pretende utilizar la biomasa como fuente de energía, ocurre el proceso inverso de la fotosíntesis, es decir, la biomasa se quema en presencia de oxígeno liberando energía, además de dióxido de carbono y agua. Este proceso ocurre de manera natural durante la respiración de los seres vivos. Los biocombustibles tienen origen biológico y se obtienen a partir de diferentes tipos de biomasa como residuos de caña de azúcar, cereales, higuerilla entre otros. Su producción y uso reducen el volumen total de dióxido de carbono emitido a la atmósfera. Desde hace varios años, se viene estudiando la importancia de diferentes tipos de aprendizajes. Uno de los investigadores sobre esta temática es Lozanov, quien descubrió que la "sugestividad" es un elemento de la personalidad independiente de la inteligencia; las sugestiones positivas aportan grandes mejoras en la personalidad del estudiante y eleva significativamente el nivel de aprendizaje [2]

\section{MATERIALES Y MÉTODOS}

Las prácticas pedagógicas se realizaron en tres sesiones de trabajo de dos horas cada una, se usaron mapas conceptuales y la construcción de "V heurística", con el fin de evaluar las actividades. "Un mapa conceptual ayuda a los aprendices tanto a aprender mejor los conceptos como a organizarlos adecuadamente para construir estructuras cognitivas más propias de los exper- 
tos" [3]. La V heurística por su parte "apoya la generación de conocimiento a través de acciones mentales, que permiten la construcción del mismo por etapas, en un proceso de interacción teórico práctico, haciendo, uso de los conocimientos previos y de la imaginación" [4]. Esta herramienta está conformada por un marco conceptual, un marco metodológico, un problema de estudio y los objetivos. Las prácticas se sustentaron en el aprendizaje significativo. "los nuevos conocimientos se incorporan en forma sustantiva en la estructura cognitiva del alumno. Esto se logra cuando el estudiante relaciona los nuevos conocimientos con los anteriormente adquiridos" [5]. Se desarrolló la práctica de laboratorio con ayuda de una guía didáctica, cuyo propósito fue familiarizar a los estudiantes con la producción de biocombustibles. Al iniciar y finalizar cada una de las sesiones, los estudiantes realizaron mapas conceptuales o las $\mathrm{V}$ Heurísticas correspondientes, con el propósito de evidenciar el cumplimiento de los objetivos planteados en cada una y de esta forma comprobar la adquisición del nuevo conocimiento.El proceso bioquímico de fermentación [6] lo realizan los microorganismos agregados (levadura) de manera anaerobia, es decir sin presencia de oxigeno, quienes transforman los azúcares en alcohol y bióxido de carbono, como se muestra en la Ec.(1):

$$
\mathrm{C}_{6} \mathrm{H}_{12} \mathrm{O}_{6} \leftrightarrow 2\left(\mathrm{CH}_{3} \mathrm{CH}_{2} \mathrm{OH}\right)+2 \mathrm{CO}_{2}
$$

\section{RESULTADOS}

En los diferentes mapas conceptuales elaborados a lo largo de la primera práctica, se observó como los elementos constitutivos del conocimiento, como conceptos y proposiciones, son representados en una estructura jerárquica. De esta manera se corroboró la apropiación del nuevo conocimiento lo cual evidencia un alto nivel de elaboración y articulación de términos entorno a la obtención de bioetanol a partir de la biomasa.En las entregas sucesivas de las $\mathrm{V}$ heurísticas, se observó cómo los estudiantes se fueron apropiando tanto del manejo de la herramienta didáctica como de la metodología para la producción de bioetanol, adquiriendo durante el proceso mayor conciencia ambiental.

De todas las muestras trabajadas, una sola produjo bioetanol, correspondiente a la muestra cargada con cáscaras de plátano, de ésta se obtuvo $35 \mathrm{ml}$ de alcohol con pureza inferior al 95\%, en la primera destilación a partir de 200 $\mathrm{ml}$ de solución líquida y en la segunda destilación se obtuvo $13 \mathrm{ml}$ de alcohol de alta pureza, superior al 97\%, lográndose mantener una llama de color azul por más de 30 segundos. A partir de $1500 \mathrm{ml}$ de solución liquida usada para destilar, se calcula una producción total de $97.5 \mathrm{ml}$ de bioetanol de $97 \%$ o más de pureza, aproximadamente, con el procedimiento realizado.

De las otras dos muestras no se obtuvo bioetanol debido, probablemente, a la inadecuada manipulación de las muestras al momento de extraer el $\mathrm{CO}_{2}$ generado, ya que aparentemente se permitió la entrada de aire 


\section{CONCLUSIONES}

Los estudiantes evidenciaron mediante evaluaciones organolépticas, físicas y químicas la existencia de etanol obtenido por ellos, lo que generó un interés académico que se manifestó en el propósito de seguir investigando, manipulando otras variables como cantidad de materiales, tiempo del proceso, condiciones de temperatura, para obtener mayores volúmenes de producto y evidenciar si estas mejoran la cantidad y concentración del bioetanol. Los estudiantes usaron y relacionaron los conceptos previos de las ciencias básicas en éste proceso de enseñanza aprendizaje, que era uno de los objetivos de las prácticas. Se generaron espacios para la innovación pedagógica, además se replantearon estrategias didácticas que facilitaron el proceso de enseñanza aprendizaje en ésta prueba piloto .Se propone emplear esta y otros tipos de prácticas similares de manera más frecuente en el desarrollo de asignaturas como Impacto Ambiental, Fundamentos de investigación y Energías renovables entre otras, de los programas de formación de tecnólogos e ingenieros tanto a nivel nacional como mundial.

\section{REFERENCIAS}

[1] ¿Qué es la Biomasa? Recuperado el 23 de mayo de 2010 de http:// www.textoscientificos.com/energia/biomasa

[2] G Losanov. Sugestología. Métodos y aplicaciones. Recuperado el 20 de septiembre de 2010 de http://www.google.com.co/books

[3] Eduteka. El desarrollo de los mapas conceptuales. Entrevista concedida por el Dr. Joseph Novak en agosto de 2006. www.eduteka.org/ Entrevista22.php, consultado 24-08-2010

[4] F.M.Mejía, La "V" Heurística: Una herramienta eficaz para el aprendizaje significativo, Letras Con Ciencia Tecnológica № 7 ETITC, pp. 10-24, Bogotá, 2009

[5] Ausubel.idoneos.com/la teoría del aprendizaje significativo

[6] I seminario taller de biocombustibles biodiesel-bioetanol. Tecnologías aplicadas para Producción de bioetanol. Bogotá- Colombia 2007 


\title{
ANÁLISIS DE VIABILIDAD DEL APROVECHAMIENTO DE LA ENERGÍA CONTENIDA EN LAS NUBES DE TORMENTA
}

\author{
Cristiam Yamid Sánchez, Diego Fernando Gómez \\ ESCUELA COLOMBIANA DE CARRERAS INDUSTRIALES \\ diegomerc@msn.com
}

Palabras Clave: Higroelectricidad, humedad, renovable, cargas eléctricas, polvo en el aire, atmósfera.

Área Temática: Aplicaciones Especiales

\section{INTRODUCCIÓN}

La energía estática siempre ha sido muy extraña y a su vez muy problemática ya que es la causante de varias averías a equipos eléctricos y dispositivos que resultan afectándose al hacer contacto con esta. Pero avances de investigadores de la Universidad de Campiña en Brasil han presentado una manera de capturar y aprovechar la electricidad contenida en la humedad de la atmósfera. El agua en la atmósfera es capaz de almacenar cargas eléctricas a partir de su contacto con partículas de polvo y gotas de otros líquidos presentes en la atmosfera. Es esta la idea a analizar; aprovechar el reservorio de electricidad presente en atmósferas húmedas [1]. En Colombia se han tenido adelantos en el tema, el profesor Francisco José Román Campos, docente de la Universidad Nacional de Colombia, ha desarrollado técnicas capaces de almacenar cantidades importantes de carga eléctrica y generar campos con dicha propiedad física durante su actividad. Tales acumulaciones hacen que exista una diferencia de potencial entre la nube y la superficie terrestre (gradiente), fenómeno que permite generar corrientes eléctricas denominadas corona, "principio en el cual se basa la investigación", afirma el ingeniero Román [2]. Las nubes de tormenta tienen la propiedad de almacenar grandes cantidades de carga, la cual genera campos eléctricos ambientales importantes que pueden considerarse constantes, ya que se encuentran a kilómetros de la superficie terrestre y sus dimensiones son también del orden de kilómetros.

\section{MATERIALES Y MÉTODOS}

Analizando el comportamiento eléctrico de las nubes tormentosas, se evidencia que se producen fuertes corrientes ascendentes y descendentes de aire, las gotas son frotadas violentamente por este, lo que hace que se electricen separándose las cargas negativas, que tienden a ir hacia abajo, de las positivas, que se van hacia arriba. Se va distorsionado el cambio eléctrico aumentando el voltaje y cuando llega a ser de casi 30000 voltios por cada cm. Es de allí de donde se pretende aprovechar la energía [1]. 
Efecto corona: Para atrapar la energía, los ingenieros dispusieron en el Laboratorio de Compatibilidad Electromagnética un arreglo de electrodos flotantes (EF) tipo corona (elemento metálico similar a una aguja), que conduce energía. Este amplifica miles de veces, alrededor de su punta, el campo eléctrico de trasfondo hasta iniciar una serie de descargas con el gas ionizado presente en la atmósfera.

"Tal fenómeno es conocido como efecto corona, y gracias a él es posible capturar, de forma circular, la corriente energética proveniente de las nubes y almacenarla en condensadores. Cuando un elemento metálico con forma puntiaguda es sometido al campo eléctrico, tiene la propiedad de amplificar el campo eléctrico que lo rodea. Hoy por hoy los electrodos tipo corona son utilizados para amplificar el campo eléctrico ambiental, debido a sus finas agujas con radios de curvaturas muy pequeñas capaces de amplificar millones de veces el campo eléctrico ambiental", explicó el ingeniero, que integra el Grupo de Investigación en Compatibilidad Electromagnética de la Universidad Nacional de Colombia (EMC-UNC) [3].

\section{CONCLUSIONES}

Esta innovadora propuesta permitirá ayudar en sectores que aun no poseen energía eléctrica, aunque en principio será empleado en aparatos de bajo consumo, esta alternativa es una muy buena opción a la hora de fijarse en otras fuentes diferentes a las fósiles o recursos no renovables. Si es de considerar que se aprovechara solamente la energía en nubes de tormenta y estas no son constantes, por lo que se tendría dificultad en tener electricidad constante; pero si puede ser un complemento de técnicas tales como la captación de energía solar, y que podrían combinarse muy bien. Según estadísticas a diciembre del 2009 , la cobertura del Sistema Interconectado Nacional (SIN) era del 95,56\%, y la de las Zonas No Interconectadas (ZNI), del $65,16 \%$. "A esa fecha -la más actualizada sobre el tema-, aproximadamente 562.000 viviendas en Colombia no tenían electrificación", explica Sandra Lizette Mojica Corchuelo. Las ZNI son aquellas que reciben dicho servicio a través de soluciones aisladas como plantas diésel, por ejemplo Leticia y San Andrés.

Según XM Compañía de Expertos en Mercados S.A. ESP (filial del grupo empresarial ISA), encargada de prestar los servicios de planeación y coordinación de la operación de los recursos del SIN, el sector eléctrico se basa en la generación de energía hidráulica (64\% de la producción) y térmica $(30 \%)$. Sin embargo, también se explora su obtención a través de fuentes alternativas como la eólica (originada por el viento) y la biomasa (materia orgánica e inorgánica como residuos vegetales, agrícolas, ganaderos, etc.). 


\section{REFERENCIAS}

[1] American Chemical Society [ACS]. Electricity collected from the air could become the newest alternative energy source. 2010. Recuperado el 2 de octubre de 2012 de http://portal.acs.org/portal/acs/ corg/content?_nfpb=true\&_pageLabel=PP_ARTICLEMAIN\&node_ $i d=223 \&$ content_id=CNBP_025779\&use_sec $=$ true\&sec_url_ var=region $1 \&$ _uuid=a9b89e9d-aed5-4345-ac91-b96c1d6c0cc2.

[2] Vera, E. Usan energía de las nubes para cargar equipos electrónicos. 2011. Recuperado el 6 de octubre de 2012 de http://www.agenciadenoticias.unal.edu.co/detalle/article/usan-energia-de-las-nubes-paracargar-equipos-electronicos.html Universidad Nacional de Colombia. Agencia de noticias un.

[3] Maldonado, J. La electricidad en las tormentas. 2009. Recuperado el 8 de octubre de 2012 de http://maldonado.eltiempo.es/la-electricidaden-las-tormentas/ eltiempo.es. 


\title{
PROTOTIPOS DEL FENÓMENO DE LA CONCENTRACIÓN SOLAR
}

\author{
Julián Andrade \\ Escuela Colombiana de Carreras Industriales \\ Julisheri@ hotmail.com
}

Palabras Clave: Concentración Solar, Fotocelda, Espejo cóncavo, Radiación directa

Área Temática: Energía solar

\section{INTRODUCCIÓN}

El ser humano hace que el mundo se desarrolle a niveles exponenciales y el motor de todos los cambios, que hay día tras día, son las energías. Existe una gran problemática alrededor de esto debido a que los recursos no renovables son los que se utilizan en mayor medida como fuentes energéticas y generan efectos negativos a nivel ambiental poniendo en riesgo la salud y la supervivencia de la humanidad. Es por ello que para combatir la problemática se han venido realizando estudios con el fin de utilizar la energía solar de formas distintas a la fotovoltaica con resultados muy interesantes; se trata de la energía solar por concentración. Esta energía que es una aplicación térmica y directa de la energía solar y consiste en utilizar el fenómeno óptico de la reflexión para concentrar la radiación solar sobre un área, una línea o un punto con el objetivo de aumentar la intensidad solar que incide sobre cierto elemento receptor [1], [2], [3].

\section{MATERIALES Y MÉTODOS}

En el estudio se han construido dos prototipos del fenómeno que permiten analizar datos y comenzar a explorar de forma práctica los beneficios y desafíos de esta energía.

\section{Espejos cóncavos con foto celda}

El primer prototipo consistió en enfocar la luz de una lámpara con varios espejos cóncavos, hacia una foto celda. Se analizo el comportamiento de los rayos de luz, la incidencia del número de espejos que enfocan la luz en el voltaje de la foto celda, y la incidencia de las distancias entre los componentes del experimento. También se emplearon elementos que hicieron el papel de concentradores de luz, utilizando espejos cóncavos, que normalmente vienen plateados por el lado convexo; para el montaje se platearon por el lado cóncavo [4].

Tanque almacenador de agua calentada por espejos cóncavos

En el segundo prototipo se realizó un montaje más real: Se utilizó un pequeño tanque el cual almacenaba agua, radiación solar y espejos mon- 
tados sobre un pequeño mecanismo que permitía el movimiento de los espejos en cualquier dirección enfocando los rayos hacia el tanque lo que aumentaba la temperatura del agua hasta llegar al punto de la evaporación. Se midieron las distintas temperaturas del agua cambiando el número de espejos [5].

\section{RESULTADOS}

En el primer montaje se verifico que el espejo cóncavo aumenta la intensidad de la luz comparado con un espejo plano:

\begin{tabular}{|l|c|c|c|}
\cline { 2 - 4 } \multicolumn{1}{c|}{} & Voltaje en la foto celda & Máxima capacidad de voltaje & Eficiencia \\
\hline Espejo plano & $0,5 \mathrm{~V}$ & $2 \mathrm{~V}$ & $25 \%$ \\
\hline Espejo cóncavo & $1,9 \mathrm{~V}$ & $2 \mathrm{~V}$ & $95 \%$ \\
\hline
\end{tabular}

El segundo montaje fue más real y hubo una recolección de datos más profunda.

\begin{tabular}{|l|c|c|c|c|}
\cline { 2 - 5 } \multicolumn{1}{c|}{} & \multicolumn{4}{c|}{ \# de espejos } \\
\cline { 2 - 5 } \multicolumn{1}{c|}{} & 1 & 2 & 3 & 4 \\
\hline Temperatura en el agua $\left({ }^{\circ} \mathrm{C}\right)$ & 80 & 90 & 95 & 100 \\
\hline
\end{tabular}

-Espejos cóncavos de $20 \mathrm{~cm} \varnothing$

-Intensidad de radiación máx.

-El volumen de agua es de $38.48 \mathrm{~cm} 3$

\section{CONCLUSIONES}

Los experimentos realizados demuestran que esta fuente de energía no es un fenómeno difícil de desarrollar en términos técnicos y económicos y se convierte en una oportunidad fácil de aprovechar en el campo investigativo y pedagógico .Los resultados de los 2 montajes verifican la eficiencia del fenómeno de la concentración solar.

En el primero hay una diferencia de eficiencia de $70 \%$ comparando el voltaje del espejo cóncavo respecto a un espejo plano y en el segundo montaje que es mas real se verifica que enfocando un área grande donde irradie el sol se puede concentrar mucha energía. Si se magnificara esto en términos económicos y técnicos es muy probable llegar a resultados muy productivos en la industria energética y dar diferentes usos a este tipo de fenómenos. 


\section{REFERENCIAS}

[1] Johnson, G. (2009- Vol 25). Conectados con el sol. National geographic, 2-23.

[2] Barreto, C. A., \& Rojas Charry, G. (2002). Diseño e implementación de un sistema de seguimiento del sol. Bogotá.

[3] Greenpeace Internacional. (2009). Energía solar térmica de concentración. Perspectiva 2009.

[4] Sánchez, J. L. (2009). Estudio comparativo de un sistema fotovoltaico. Andalucía: edición electrónica ha sido realizada en 2010.

[5] Andrade Vargas, j. S., Molano, j. A., Vásquez, I., \& Gómez, M. (2008). Calentador de agua termosolar. 


\title{
VEHICULOS HIBRIDOS EN COLOMBIA
}

\author{
Sergio Carrión*, Álvaro Hernández*, Fabián Forero* \\ "Universidad Santo Tomas \\ sergio.carrion@usantotomas.edu.co \\ "Universidad Santo Tomas \\ alvaro.hernandez@ usantotomas.edu.co \\ fabian.forero@ usantotomas.edu.co
}

Palabras Clave: Consumo de Combustible, Prueba de los Cinco Ciclos y Vehículo Híbrido.

Área Temática: Eficiencia Energética

\section{INTRODUCCIÓN}

El interés que se ha manifestado a nivel mundial por encontrar fuentes de energía alternativas desde hace ya varios años ha llevado a diversas compañías del sector automotriz a desarrollar novedosos sistemas que ayuden a disminuir las emisiones de gases contaminantes y a bajar los costos de operación reduciendo el consumo de combustible. El sistema híbrido con el que cuenta el vehículo objeto de estudio se deriva de dicha labor de ingeniería y consta de un motor de combustión y un motor eléctrico. En razón a que ésta es una tecnología nueva a nivel mundial son pocos los estudios que se han realizado en materia de consumo de combustible y la mayoría de ellos se han llevado a cabo en países industrializados, donde se desarrollan dichas tecnologías. A nivel latinoamericano en Venezuela y Ecuador ya se han comercializado vehículos híbridos, pero los estudios de mercado y de validación de la tecnología han estado a cargo de las compañías que venden los vehículos, por cuanto sus resultados son confidenciales. Examinando el panorama nacional encontramos que en Colombia hasta el momento no se había ejecutado ningún proyecto en el que se evaluara el consumo de combustible de un vehículo híbrido.

\section{MATERIALES Y MÉTODOS}

Para la realización del estudio se tomaron como referencia la prueba de Los Cinco Ciclos establecida por la EPA y la norma SAEJ1711; se realizó una adaptación de estos protocolos al entorno Colombiano y a la disponibilidad de equipos y recursos con que se contaba para el proyecto. Para la realización de las pruebas se elimino el quinto ciclo de la prueba de la EPA, ya que este hace referencia a condiciones de baja temperatura que no se dan en el país, pues esta prueba simula temperaturas cercanas a las que se dan en temporada de invierno en los países con estaciones, pero se introdujo un nuevo ciclo de ascenso en zona montañosa. 


\section{RESULTADOS}

El proyecto consistió [1] en realizar un estudio de carácter técnico en el que se evaluó la viabilidad de poner al servicio de la Policía Nacional de Colombia el vehículo Híbrido Chevrolet Tahoe. Durante el desarrollo de la investigación se realizaron pruebas en los diferentes pisos térmicos del territorio nacional para evaluar el consumo de combustible de la camioneta cuando transita en ciudad, en carretera, con aire acondicionado, en ascenso de montaña y especialmente cuando es sometida a manejo agresivo de acuerdo a las necesidades de la institución. La finalidad del proyecto, que se estructuro a partir de la norma SAE J1711 [2] y a estándares internacionales establecidos por la EPA [3], fue evaluar la eficiencia del sistema híbrido cuando trabaja en un entorno con las características topográficas y la malla vial con la que se cuenta en el país para luego establecer por medio de un estudio económico si es viable que la Policía adopte este sistema. En la figura 1, se presenta un resumen de los resultados obtenidos.

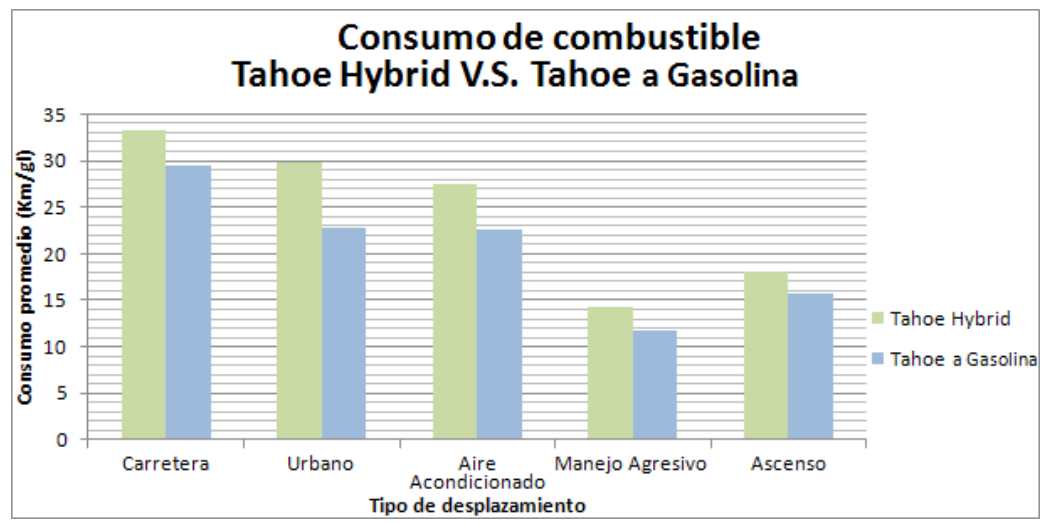

Figura 1. Consumo de combustible global de las camionetas Tahoe híbrida y a gasolina.

\section{CONCLUSIONES}

Tras analizar el estudio técnico se encontró que el funcionamiento del motor eléctrico del vehículo híbrido no está regido por la velocidad a la que éste se desplaza. El parámetro bajo el cual se está decidiendo realmente el funcionamiento alternado o simultaneo del motor eléctrico y del motor de combustión es: la potencia requerida, que se puede decir está en función de diversos parámetros, principalmente tipo de manejo, posición del acelerador (RPMS del motor), inclinación del terreno, condición de carga y en menor medida del funcionamiento de accesorios como el aire acondicionado. De la misma manera se identificó que la eficiencia del sistema híbrido disminuye conforme aumentan los requerimientos de potencia. 


\section{REFERENCIAS}

[1] Carrión, S., Hernández, A., Forero, F. Estudio Técnico de la Viabilidad en la Implementación de las Camionetas Híbridas Chevrolet Tahoe para la Policía Nacional de Colombia. Proyecto de Investigación, Universidad Santo Tomás, Bogotá, 2011.

[2] Norma SAE J1711. Recommended Practice for Measuring the Exhaust Emissions and Fuel Economy of Hybrid-Electric Vehicles, Including Plug-in Hybrid Vehicles.

[3] EPA's Fuel Economy Program. How Vehicles are Tested, How are Label Estimates Calculated. EPA420-F-09-067, October 2009. 


\title{
EFECTO DE LA LUZ Y LA AIREACIÓN EN LA ACUMULACIÓN DE ACEITES EN LA MICROALGA Chlorella vulgaris
}

\author{
Luis Miguel Serrano Bermúdez*, Luis Carlos Montenegro Ruiz*, \\ Rubén Darío Godoy ${ }^{* *}$ \\ "Universidad Nacional de Colombia, Imserranob@unal.edu.co, \\ *Universidad Nacional de Colombia, Icmontenegror@unal.edu.co \\ ** Universidad Nacional de Colombia, rdgodoys@ unal.edu.co
}

Palabras Clave: Chlorella vulgaris, contenido de CO2, Irradiancia, Fotoperiodo, aireación, productividad de lípidos, biodiesel.

Área Temática: Biomasa y Bioenergía

\section{INTRODUCCIÓN}

Las condiciones climatológicas e hídricas de Colombia hacen de éste un país propicio para el cultivo masivo de microalgas, las cuales gracias al contenido de lípidos y a su elevada velocidad de crecimiento se convierten en una fuente de interés para la obtención de biocombustibles [1;2].

Para el cultivo masivo de microalgas con el objeto de producir biodiesel se debe tener en cuenta entre otros, los siguientes aspectos: seleccionar la cepa adecuada, la cual debe tener tanto altas productividades de lípidos, como porcentajes de acumulación lipídica intracelular superiores al 30\% del peso seco debido a los altos costos asociados con el proceso de extracción de aquellos [1;3]; seleccionar las condiciones del cultivo adecuadas, seleccionar el modo de cultivo indicado [4] y seleccionar el método de recuperación de biomasa y lípidos [5] que permitan que el proceso sea viable económicamente. La microalga Chlorella vulgaris LAUN 002 es una cepa promisoria en el contexto colombiano, gracias a que las tasas de crecimiento, los tiempos de cultivo y las productividades de lípidos obtenidos por ésta fueron mejores que en otras microalgas nativas evaluadas, adicionalmente, la composición de los ácidos grasos obtenidos se asemejó a la composición del aceite de soya.

Por lo anterior, el objetivo de esta investigación fue evaluar el efecto de la Irradiancia, fotoperiodo, contenido de $\mathrm{CO} 2$ y aireación, además de la interacción entre éstos, sobre el crecimiento, la productividad de biomasa, la acumulación de lípidos y la productividad de lípidos en la microalga Chlorella vulgaris LAUN 002.

\section{MATERIALES Y MÉTODOS}

El cultivo de las diferentes microalgas se realizó por triplicado en botellas de vidrio. Se emplearon lámparas fluorescentes como fuente de iluminación artificial. El tiempo de cultivo fue hasta llegar a fase estacionaria. Al finalizar 
el cultivo se recuperó la biomasa por centrifugación, se llevó a peso seco por liofilización y se extrajeron los lípidos producidos según método de Bligh \& Dyer [6] y se cuantificaron según metodología de Marsh \& Weistein [7].

\section{RESULTADOS}

El efecto del CO2, la irradiancia, el fotoperiodo y la aireación fueron evaluados como parámetros de producción y acumulación de biomasa y lípidos en la microalga Chlorella vulgaris. Para la productividad de biomasa, el único factor que no fue significativo fue la aireación, para la productividad de lípidos todos los factores fueron significativos $(\alpha=5 \%)$. La productividad de lípidos óptima predicha por el modelo fue 72,2 \pm 5,9 mg-L-1·día-1, 14,4 veces superior a la productividad de aceites de la palma africana, para un contenido de CO2 de $2 \%$, irradiancia de $114 \mu \mathrm{E} \cdot \mathrm{m}-2 \cdot \mathrm{s}-1$, fotoperiodo de 24:0 LO y aireación de 1,2 vvm; el contenido de lípidos bajo las condiciones mencionadas fue de $16,4 \pm 1,4 \%$. La optimización de los factores para maximizar el contenido de lípidos y minimizar la disminución de la productividad de lípidos se logró para un contendido de $\mathrm{CO} 2$ del $1,2 \%$, irradiancia de $22 \mu \mathrm{E} \cdot \mathrm{m}-2 \cdot \mathrm{s}-1$, fotoperiodo de 12:12 LO y aireación de 0,4 vvm con valores de $32,7 \pm 1,4 \%$ y $46,1 \pm 5,9$ $\mathrm{mg} \cdot \mathrm{L}-1 \cdot$ día-1, respectivamente.

\section{CONCLUSIONES}

La optimización de los parámetros contendido de CO2, irradiancia, fotoperiodo y aireación para un potencial cultivo masivo de la microalga Chlorella vulgaris como fuente viable de biodiesel se logró en los valores de $1,2 \%$, $22 \mu \mathrm{E} \cdot \mathrm{m}-2 \cdot \mathrm{s}-1,12: 12 \mathrm{LO}$ y 0,4 vvm, respectivamente, donde los valores estimados de contenido de lípidos y la productividad de lípidos son $32,7 \%$ y 46,1 mg.L-1.día-1, respectivamente. En el caso de los valores ajustados de iluminación, es decir irradiancia y fotoperiodo, son factibles de alcanzar en el territorio colombiano, mientras que los factores de $\mathrm{CO} 2$ y aireación pueden ser controlados a escala industrial.

\section{REFERENCIAS}

Chisti, Y. (2007). Biodiesel from microalgae. Biotechnology Advances, 25(3), 294-306.

Huang, G., Chen, F., Wei, D., Zhang, X. and Chen, G. (2010). Biodiesel production by microalgal biotechnology. Applied Energy, 87(1), 38-46.

Griffiths, M. J. and Harrison, S. T. (2009). Lipid productivity as a key characteristic for choosing algal species for biodiesel production. Journal of Applied Phycology, 21(5), 493-507. 
Kunjapur, A. M. and Eldridge, R. B. (2010). Photobioreactor Design for Commercial Biofuel Production from Microalgae. Industrial \& Engineering Chemistry Research, 49(8), 3516-3526.

Molina Grima, E., Belarbi, E. H., Acién Fernández, F. G., Robles Medina, A. and Chisti, Y. (2003). Recovery of microalgal biomass and metabolites: process options and economics. Biotechnology Advances, 20(7-8), 491-515.

Bligh, E. and Dyer, W. (1959). A rapid method for total lipid extraction and purification. Canadian Journal of Biochemistry and Physiology, 37(8), 911917.

Marsh, J. B. and Weinstein, D. B. (1966). Simple charring method for determination of lipids. The Journal of Lipid Research, 7(4), 574-576. 


\section{PROPUESTA PARA EL DESARROLLO TECNOLÓGICO DE ENERGÍA POR CONCENTRACIÓN SOLAR EN COLOMBIA}

Jaime Enrique Mora M., Edison David Riaño, Gerson Fabián Balaguera, Hernán Camilo Mora M.

jaime_m78@ hotmail.com, ing.edison.d@ hotmail.com, nirvanogfb83@ hotmail.com, hernancamilo_mora@ hotmail.com

ESCUELA COLOMBIANA DE CARRERAS INDUSTRIALES

Palabras Clave: Termosolar, Geotérmica, Radiación solar, Energía solar. Área Temática: Energía Solar

\section{INTRODUCCIÓN}

Cada año la superficie de la tierra recibe del Sol 10 veces la energía conocida de carbón, petróleo y gas juntas [1], esto es aproximadamente 15000 veces el consumo de energía el mundo [2] al año. Actualmente se están construyendo de plantas de generación eléctrica con energía solar [3], esta energía se aprovecha por medio de espejos curvos o planos dependiendo si la planta se basa en torre de concentración o en canal de concentración solar [4]. En España, potencia en el desarrollo de plantas termosolares, se tiene instalado el $72,85 \%$ de la potencia instalada en el planeta [5], en agosto, en un periodo de dos horas, se estableció una marca de generación eléctrica llegando a 1,2 millones de kWh [6] suministrados en territorio español.

Colombia tiene gran potencial energético en términos solares en regiones como La Guajira, según estudios de la Unidad de Planeación Minero Energética (UPME) y el IDEAM, apoyados con la NASA [7]. Los datos obtenidos de radiación solar ( $\mathrm{kWh} / \mathrm{m} 2 / \mathrm{año}$ ) [8], son los siguientes:

Guajira:

Costa Atlántica

Orinoquia:

Región Andina:

$\begin{array}{ll}- & 2000-2100 . \\ - & 1730-2000 . \\ - & 1550-1900 . \\ - & 1550-1750 .\end{array}$

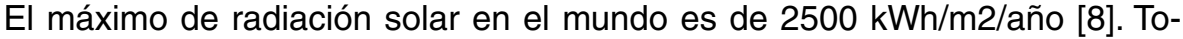
mando los valores de radiación solar en La Guajira, y comparándolos con el máximo de radiación mundial se tiene un $80 \%$ de capacidad de generación solamente en esta región del país.

\section{MATERIALES Y MÉTODOS}

Para el desarrollo de este proyecto se tienen en cuenta aspectos importantes como la geografía [7], el enfoque es la constante energía solar que se pueda presentar la mayor parte del año, la demografía en la región donde se pre- 
tenda construir una planta de generación [9] y el consumo de energía en las poblaciones cercanas. Otro aspecto importante, son las finanzas del proyecto [10], ya que el montaje y puesta en marcha requerirán una inyección gigantesca de dinero.

\section{RESULTADOS}

Al transportar vapor de agua por un canal que consta de dos tubos concéntricos separados por una capa de vacío [11], y dadas las experiencias de diferentes compañías alrededor del mundo [11] que se enfocan en el desarrollo energético, se presentan valores aproximados de terreno cubierto de espejos para generación de diferentes cantidades de MW.

\begin{tabular}{|c|c|}
\hline Potencia de Instalación & Superficie en (hectáreas) \\
\hline $20 \mathrm{MW}$ & 95 \\
\hline $100 \mathrm{MW}$ (Básico) & 192 \\
\hline $100 \mathrm{MW}$ (Con almacenamiento de 7 horas) & 380 \\
\hline
\end{tabular}

Si se construyera una planta energética en la Costa Atlántica con los factores mencionados anteriormente [8], y con un consumo energético de $(20.000$ GWh/año) [12], con una planta de generación de 380 hectáreas, se entregaría energía eléctrica a una población cercana a los 132.000 habitantes, con un promedio de consumo de energía eléctrica por hogar de 3kW/día [13].

\section{CONCLUSIONES}

Con la instalación de plantas termosolares en la Costa Atlántica del país, se impulsaría la región en competitividad y desarrollo. Además, con este avance tecnológico, el país aportaría al cuidado del medio ambiente [14], evitando así el consumo desmedido de combustibles fósiles.

\section{REFERENCIAS}

[1] John C. Kotz, Paul M Reichel, Gabriela C. Weaver. Quimica y Reactividad Quimica.Ed. Thomson (Sexta Edicion).

[2] US Department of Energy, Energy Efficiency \& Renewable Energy. Recuperado de http://www.eere.energy.gov.

[3] Abengoa Solar - Energia solar para un mundo sostenible. Recuperado de http://www.abengoasolar.com/web/es/nuestras_plantas/plantas_en_construccion

[4] Torresol Energy. Reinventing solar powe. Recuperado de http://www. torresolenergy.com/TORRESOL/planta-gemasolar/es 
[5] Asociacion Colombiana de Ingenieros (ACIEM). Capitulo Cundinamarca, La termosolar base su marca historica de generacion electrica diaria. Agosto 2012.

[6] Ingenieros.es - Plataforma de ingenieria y desarrollos tecnologicos S.L. Recuperado de www.ingenieros.es

[7] Unidad de Planeacion Minero Energetica de Colombia (UPME). Recuperado de www.upme.gov.co/Docs/Atlas_Radiacion_Solar/1Atlas_Radiacion_Solar.pdf.

[8] Rodriguez H. Desarrollo de la energia solar en Colombia y sus perspectivas. Murcia. 2009. Revista de ingenieria. Universidad de los Andes. Bogota, Colombia. rev.ing. ISSN. 0121-4993. 2008.

[9] Instituto Geográfico Agustin Codazzi. Recuperado dde http://www. igac.gov.co/igac

[10] Banco Interamericano de Desarrollo (BID). Colombia promueve la energía geotérmica con el apoyo del BID. Recuperado de http://www. iadb.org/es/banco-interamericano-de-desarrollo,2837.html

[11] Opex-Energy. Operación y Mantenimiento de plantas de energía. Recuperado de http://www.opex-energy.com/index.html

[12] Unidad de Planeacion Minero Energetica de Colombia (UPME). Recuperado de www.upme.gov.co/Docs/Proyeccion_Demanda_Energetica.pdf.

[13] Departamento Administrativo Nacional de Estadistica (DANE). Recuperado de http://www.dane.gov.co

[14] G.Tyler Miller, Jr. Ciencia Ambiental. Preservemos la Tierra. Quinta edición. Ed. Thomson. 


\title{
DISEÑO Y CONSTRUCCIÓN DE UN MOTOR STIRLING PARA EL APROVECHAMIENTO DE ENERGÍA TÉRMICA GENERADA POR COMBUSTIBLES FÓSILES Y/O ENERGÍAS RENOVABLES
}

\author{
Angelo Giovanni Ariza García, Miguel Andrés Buitrago, \\ Víctor Alejandro Sepúlveda \\ ESCUELA COLOMBIANA DE CARRERAS INDUSTRIALES \\ angelo.1508@ hotmail.com \\ mabr1987@ hotmail.es \\ valejanse78@ hotmail.com
}

Palabras Clave: Motor Stirling, Combustibles fósiles.

Área Temática: Eficiencia térmica.

\section{INTRODUCCIÓN}

El presente trabajo de investigación desarrollará el diseño de un motor Stirling para maximizar su rendimiento termodinámico o eficiencia por medio de diversos gases como el Oxígeno, Helio, Hidrógeno, en la cual se realizarán estudios sobre el diferencial de temperatura para la ejecución del motor Stirling con diferentes métodos para el aprovechamiento de energía térmica producida por combustibles fósiles como la gasolina, diesel, alcohol y gas natural. También se busca la viabilidad de emplear energías renovables como las celdas solares [1]. De esta manera se podrá generar trabajo mecánico de formas menos contaminantes ya que actualmente en la quema de combustibles fósiles no se aprovecha la energía térmica generada. Actualmente es más relevante este tipo de motor porque el consumo de combustible es mucho menor por lo tanto podrá obtener un menor costo de operación debido a su fácil diseño, construcción y operación [2].

De igual forma se busca adquirir dicha energía almacenada en las celdas solares u otros sistemas de energías alternativas. Esto ayudará a la generación de energía en zonas rurales o de difícil acceso, operación de equipos en donde el costo de operación es muy alto, como en la agricultura ya que se podrá accionar el motor con cualquier tipo de combustible o energía o muchas más aplicaciones en las cuales son de difícil acceso para su mantenimiento o disponen de sitios en los cuales los niveles de ruido son un inconveniente y el motor Stirling ofrece esa ventaja ya que tiene menos partes móviles. Los motores Stirling no se han difundido por los inconvenientes que presentaron cuando se inventaron como su relación de potencia respecto al excesivo tamaño y peso, sin embargo a través de los años han ido evolucionando y se encuentran diferentes configuraciones de motores Stirling en las cuales se determinará la aplicación, como el tipo beta que genera mayor trabajo respecto al tipo alfa y gamma [3]. 


\section{MATERIALES Y METODOS}

Para la fabricación del motor Stirling los materiales necesarios son acero al carbón, cobre, aluminio o bronce y rodamientos. El acero se determinó adecuado debido a los esfuerzos que es sometido, el cobre se utiliza debido a su propiedad física de conductividad térmica el cual será muy eficiente en la disipación del calor producido por el trabajo realizado, y la debida selección del aluminio o bronce se debe a su calor especifico, Así mismo el método para fabricarlos, será por medio de maquinaria de corte, como tornos y fresadoras para darles acabados de gran precisión.

\section{RESULTADOS}

Disponer de los mejores materiales para la fabricación de un motor Stirling, como también aumentar la eficiencia térmica y maximizar la obtención de energía mecánica por medio de quema de combustibles fósiles o energías alternativas y comparar los datos obtenidos en la selección del combustible o energía para las diferentes aplicaciones mencionadas.

\section{CONCLUSIONES}

Con la realización de la investigación de trabajo se pretende llegar a las conclusiones de cuáles son los mejores métodos de obtención de energía mecánica por medio del motor Stirling, como su gas más óptimo de operación, verificar los mejores diferenciales de temperatura para el regenerador como el material con mayor conductividad térmica y calor especifico y así finalizar definiendo las mejores condiciones de operación del motor Stirling respecto a las condiciones a las que será sometido.

\section{REFERENCIAS}

[1] Stoian Petrescu, Camelia Petre, Monica Costea, Octavian Malancioiu, Nicolae Boriaru. A methodology of computation, design and optimization of solar Stirling power. 2010. Energy, pp. 729-739.

[2] Chin-Hsiang Cheng, Hang-Suin Yang. Optimization of geometrical parameters for stirling engines based on theoretical analysis. 2012, Applied Energy, pp. 395 - 405.

[3] Invernizzi, Costante M. Stirling engines using working fluids with strong real gas effects. 2010. Applied Thermal Engineering, pp. 1703 $-1710$. 


\section{COCINAS SOLARES DE ACUMULACION Y CONCENTRACION}

Daniela Castro*, Diana Alcaraz*, Heidy Gonzalez*, Laura Guerrero*, ESCUELA COLOMBIANA DE CARRERAS INDUSTRIALES. picasdani.93@gmail.com* , dialcla_71@ hotmail.com*, ESCUELA COLOMBIANA DE CARRERAS INDUSTRIALES. heidygh_23@ hotmail.com*, lanague44@ hotmail.com*.

Palabras Clave: Acumulación, Cocina solar, Concentración, Energía, Radiación.

\section{INTRODUCCION}

Las cocinas solares son un ejemplo perfecto de tecnologías apropiadas que proveen alternativas para coayudar en el mejoramiento de las condiciones de vida de cientos de miles de personas en Colombia (Ross, 2002; Gordon, 1996). la desigual distribución de los recursos energéticos aunado a los bajos niveles de vida, los bajos ingresos y la adolescencia de adecuados servicios públicos (luz, acueducto, alcantarillado y teléfono), en muchas regiones y lugares del país, hacen necesario el estudio y la aplicación de este tipo de tecnologías alternativas eficaces y de bajo costo.

"El uso de combustibles no renovables provistos desde zonas más pobladas resulta difícil y oneroso debido a la situación de aislamiento de la mayoría de las comunidades" [1]. a nivel mundial por diversas actividades y procesos se dan grandes emisiones de contaminantes, pero lo que pocos saben es que en una tarea tan sencilla como cocinar se emiten ciertas cantidades de gases contaminantes debido a que se involucran procesos de combustión propiciando un tipo de contaminación domestica, donde "considerando la cantidad en que esas sustancias son emitidas y su grado de toxicidad podemos decir que los principales contaminantes son el anhídrido sulfuroso $\left(\mathrm{SO}_{2}\right)$, el monóxido de carbono $\left(\mathrm{CO}_{2}\right)$ y los óxidos de nitrógeno (NOx)" [2].

\section{METODOLOGÍA}

Cocinas solares de Concentración:

1. Diseño del prototipo de la cocina solar de concentración.

2. Construcción en madera de la estructura que sostiene la cocina solar.

3. Calculo del foco correspondiente a la parábola utilizada en este prototipo por medio de la formula ${ }^{Y=\frac{X^{2}}{4 X f}}$, es decir, el foco corresponde a $f=\frac{X^{2}}{4 X Y}$ $f 1=\frac{30,5^{2}}{4 \times 7}=930, \frac{25}{28}=33, \quad f 2=\frac{35^{2}}{4 \times 7}=\frac{1225}{28}=43,75 f=\frac{X^{2}}{4 X Y}$

4. Fabricación de platinas que sostienen la parábola teniendo en cuenta el cálculo realizado anteriormente.

5. Elaboración del soporte de la olla con varilla roscada para ajustar la parábola a las diferentes posiciones que toma el sol durante el día.

6. Recubrimiento de la superficie parabólica con papel espejo para conseguir una refracción satisfactoria de la radiación solar. 
Se necesitan dos cajas de cartón, una interior de $34 \mathrm{~cm}$ x $26 \mathrm{~cm}$. la exterior deberá ser más grande por lo menos $2,5 \mathrm{~cm}$ que la interior, un rollo pequeño de papel aluminio, un tarro de pintura negra mate sin plomo, silicona, cinta aislante, una plancha de vidrio con marco de madera del tamaño de la caja interna, laminas de icopor del tamaño de la caja interna y una lamina de aluminio $2 \mathrm{~cm}$ más pequeña que las dimensiones de la caja interna.

Cierre las tapas de la caja externa y ponga la caja interna dentro de la externa, forre por dentro todas las paredes de la caja interna con papel aluminio incluyendo el fondo, corte laminas de icopor del mismo tamaño de la caja interna pero $3 \mathrm{~cm}$ más altas e introdúzcalas en el espacio que queda en medio de las dos cajas, este va a ser el aislante que evita las pérdidas de calor. pinte de color negro la lámina de aluminio e introdúzcala en el fondo de la caja interna con la cara negra hacia arriba. Tome la plancha de vidrio y póngala encima de la base de manera que el marco debe tapar toda el área de la caja interna.

El reflector construido tendrá tres caras de las mismas dimensiones de la caja interna. cubra el interior de este reflector con papel aluminio y péguelo con cinta aislante de color negro. y colóquelo sobre el vidrio de esta manera la cocina solar está terminada y lista para usarse.

\section{RESULTADOS (Ensayos Preliminares)}
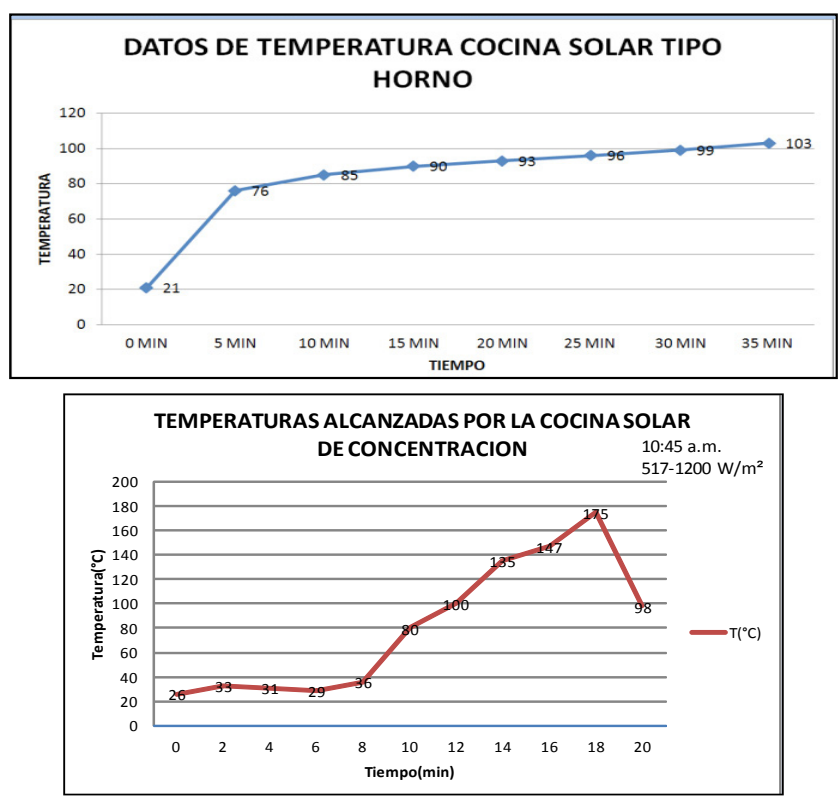


\section{CONCLUSIONES}

Las pruebas realizadas con las cocinas solares nos demuestran que es factible emplear energías alternativas en actividades cotidianas, contribuyendo a la disminución de la contaminación ambiental generada por el dióxido de carbono.

\section{REFERENCIAS}

[1] Saravia I. R., Cadena C., Caso R. y Fernández. Cocinas solares comunales de uso múltiple. Inenco, instituto de investigación en energía no convencional. (unsa-conicet) universidad nacional de salta, calle buenos aires 177, 4400, salta, argentina.

[2] Contaminación atmosférica dentro del hogar por estufas y cocinas. (Publicado en revista creces, noviembre 1980.) 